\title{
The Role of the Clearance Crisis on Public Expenditure and Budget Deficit in Palestine
}

Bahaa Suphi Awwad*

Palestine Technical University,

Tulkarm, Palestine.

Email: dr.awwadb@hotmail.com

\section{Jafar Salam Zidan}

Palestine Technical University,

Tulkarm, Palestine.

Email: jafar281091@gmail.com

Received October, 2020; Accepted December, 2020

\begin{abstract}
This study aims to analyze the effect of the clearance tax on the level of public debt and the deficit of the balance of payment in Palestine for the years 1996-2019. Data was collected from the Palestinian Monetary Authority and the Ministry of Finance. The study applies the ordinary least square to test the effect of the clearance tax on the public expenditures (current and budgeted) from one side and on the balance of payment from the other side. Findings show that current expenditures and budget deficit are positively associated with the clearance tax while budgeted expenditures are not correlated with the reported tax. The study stresses on the importance to restructure the economic agreements with Israel, more specifically the Paris Economic Protocol. The study concludes with important recommendations. Palestinian authorities and relevant policymakers should reinforce their strategies to improve the tax system and the efficiency of tax collection. They should diversify their revenues, rationalize their spending, and undertake new projects to reduce the public debt level.
\end{abstract}

Keywords: Clearing crisis; Development Expenses; Transferred expenses; Budget deficit.

Type: Research paper

(c) (i)

EY This work is licensed under a Creative Commons Attribution 4.0 International License.

DOI: 10.51325/ijbeg.v4i1.59

دور أزمة المقاصة على النفقات العامة وعجز الموازنة في فلسطين الملخص:

تهذف هذه الدراسة الى دراسة وتحليل إيرادات ضريبة المقاصة والإنفاق العام وعجز الموازنة ما بين الاعوام (2019-1996) في فلسطين، والكثف عن أثر ازمة ضريبة المقاصة على النفقات الجارية والنفقات التطورية وعجز الموازنة. ولاتمام هذه الدراسة وتحقيق الغرض منها، فقد تم اعتماد المنهي الوصفي التحليلي والمنهج الكمي ولهي

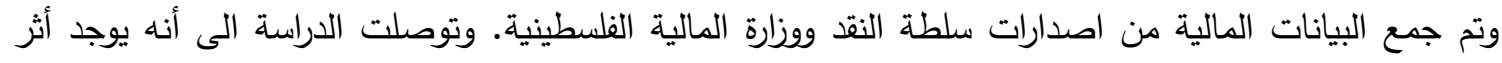
لأزمة إيرادات المقاصة على النفقات الجارية ولا يوجد اثر لهذه الازمة على النفقات التطويرية، ويوجد أثر لأزمة

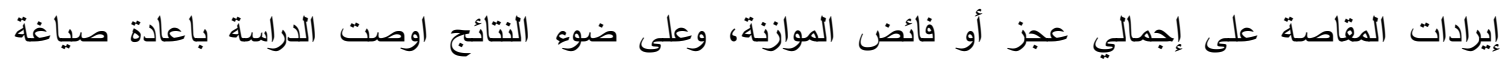

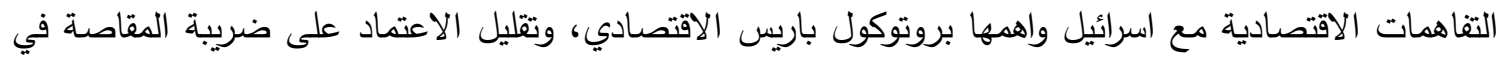
تمويل النفقات التشغيلية والتطويرية وذلك من خلال تتويع مصادر الايرادات العامة عن طريق المشاريع الاستثمارية

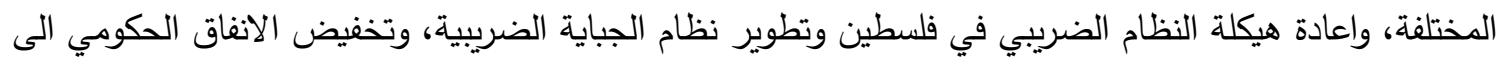
الحد الاقصى من اجل تخفيض العجز في الموازنة وسداد الدين العام.

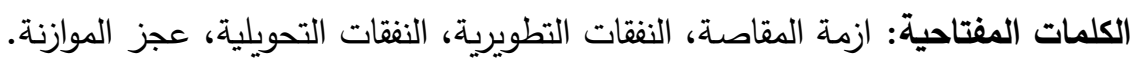


مقدمة الدراسة

ترافق تطور دور الدولة واتساع مجالات عمها، وظهور العديد من الأزمات المالية والاقتصادية، إلى إعادة هندسة إدوار الدولة وأدواتها المستخدمة في الاقتصاد والمالية العامة (Khalidi, 2019)، ومنذ ذلك الحين ازداد الادهاد الانمام بالمالية العامة والسياسيات المالية والاقتصادية للدولة ، وأثرت تلك السياسهات ولهات في مواجهة التقلبات الاقتصادية وتحقيق نمو اقتصادي من خلال الإنفاق، حيث يعدّ نمو الإنفاق الحكومي وقلة الموارد من أهم المشكلات التي لتئي

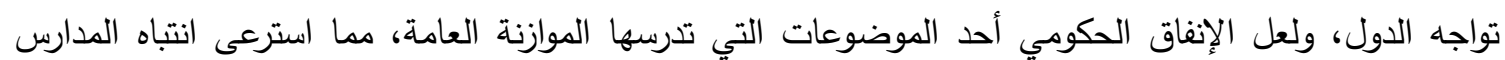

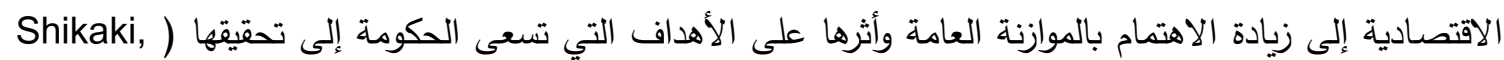
.(Al-Naser, 2019; Al-Afifi, 2019; Alareeni, 2019; Alsuwaigh, et.al,2020; 2019; يقع على كاهل الحكومات مسؤوليات كبيرة أهمها توفير الموارد المالية التي تلبي احتياجات المجتمع من خلال

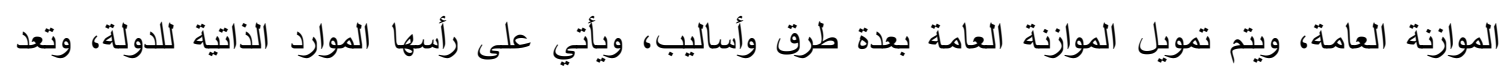

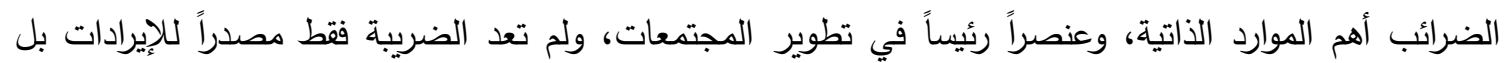

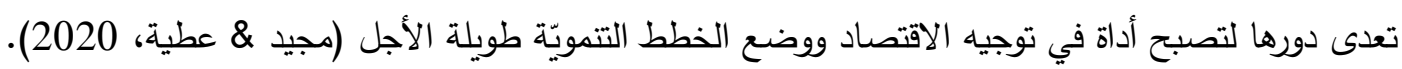
وبسبب خصوصية الوضع الفلسطيني ظهر مصطلح جديد وهو ضريبية المقاصّة، وهو مصطلحُ ظهر بعد اتفاق باريس الاقتصادي، الذي وقع في تاريخ 29 نيسان 1994 (Khalidi, 2019)، والذي أبقى على النظام الجمركي وضي وندي الموحّد بين الطرفين الفلسطيني والإسرائيلي، و بدوره أدى إلى غياب الحدود الاقتصادية مما أحدث سيادة منقوصة

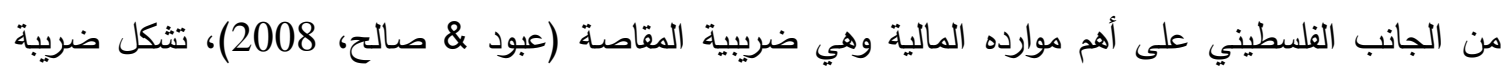

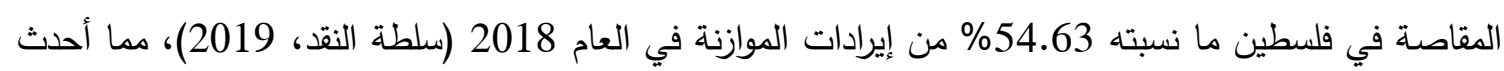

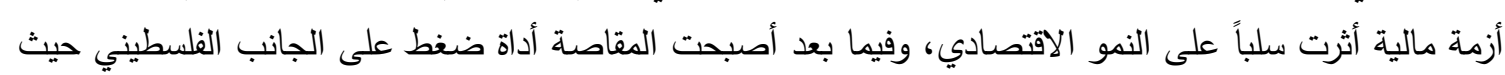

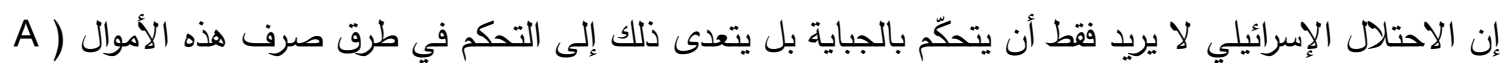

.(Alazzeh, 2020

بعد مرور 25 عام على توقيع اتفاق باريس الاقتصادي، يبدو أن الأمور تتجه نحو طريق غير واضح المعالم، حيث إن البنية التحتية الأساسيّة للاقتصاد الفلسطيني في تراجع مستمر وهذا يحد من قدرت الإنسي الاقتصاد على مواجهة السياسات الإسرائيلية، وفي الآونة الأخيرة لم يشه الاقتصاد الفلسطيني أي نمو يذكر مما انعكس سلبا على إيجاد

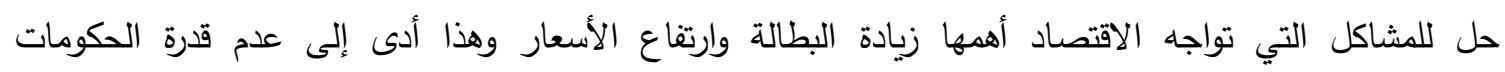

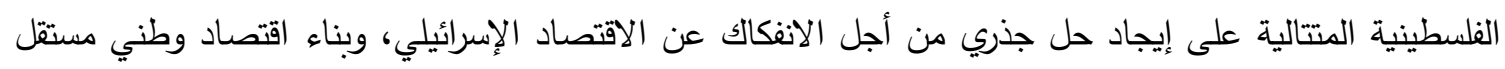
(Fannoun, 2019)، عليه سيقوم الباحث بدراسة دور ازمة المقاصة على النفقات العامة وعجز الموانة في الإني

فلسطين.

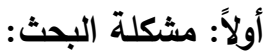

يواجه الاقتصاد الفلسطيني ظروفاً استثنائية خاصة متعلقة باتفاق باريس الاقتصادي، والذي يحوي على قيود بثأن

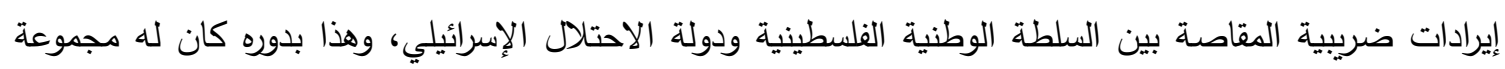
كبيرة من الانعكاسات السلبية على الوضع الاقتصادي بشكل عام وعلى الموازنات العامة التقديرية والفعليّة بشكل بلتهل

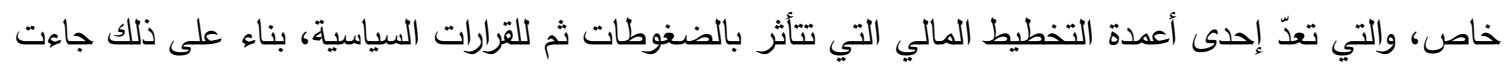
هذا الدراسة لإلقاء الضوء على انعكاسات إيرادات أزمة ضريبية المقاصة على أهم بنود الموازنة العامة، وهي النفقات العامة بأنواعها وعجز الموازنة العامة. 
ويمكن صياغة مشكلة الدراسة من خلال السؤال الرئيس التالي:

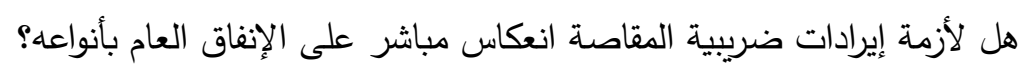
ويمكن اثتقاق عدة تساؤلات فرعية من السؤال الرئيس على النحو التالي:

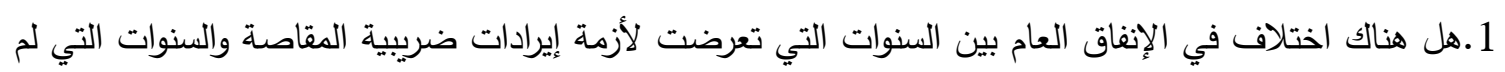
تتعرض لها؟

2.هل كان لأزمة إيرادات ضريبية المقاصة انعكاس مباشر على (عجز/فائض) الموازنة؟

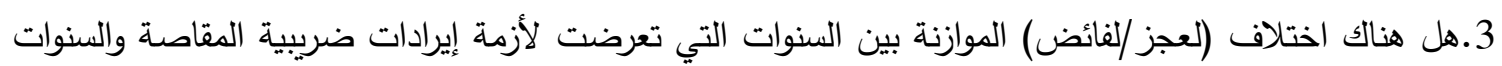
التي لم تتعرض لها؟ فروض البحث:

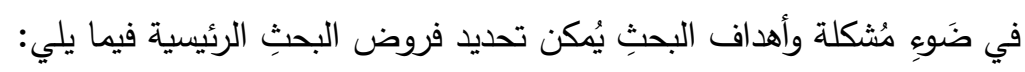

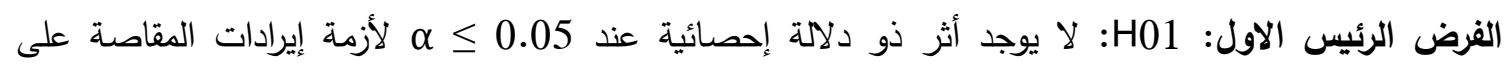
الإنفاق العام.

ويتفرع عنه الفروض التالية:

H01.1 لا يوجد أثر ذو دلالة إحصائية عند 0.05 ئ 0 لأزمة إيرادات المقاصة على النفقات الجارية.

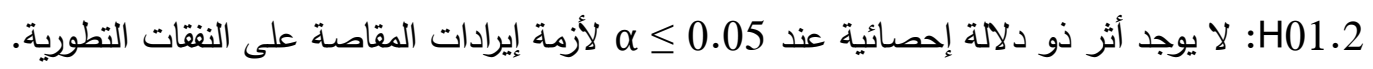

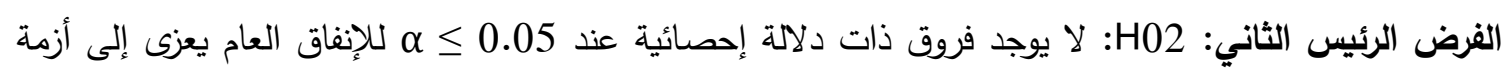
إيرادات المقاصة.

\section{ويتفرع عنه الفروض التالية:}

H02.1 لا يوجد فروق ذات دلالة إحصائية عند 0.05 ئ $\alpha$ للنفقات الجارية تعزى إلى أزمة إيرادات المقاصة.

H02.2 لا يوجد فروق ذات دلالة إحصائية عند 0.05 ي $\alpha$ للنفقات التطويرية تعزى إلى أزمة إيرادات المقاصة.

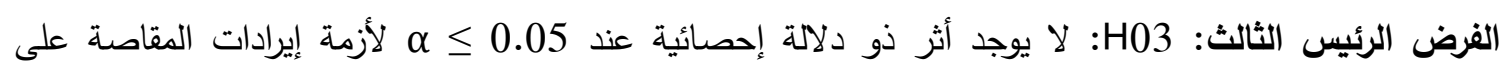
إجمالي عجز أو فائض الموازنة. الفرض الرئيس الرابع: H04: لا يوجد فروق ذات دلالة إحصائية عند 0.05 × $\alpha$ لعجز أو فائض الموازنة يعزى إلى أزمة إيرادات المقاصة.

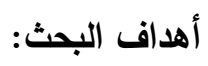

بعد إدراك أبعاد مشكلة الدراسة التي سعت لتقييم انعكاسات إيرادات أزمة ضريبية المقاصة على أهم بنود الموازنة العامة وذلك للوصول للأهداف التالية:

1- دراسة وتحليل إيرادات ضريبة المقاصة والإنفاق العام وعجز الموازنة.

2- الكثف عن أثر ازمة ضريبة المقاصة على النفقات الجارية .

3- الكثف عن أثر ازمة ضريبة المقاصة على النفقات التطورية .

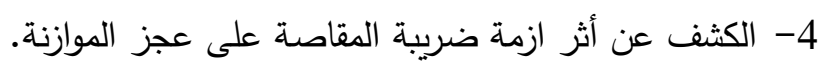
أهمية البحث:

تكمن أهمية هذه الدراسة في أنها تلقي الضوء على درجة مساهمة إيرادات ضريبية المقاصة في إجمالي إيرادات

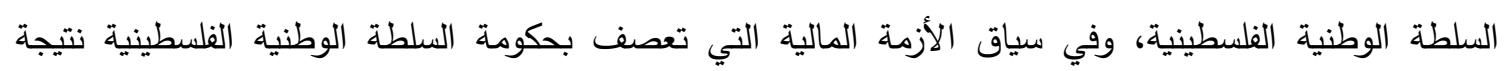
استمرار احتجاز أموال المقاصة، تسح لنا هذه الدراسة بإعطاء صورة أكثر وضوحاً عن سياسة الإنفاق العام 
الحكومي خلال تلك الأزمة، وطبيعة العلاقة بين العجز في الموازنة العامة وأزمة المقاصة وتقييم خطورة الوضع الذي تمر فيه السلطة الوطنية الفلسطينية نتيجة اعتمادها على تمويل جزء كبير من الموازنة من خلال إيرادات ضريبية المقاصة.

إن أحد أهم أسباب اختيار هذه الدراسة هو الحدوث المتكرر لهذه الأزمة والذي جعل منها محور اهتمام كثير من

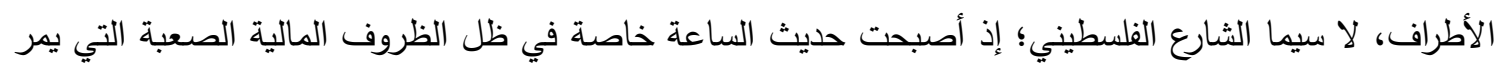

$$
\text { بها الاقتصاد الفلسطيني في الوقت الحالي. }
$$

حدود الاراسة:

تتمثل حدود هذه الدراسة في تتبع دور أزمة المقاصة على النفقات العامة وعجز الموازنة في فلسطين وتغطي الفترة الزمنية (1996 -2019) وقد تم البدء من العام 1996 لوجود أول موازنة منشورة واختيار العام 2019 كنقطة نهاية لوجود آخر موازنة منشورة. انموذج الدارسة

الثكل رقم (1) انموذج الاراسة

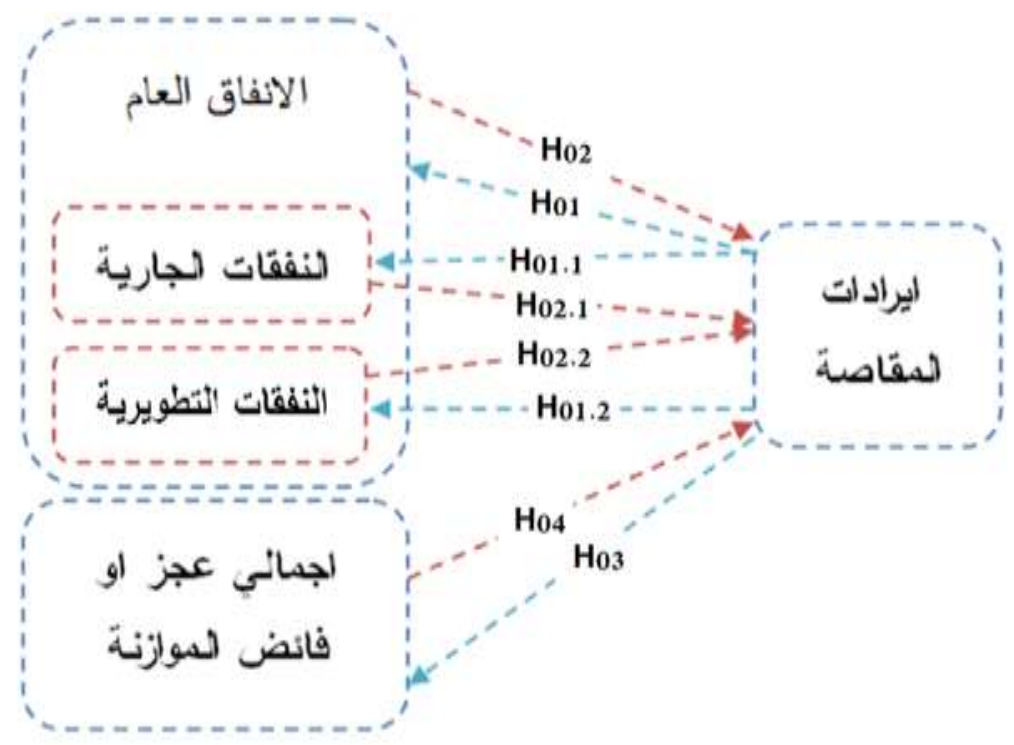

الإطار النظري الاقصاد واهميته الإن الهزي

إن علم الاقتصاد هو العلم الذي يدرس السلوك الإنساني وانثطة المجتمع في مجالات الإنتاج والاستهلاك بهدف اثباع الحاجات المتعددة حاضرا ومستقبلا باستخدام ما لديه من موارد متاحة (عباس، 2020)، والاقتصاد الكلي هو منظومة تربط بين عدد لا حصر لله من السياسات والموارد والتقنيات التي تحدث من خلالها التتمية الاقتصادية (Haji \& Akrawee, 2020) من الفقر وتحقيق العدالة الاجتماعية (ناصر \& \& هادي، 2019).

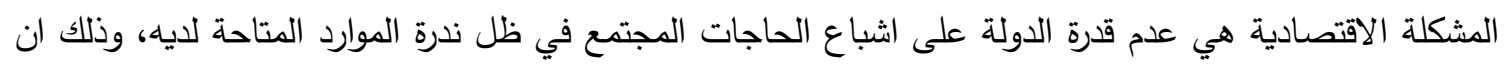

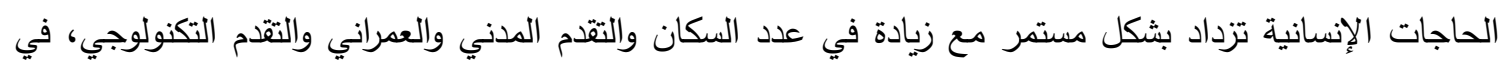

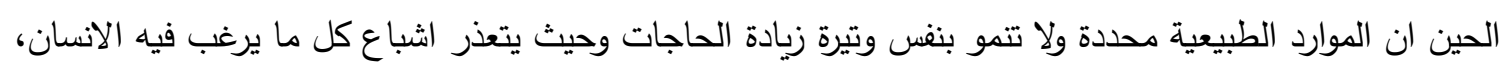


ولكي نتمكن من اشباع الحاجات الإنسانية بثكل الأمثل، فانه يجب علينا استخدم الموارد المتاحة بأفضل طريقة ممكنة (Ilmakunnas, 2019).

يعد الجانب الاقتصادي مهما جدا لارتباطه الوثيق بتوفير الاحتياجات الاساسية للدولة ، وضمان قدرتها على

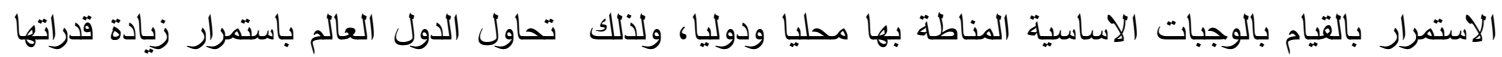
المالية والاقتصادية، وتعمل على توفير كافة السبل من اجل تحقيق النمو الاقتصادي (Smol, 2019)، وتحاول

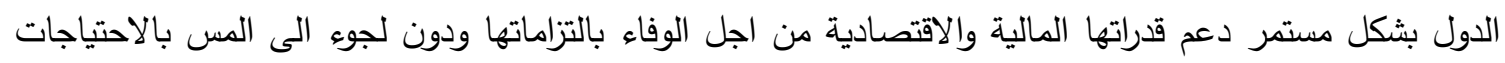

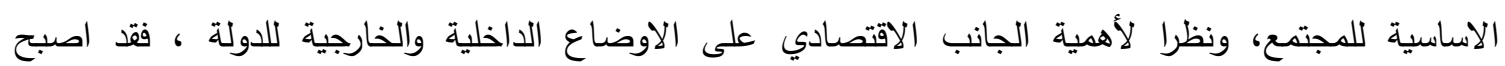
للمعلومات الاقتصادية اهمية كبيرة تضاهي بأهميتها المعلومات العسكرية ، ولذلك اصبح الألفيك المجال الاقتصادي لله تأثير كبير وخطير على الامن القومي للدول (Lang et al., 2020). لم يعد الهدف الرئيسي من القوة الاقتصادية فقط الاكتقاء الذاتي من الغذاء والتصنيع والتجارة، ولكن اصبح الهدف

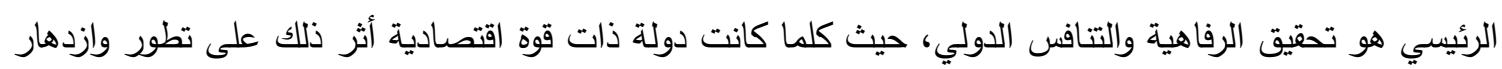

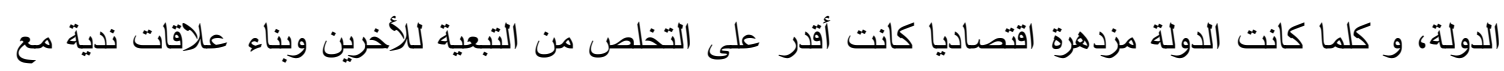

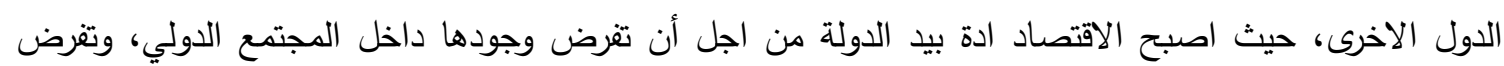
تفوقها على الدول الاخرى، حيث نجد ان القوة الاقتصادية تكسب الدولة هيمنة وقوة كبيرة، كما تعطي القوة الاقتصادية الدولة تفوق ثقافي حيث سيطرت دول كثير من الدول على دول اخرى من خلال الغزو التقافي لها

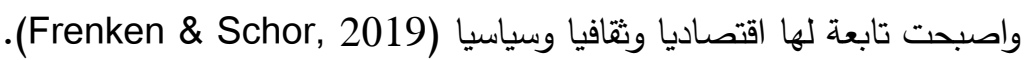
الاقتصاد في فلسطين: الاقتصاد الفلسطيني هو مصطلح يطلق على الاقتصاد في الأقاليم التابعة لإدارة السلطة الوطنية الفلسطينية في قطاع غزة الضفة الغريبة، حيث يعاني الاقتصاد الفلسطيني من كثير من المشاكل بسب التبعية الاقتصادية

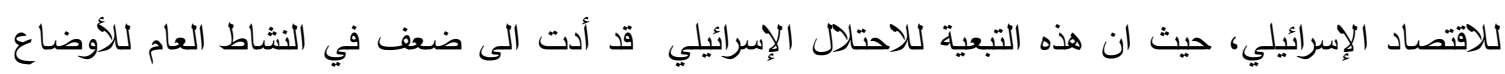
الاقتصادية في الأراضي الفلسطينية، وارتفاع كبير في مستويات البطالة، وارتفاع كبير في الدين العام، وبيئة طاردة

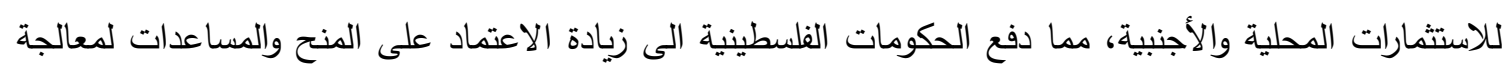

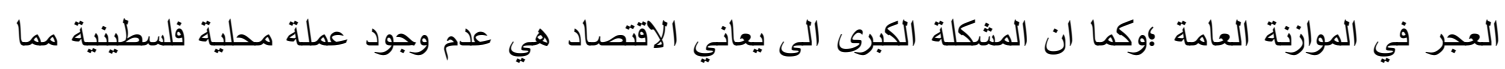

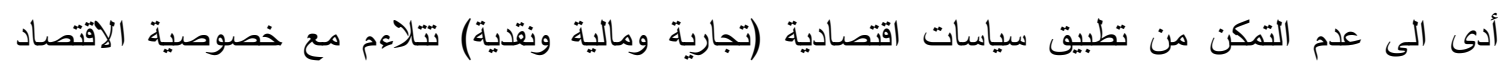
الفلسطيني (عكاشة، 2018).

في الأعوام الأخيرة شهد الاقتصاد الفلسطيني عدة تحديات وكان من أبرزها (Dana, 2020):

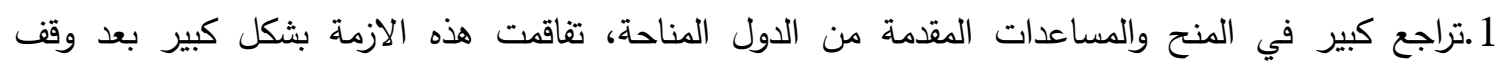
المساعدات الامريكية المقدمة للحكومة الفلسطينية ووقف دعم برامج المقدمة المؤسسات الدولية للشعب الفلسطيني (الأونروا والوكالة الأمريكية للتنمية). 2.ازمة إيرادات المقاصة في بداية عام 2019 بسب الخلاف السياسي بين الحكومة الفلسطينية ودولة الاحتلال الإسرائيلي، حيث تقوم دولة الاحتلال الإنرائيلي بجباية هذه الإيرادات نيابة عن الحكومة الفلسطينية ثم تقوم بتحويلها

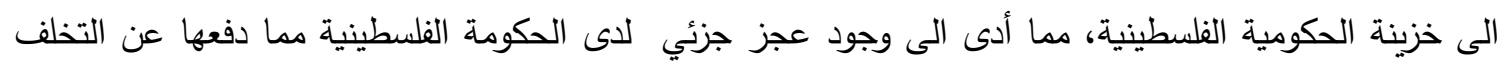
عن دفع بعض المستحقات للعاملين في القطاع العام، وقف بعض التحويلات للقطاع الخاص مما أدى لتراكم الديون لصالح القطاع الخاص على الحكومة (Dana, 2020). 
3.زيادة تعنت الإسرائيلي والاستهتار بالقوانين الدولية وزيادة التوسع الاستيطاني وسيطرة على المزيد في الأراضي

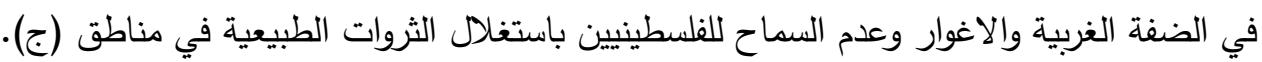
4.استمرار حالة الانقسام الفلسطيني بين شقي الوطن في الضفة الغربية وقطاع غزة. 5.الحصار المستمر لقطاع غزة والاغلاق التعسفي للمعابر التجارية للقطاع. وما يزال الاقتصاد الفلسطيني يعيش تحت وطأة ازمة المقاصة، مع استمرار هذه الازمة بشكل متكرر مما ينذر المارك بكارثة حقيقة على الأوضاع الاقتصادية في فلسطين، عليه تستدعي هذه الأوضاع تكافل جميع المؤسسات الوطنية

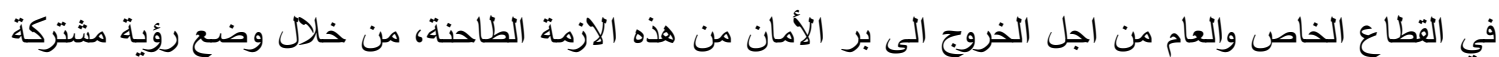
بين القطاع العام والخاص من خلال تفادي الاضرار المتحملة وقعها او تخفيفها من اثارها الاقتصادية المحتملة

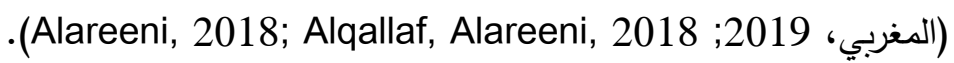
والباحث في الاقتصاد الفلسطيني يلاحظ ان هنالك تذبذب واضح في مستويات (نسب) النمو الاقتصادي عبر السنين

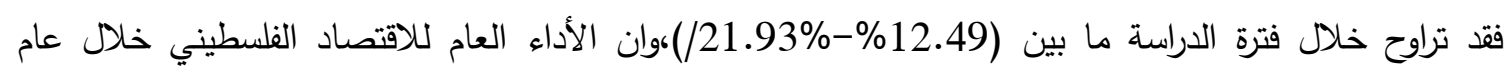
2019 حققت فيه فلسطين نمو يقدر 1.2\% في الناتج المحلي الإجمالي بالمقارنة في عام 2018، أي ان الاداء الاقتصاد الفلسطيني حقق نمو اقتصادي برغم من الظروف الصعبة التي مر فيها خلال عام 2019 من احتجاز أموال المقاصة على مدار 6 أشهر، مما أحدث ازمة خانقة لدى الحكومة الفلسطينية، ولكن على الرغم من النمو في الناتج

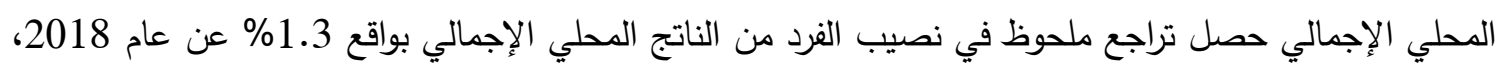
وذلك بسب زيادة الطبيعة في النمو السكاني في فلسطين (PMA, 2019). التبعية الاقتصادية للاحتلال الإسرائيلي: التبعية الاقتصادية هو خضوع وتأثر اقتصاد بلد ما بالتأثيرات والتغيرات في القوى الخارجية بفعل ما تملكه هذه القوى من إمكانات السيطرة على الاقتصاد التابع، بثكل يتيح للاقتصاد المسيطر من جني أكبر نفع ممكن من موارد

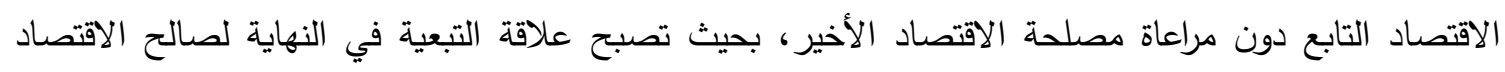
المسيطر (محمد \& عطية، 2020). - أثكال التبعية الاقتصادية لاقتصاد الاحتلال وإنعكاسها على الاقتصاد الفلسطيني:

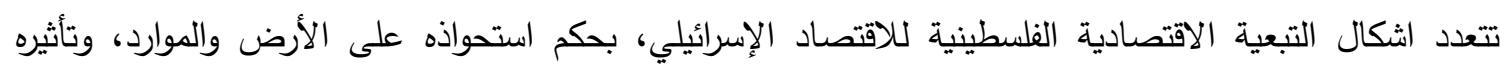
الكبير في صناعة القرار الفلسطيني. وفيما يلي بعض أثكال التبعية لاقتصاد الاحتلال:

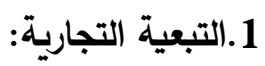

حرص الاحتلال الإسرائيلي على تطويع الاقتصاد الفلسطيني الاستفادة القصوى من هذا الاقتصاد الناشئ ولهذا

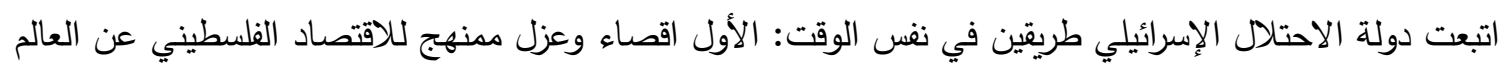

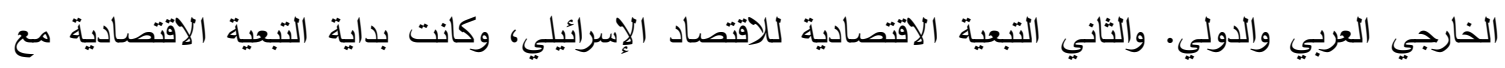
الاحتلال الإسرائيلي للأراضي الفلسطينية في عام 1967 (حمدان، 2019).

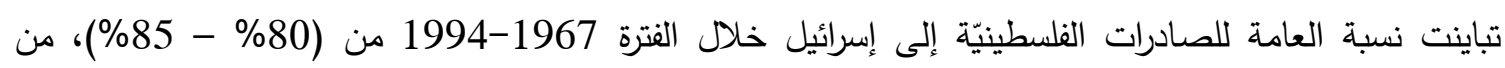
إجمالي الصادرات الفلسطينية، بينما تباينت نسبة الواردات الفلسطينية من إسرائيل، من إجمالي الواردات، في السنوات ذاتها، بين (80\% - 90\%)، فالاحتلال الإسرائيلي عمد مباشرة الى السيطرة على التجارة الفلسطينية

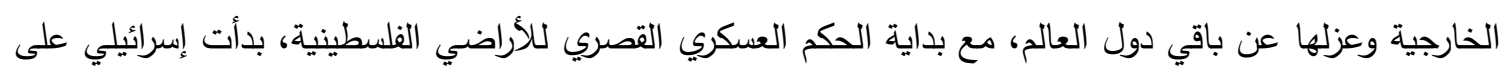
ربط الاقتصاد الفلسطيني في اتحاد جمركي احادي الجانب (عبود \& صالح، 2008). 
وقد استمر هذا النمط من السيطرة خاصة بعد توقيع اتفاق أوسلو، وبروتوكول باريس الاقتصادي، حيث ان هذا

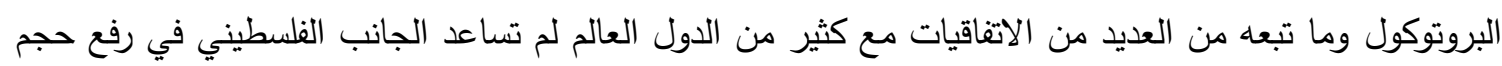

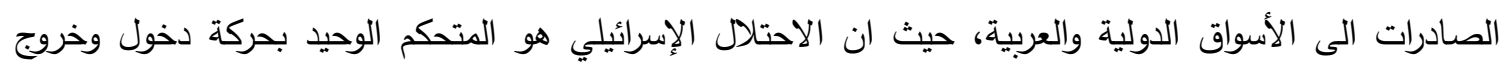
السلع والبضائع الفلسطينية (Khalidi, 2019).

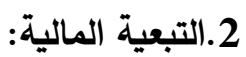

وفقا لبروتوكول باريس الاقتصادي فان دولة الاحتلال الإسرائيلي هي المسؤولة عن تحصل ضريبة القيمة المضافة

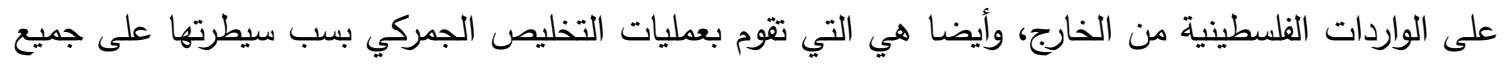

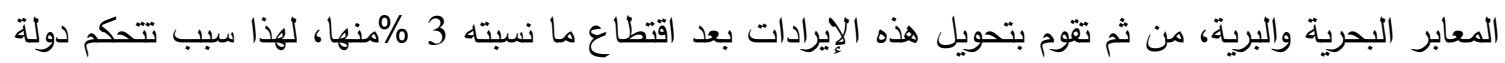

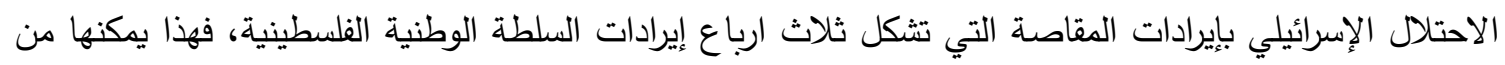
السيطرة على الثؤون المالية للسلطة الفلسطينية (عزريل، 2017). ان استخدام إسرائيل ورقة احتجاز إيرادات المقاصة المستمر يشكل خطر حقيقي على الاستقرار المالي للسلطة

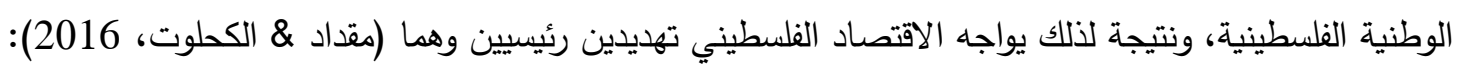
التهديد الأول: هو عدم القدرة على توقع حجم الإيرادات المتحملة، رغم أهمية هذه الإيرادات للاقتصاد، فهذه الإيرادات التي تعد المكون الأساسي للإيرادات المحلية وحيث تثكل ثلاثة ارباع إيرادات السلطة الوطنية الفلسطينية، من دون هذه الإيرادات لن تكون السلطة الوطنية قادرة على الوفاء بالالتزامات. التهديد الثاني: التسرب المالي من خزينة السلطة الوطنية الفلسطينية، حيث تكبد خزينة السلطة الوطنية الفلسطينية خسائر فادحة بسب فقدان حصيلة قيمة ضريبة القيمة المضافة وجمارك المستوردات بسبب عدم الاسترداد بطريقة

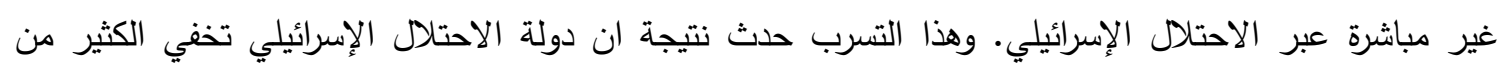

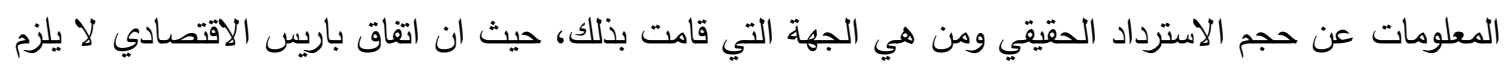

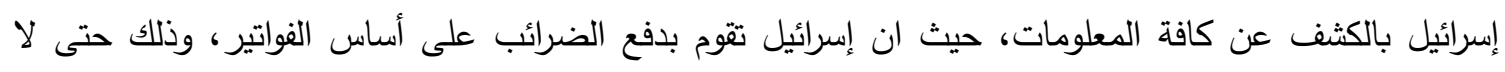
يكثفوا عن الحجم الحقيقي لاعمالهم، التي يدفعون من خلالها ضريبة الدخل ومن مصادر التسرب المالي أيضا للبضائع المهربة من السوق الإسرائيلي. تثير التقديرات ان حجم التسرب المالي للضرائب المباشرة والغير مباشرة المحجوزة من قبل الاحتلال الإسرائيلي تقدر 17\% من الإيرادات الضريبة للسلطة الوطنية الفلسطينية وهذا يشكل 3.6\% من الناتج المحلي الإجمالي (مقداد \& الكحلوت، 2016).

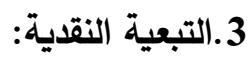

ان الوضع الأساسي النقدي الفلسطيني في اتفاقية باريس الاقتصادية في عام 1994، حيث تم الاتفاق على عدم

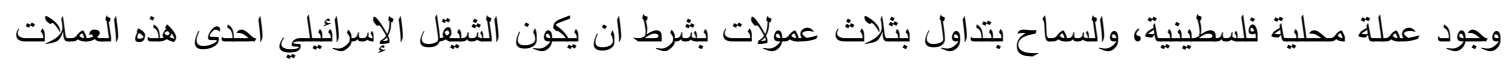

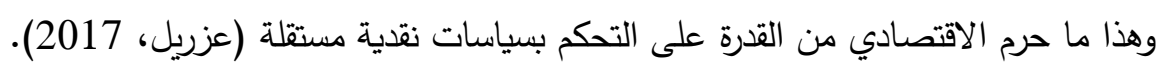

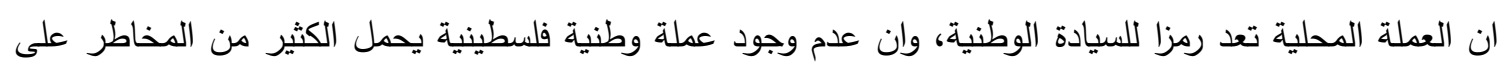
الاقتصاد، وهي كما يلي: •ان اصدار عملة محلية يحمل الكثير من الفوائد يمكن من خلالها تحقيق إيرادات للقطاع العام، ومن هذه الإيرادات ايراد سك العملة، كما تستطيع الحكومة اصدار سندات وأذونات الخزبنة التي تساعدها من تقليل الاعتماد على إلى القروض الخارجية في سد العجز في الموازنة العامة، كما يمكن للحكومة خفض قيمة العملة المحلية لتثجيع

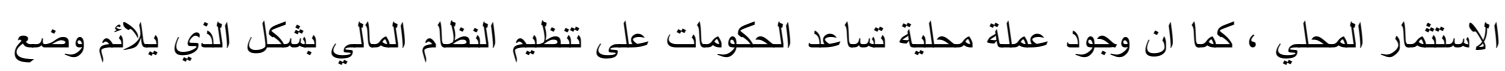


الخاص للبلد ، حيث حرم اتفاق باريس الاقتصادي السلطة الوطنية الفلسطينية من جميع هذه الميزات وجعل سياسته النقدية مرهونة للاحتلال الإسرائيلي (عزريل، 2017). • يثكل عدم وجود عملة محلية ضربة قوية للاقتصاد حيث يجعل الاقتصاد هش وعرضة بصورة كبير للصدمات الإنسات ولتقلبات مثال ذلك اغلاق الحدود، وتغير في معدل صرف العملات المتداولة في فلسطين (عوض، 2016).

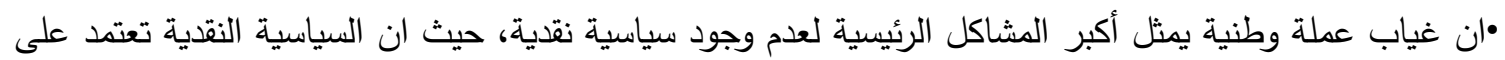
نوعين من الأدوات لتتحكم في حجم الائتمان وعرض النقد: النوع الأول هي الأدوات الكمية التي تمثل سياسية إعادة الخصم، وتحكم في الاحتياطي القانوني، النوع الثاني تتمثل في الأدوات النوعية مثل تطبيق معايير الرقابة الدولية

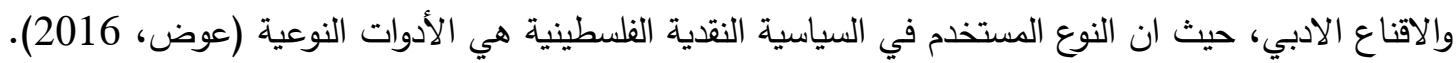
4.تبعية سوق العمل الفلسطيني: من طرق ادماج الاقتصاد الفلسطيني في الاقتصاد الإسرائيلي السماح للأيادي العاملة الفلسطينية العمل في الداخل

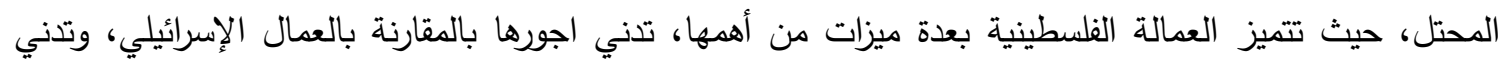

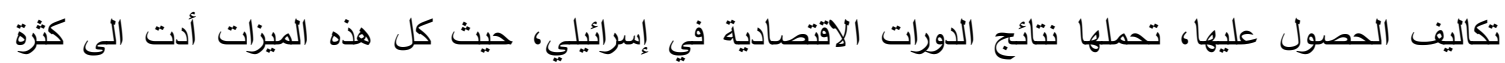
الاعتماد على العمالة الفلسطينية في السوق الإسرائيلي (Oberschall, 2019). واما الجانب الفلسطيني فيرى في العمالة الفلسطينية في إسرائيلي احدى طرق معالجة البطالة والتخفيف من اعداد الإني

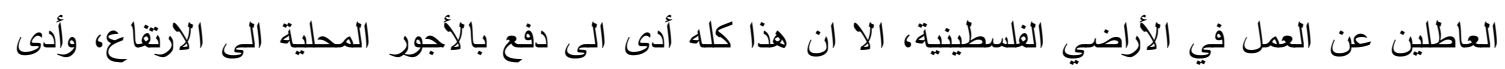

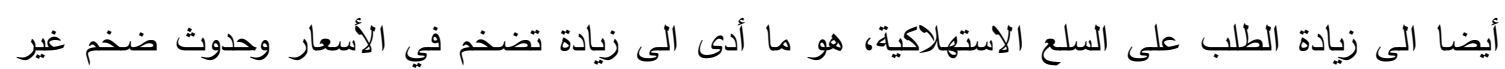
مرغوب به (Darwish, 2013). اتفاق باريس الاقتصادي بين السلطة الوطنية الفلسطينية والاحتلال الإسرائيلي:

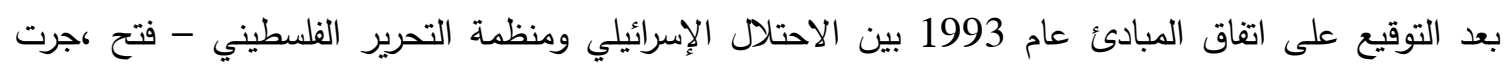

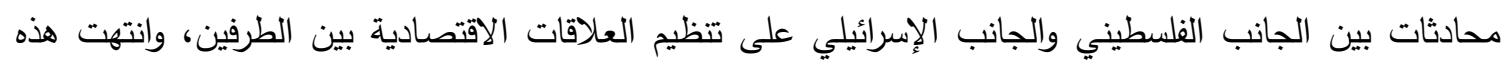
المحادثات بتوقيع اتفاق باريس الاقتصادي في 29 نيسان 1994 (مقداد \& الكحلوت، 2016)، الذي عالجين عالج عدة

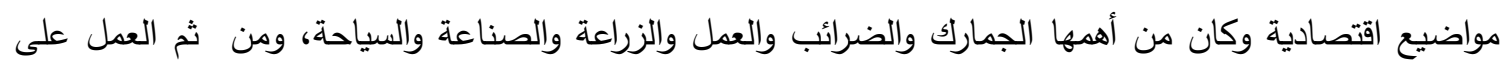

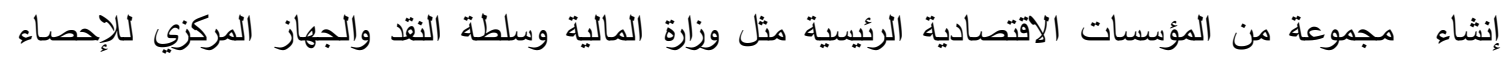

(جابر ، 2019).

وكان من اهم بنود هذا الاتفاق هو الاتحاد الجمركي بين الطرفين، مما أدى الى إزالة جميع الحواجز بين

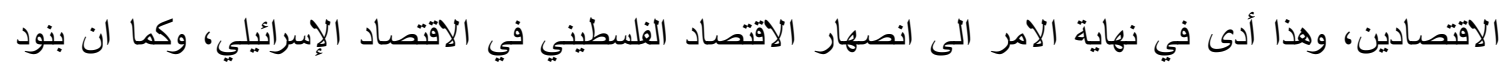

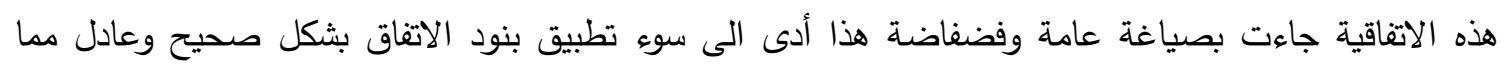

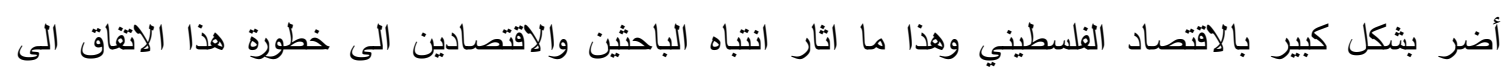

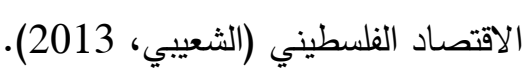
- نقاط الضعف الرئيسية في اتفاق باريس الاقتصادي:

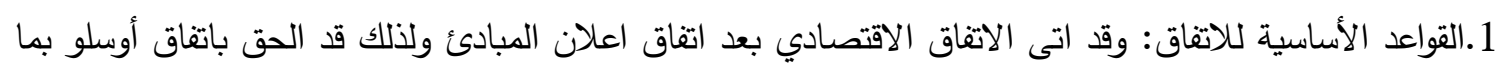

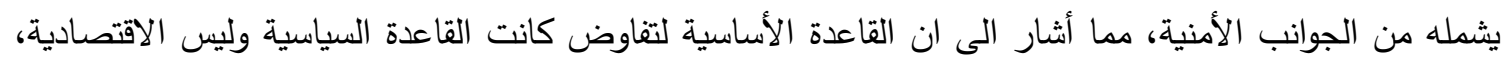

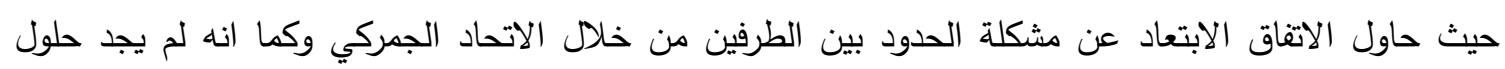

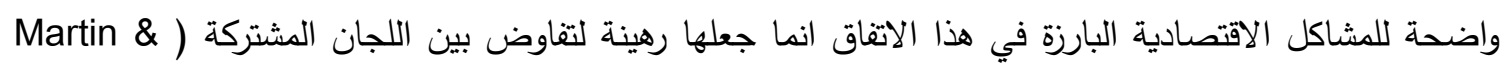

.(Boatman, 2019 
وكما ان الاتفاق جعل من قطاع غزة والضفة الغربية وحدة اقتصادية وجغرافية واحدة وما يتبعه من حرية التتقل

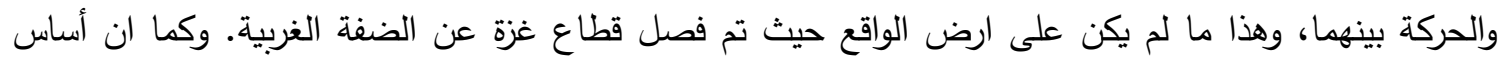

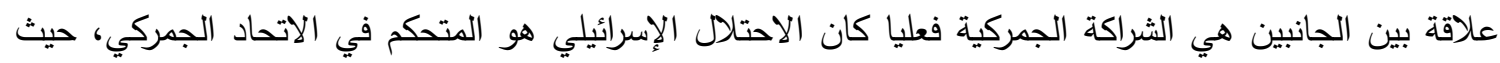

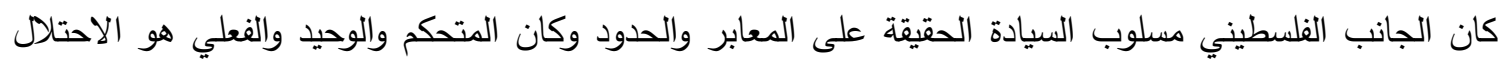
الإسرائيلي (Asfour, 2018).

2.السياسات المالية والتجارية والضريبية والجمركية: جاءت المادة الثالثة من البروتوكول والبنود التابعة لهذه المادة

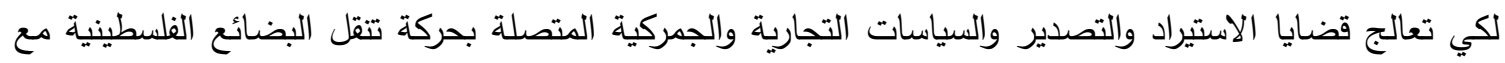
ومن خلال دولة الاحتلال الاسرائيلي، حيث فرض على الجانب الفلسطيني نفس السياسات الاسرائيلية في الجمارك والضرائب والمواصفات والمقاييس، مع اعطاء الجانب الفلسطيني القليل من الحرية في بعض الجنائ الجوانب حيث سمح Klein, ) للسلطة الفلسطينية بتسعير المشتقات النفطية باقل 15 \% من اسعار البيع في دول الاحتلال الاسرائيلي . $(2018$ وكذلك في ضريبة القيمة المضافة سمح للجانب الفلسطيني ان تكون ضريبة القيمة المضافة في الاراضي الفلسطينية باقل نقطتين مئويتين من المطبقة في دولة الاحتلال الاسرائيلي مع تطبيق نفس نسب في ضريبة ضرية الشراء على الانتاج المحلي والبضائع المستوردة (Schenker \& AbuZayyad, 2018).

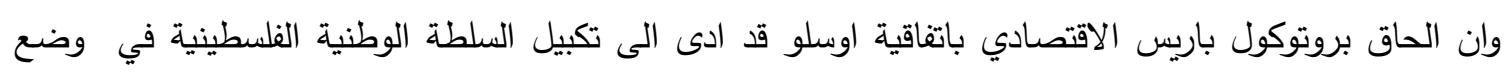

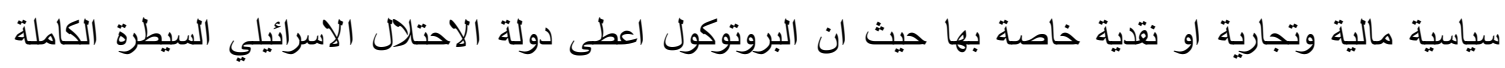

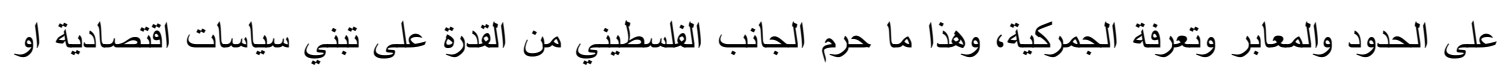

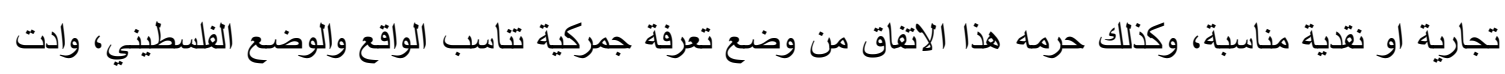

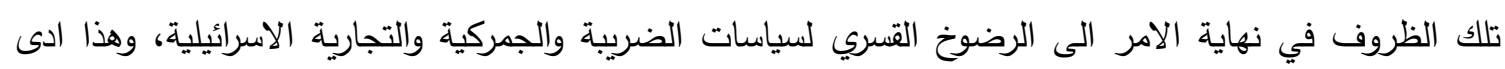

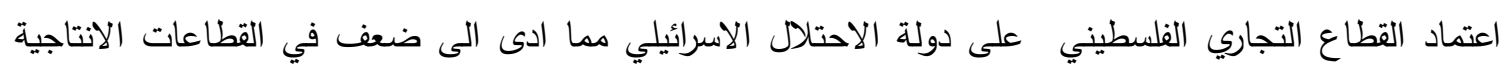
الفلسطينية وعدم قدرتها على المنافسة (Asfour, 2018). 3.بروتوكول باريس الاقتصادي وأداء الاقتصاد الفلسطيني: ان أي تقدير لدور بروتوكول باريس الاقتصادي لابد ان

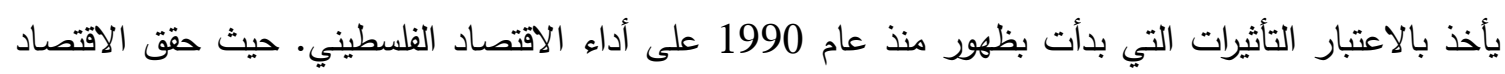

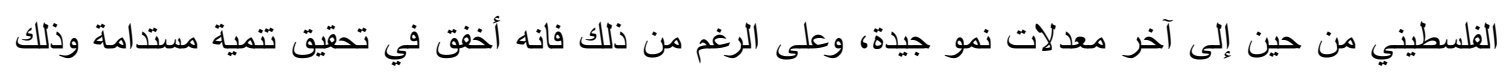

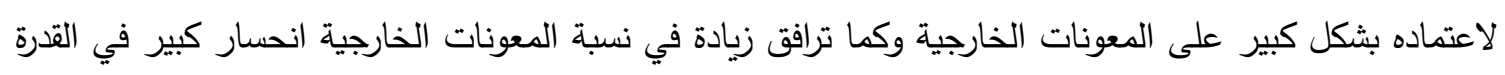

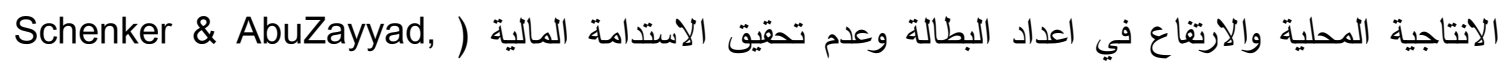

. $(2018$

وفي تقرير لصندوق النقد الدولي عن عام 2012 إثارة إلى أن الاقتصاد قد تراجع بشكل ملفت للنظر كما وان

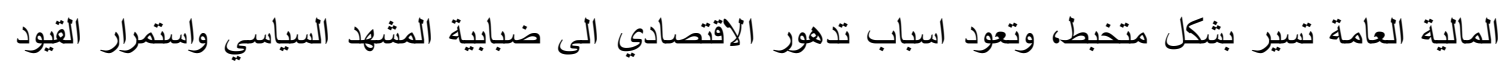

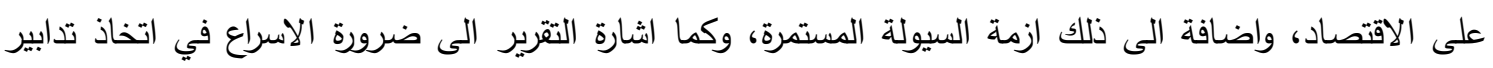

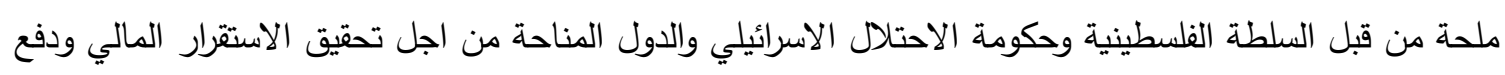
عملية التمية المستدامة في الاراضي الفلسطينية (صندوق النقد الدولي، 2012).

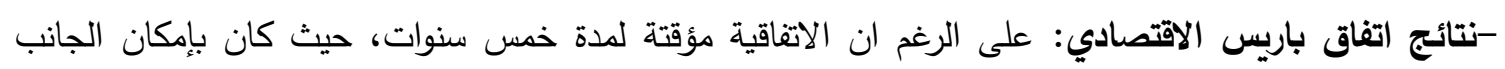

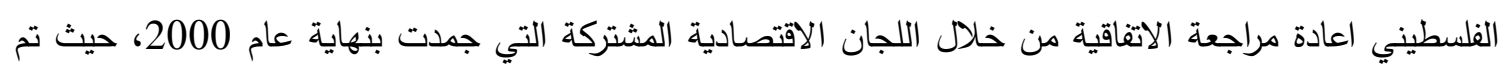
الغاء الوجود الفلسطيني في المعابر .فاتفاقية اوسلو جعلت 62 \% من مساحة الضفة الغريبة تحت الهيمنة 
الاسرائيلية وهي التي تسمى بالمناطق (ج) وهي تحت السيطرة الاسرائيلية الكاملة مما اعاق التتمية والاعمار فيها

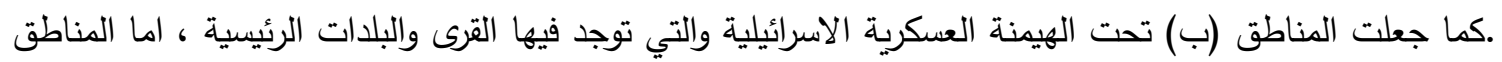

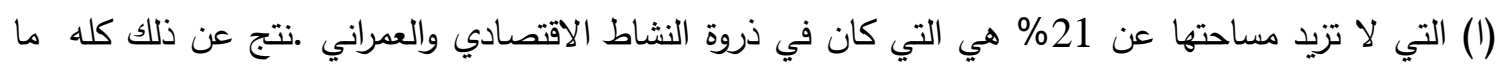
يلي (زهرة، 2016): 1.نمو وهمي غير حقيقي يستند إلى مقياس غير دقيق (معدل دخل الفرد ونسبة النمو في الناتج المحلي) حيث انه لا يمكن تطبيق هذه المقاييس على فلسطين لكونها تخضع تحت الاحتلال الاسرائيلي وليست دولة ذات سيادة.

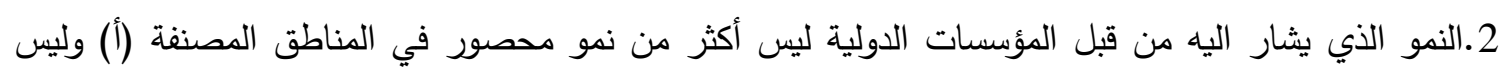
جميع الاراضي الفلسطينية خاصة المنطقة (ج) وهي تحت السيطرة الاسرائيلية الكاملة، وايضا تركزت المشاريع التتمية الكبيرة في مدن محدود وخاصة محافظة رام الله /البيرة. 3.انتشار المستوطنات في الضفة الغربية مثل النار بالهشيم مما ادى الى اعاقة جهود التتمية الاقتصادية كما تمنع من إقامة المشاريع الكبيرة والاستراتيجية. 4.الاقتصاد الفلسطيني يمنع من التعامل التجاري مع الدول التي ليس لدول الاحتلال الاسرائيلي علاقات سياسية

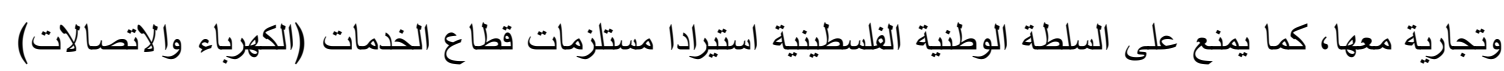
بدون التتسيق مع الاحتلال والحصول على الموافقة منه.

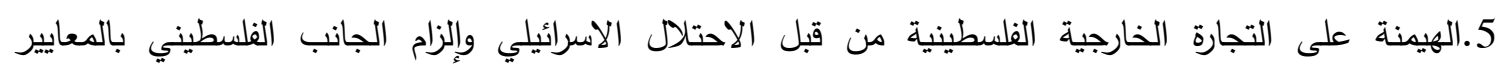
والمواصفات الإسرائيلية، فلا يمكن للمستورد الفلسطيني شراء بضائع لا تتطبق عليها المواصفات الإسرائيلية، وايضا

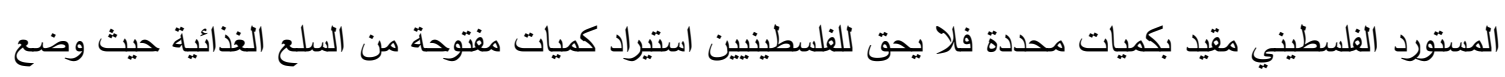
الاحتلال حد اعلى للاستيراد من هذه السلع يتم مناقشته من قبل اللجنة الفرعية كل ستة أشهر . 6.تخضع التجارة الخارجية الفلسطينية لنظام جمركي موحد مع دولة الاحتلال الاسرائيلي هذا يؤثر على أسعار البضائع في السوق المحلي الفلسطيني. حيث يفرض المستوردة الفلسطيني نفس الرسوم والجمارك والضرائب التي دوري الإني تفرض على المستوردات الإسرائيلية. وتأتي خطورة هذا الموضوع. 7.تقوم دول الاحتلال الإسرائيلي بجمع الإيرادات الجمركية على البضائع المستوردة وتبقيها لديها بعدها تقوم بتحويلها الىى الحكومة الفلسطينية بعد خصم 3 \% مقابل خدمات التحصيل. وفي العديد من المرات تم رفض الإنس تحويل هذه الأموال لديها بأعذار مختلفة لا أساس لها من صحة. 8.كل عيوب اقتصاد دولة الاحتلال الإسرائيلي، تتتقل الى الاقتصاد الفلسطيني مع عدم القدرة على ايجاد أي اليات للحد من آثارها. الموازنة العامة: المن التها:

لقد انتقلت السياسة المالية من الحياد الي التتخل مع اتساع دور الدولة ليشمل تقويم المسار الاقتصادي وتحقيق التوازن الاجتماعي، فالموازنة العامة للدولة تتضمن تقديرًا للإيرادات العامة والنفقات العامة عن مدة قادمة فهي خطة فئة

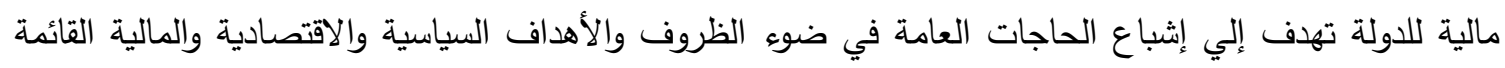
في المجتمع، ويمكن القول أن الموازنة العامة للدولة ليست مجرد بيان يتضمن الإيرادات العامة والنفقات العامة، إنما وثيقة الصلة بالاقتصاد القومي والأداة الرئيسية التي يمكن عن طريقها تحقيق أهداف الدولة السياسية والاقتصادية الاجتماعية (Saqer, 2019). 
إن ابرز التعريفات والمفاهيم المتعلقة بالموازنة العامة ليست مفاهيم فنية وكأنها مسألة حسابية فحسب، فالموازنة في

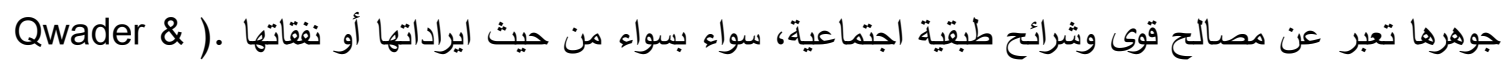
(Aloshaibat, 2020 فالموازنة العامة حسب (Williams \& Calabrese, 2016) " برنامج مفصل لنفقات الدولة وإيراداتها لسنة مالية معينة ويشمل التقديرات السنوية للإيرادات والمنح والقروض والمتحصلات الأخرى لها والنفقات والمدفوعات المختلفة"، ويعرفها (Qwader \& Aloshaibat, 2020) على انها: "الأداة المالية الأساسية وبرنامج الدولة التفصيلي للنفقات والإيرادات لمختلف النشاطات المقدرة لسنة مالية معينة، لتحقيق الأهداف والسياسات المالية والاقتصادية والاجتماعية، وما لم يكن استثناء بحكم القانون أو اتفاقية دولية أو عقد قانوني، فإن الموازنة العامة تحتوي على الصندوق الموحد وكل الصناديق الخاصة". وحسب رأي الباحث فان الموازنة العامة هي عبارة عن عملية توقع وعملية إجازة لكل من النفقات العامة والإيرادات العامة خلال مدة سنة مالية قادمة، ونظرًا للدور الذي تلعبه الموازنة العامة في الاهتمام بالبعد الاجتماعي كركيزة

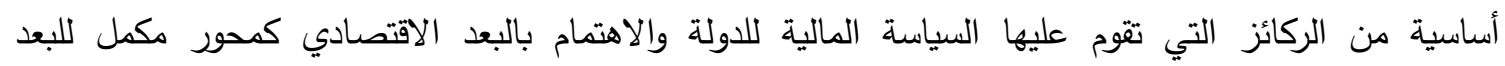
الاجتماعي، وذلك بهدف إحداث التتمية الثاملة والمتواصلة وزيادة معدلاتها السنوية بما يفوق معدلات الزيادة الطبيعية في السكان. إيرادات المقاصة في الموازنة العامة في فلسطين: يمكن تعريف ضريبة المقاصة (الفاتورة الموحدة) على انها "ضريبة القيمة المضافة التي تحصلها السلطات الضريبية

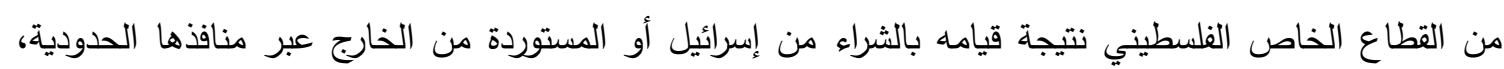
حيث تدفع لدى الجانب الإسرائيلي والذي يقوم بدوره بتحويلها إلى وزارة المالية في نهاية كل شهر عبر آلية المقاصة

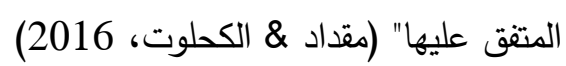
- مكونات إيرادات المقاصة: تتقسم الايرادات المتحصلة من ضريبة المقاصة الى البنود التالية (عزريل، 2017):

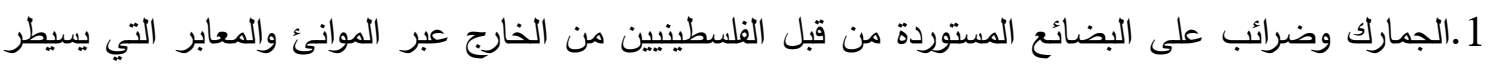
عليها الاحتلال الإسرائيلي حيث قامت السلطة الوطنيّة الفلسطينيّة بتوكيل الاحتلال الإسرائيلي بجمع هذه الجني الجمارك والضرائب بناء على اتفاق باريس الاقتصادي: ولقد جاء البند 15 من اتفاقية باريس الاقتصادية على انه مقاصة

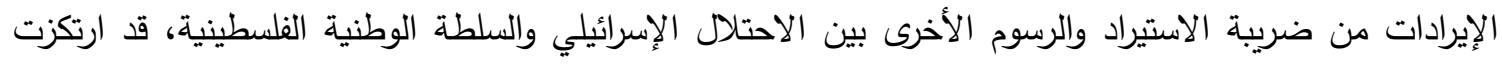

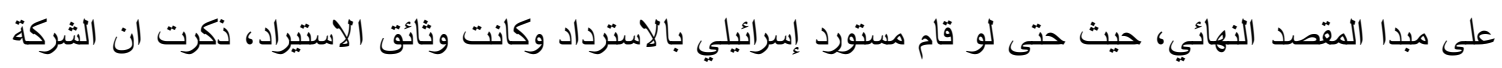

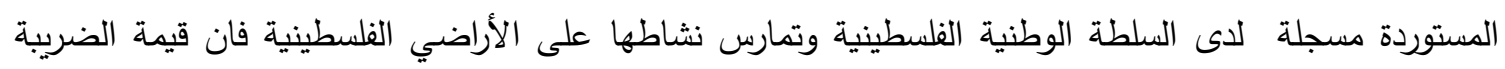
تكون للسلطة الفلسطينية. 2.ضريبة الدخل على أجور العمال الفلسطينيين في إسرائيل والمستوطنات: ان دولة الاحتلال سوف ترسل الى فلى السلطة الوطنية الفلسطينية ما يساوي 75\% من قيمة ضريبة الدخل على العاملين الفلسطينيين من قطاع غزة واريحا

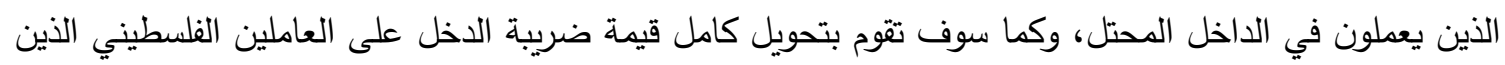
يعملون في المستوطنات. 3.الضرائب غير المباشرة على المشتريات من إسرائيل: ولقد نص البند 36 من اتفاق باريس الاقتصادي على قيام دائرة الضرائب الإسرائيلية على تحصل ضريبة المضافة، واي ضريبة غير مباشرة، بعدها تقوم بتحوليها الى السلطة الفلسطينية بعد اجتزاء ما نسبته 3 \% من قيمة الإيرادات المحصلة. 
- أهمية إيرادات المقاصة:

تتبع أهمية فاتورة المقاصة، بسب التداخل الكبير بين الاقتصادي الفلسطيني والإسرائيلي وحرية التتقل البضائع بين الطرفين، وهنا يأتي دور فاتورة المقاصة في المساعدة في حصر عمليات التبادل التجاري بين الجانبين ويمكن

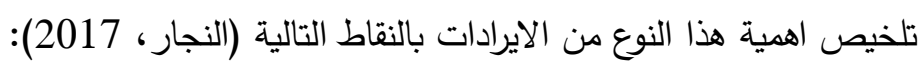
1-فاتورة المقاصة تعد أكبر إيراد للسلطة الوطنية الفلسطينية، فهي تثكل ثلثين إيرادات الحكومة الفلسطينية، حيث تعتمد عليها الحكومة الفلسطينية بشكل كبير في التمويل النفقات العامة الجارية. 2-تعتبر فاتورة المقاصة أداة لتحديد استحقاقات السلطة الوطنية لفلسطينية لدى الجانب الإسرائيلي.

3-الاسترشاد بالمعلومات صادرة عن دائرة المقاصة المركزية من قبل الوزارات والدوائر الحكومية وذلك من اجل: وضع الإحصائيات اللازمة لتحديد حجم التبادل التجاري بين الجانب الفلسطيني والاحتلال الإسرائيلي، وبناء صورة عن حجم هذا التبادل وأثره على الاقتصاد الفلسطيني.

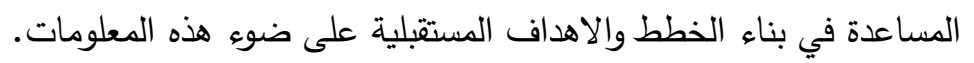
- تحكم الاحتلال الاسرائيلي في ضريبة المقاصة:

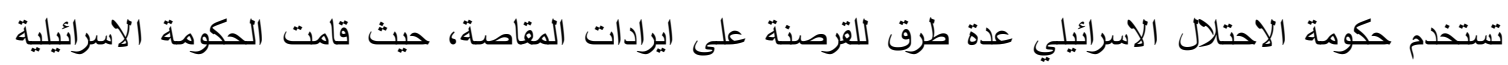

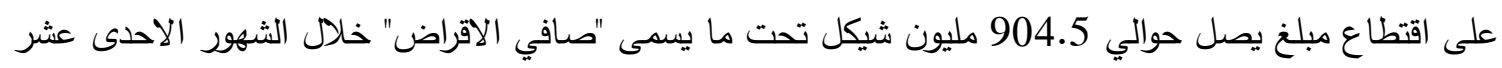
الاولى من عام 2017 (النجار، 2017). يقصد بصافي الإقراض: " هو ما يخصمه الجانب الاسرائيلي من ايرادات المقاصة لتغطية فواتير الكهباء، والمياه، والصرف الصحي، المتراكمة على وحدات الحكم المحلي (وزارة المالية،

وضمن سلسلة الابتزاز المستمرة قامت حكومة الاحتلال الاسرائيلي على تقديم مشروع جديد، يقوم على خصم

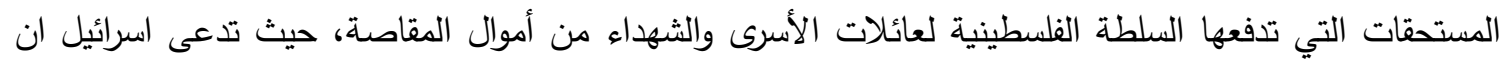
هذه الاموال التي تدفعها السلطة الوطنية لهذه الاسر تدعم الارهاب، و حيث تبلغ قيمة هذه المخصصات 400 مليون دولار امريكي سنويا (النجار، 2017). النفقات العامة في فلسطين - - تعريف النفقات العامة للنفقات العامة العديد من التعاريف نذكر منها "بأنها مبلغ من المال يخرج من الذمة العامة للدولة (خزينة الدولة)، أو

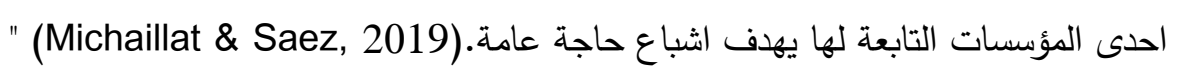

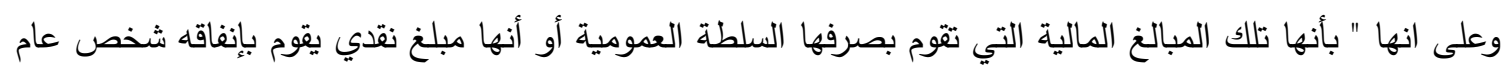

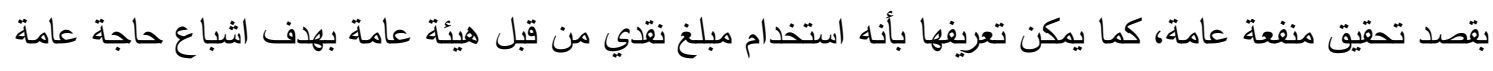
(Sasmal \& Sasmal, 2016).

وتعرف ايضا " هي ما يعبر عن حجم التدخل الحكومي والتكفل بالأعباء العمومية سواء من قبل الحكومة المركزية

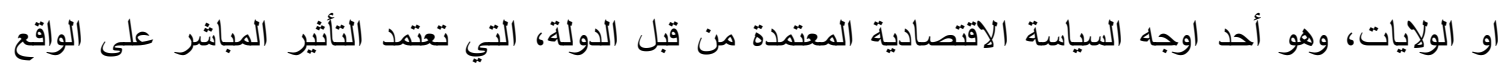

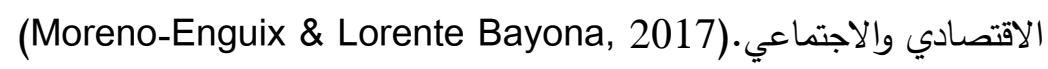
- أنواع النفقات العامة في فلسطين يمكن تقسيم النفقات العامة في فلسطين الى نوعين راسين ها كما يلي: 
النفقات الجارية: "وتثمل الرواتب والأجور والعلاوات والنفقات التشغيلية والتحويلية للوزارات والمؤسسات العامة

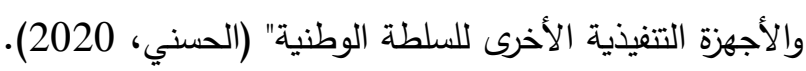
تنقسم النفقات الجارية الى خمس انواع رئيسية وهي كما يلي:(Abu-Eideh, 2015) - الرواتب والأجور : تشمل رواتب وأجور الموظفين والعاملين في أجهزة السلطة الفلسطينية المدنية والعسكرية. - النفقات التثغيلية: هي نفقات تتفقها الدولة من خلال عملياتها اليومية الاعتيادية وتثمل مصاريف الديف المياه والكهرباء والهاتف والبريد والمواصلات والصيانة ومصاريف أخرى.

- النفقات التحويلية: يشمل هذا البند مساهمة الحكومة الفلسطينية في الضمان الاجتماعي 12.5\% التي تدفعها

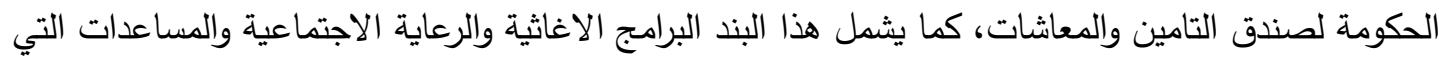
تقدمها السلطة الفلسطينية للمواطنين المتضررين من الاحتلال الاسرائيلي.

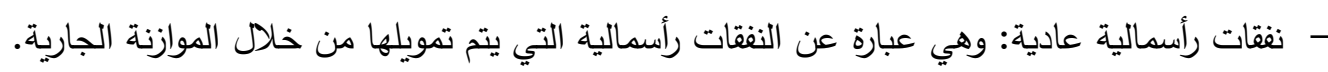
- صافي الإقراض: هو ما يخصمه الجانب الإسرائيلي من ايرادات المقاصة لتغطية فواتير الكهرباء، المياه،

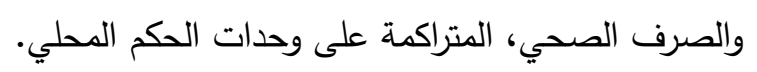
ثانيا: النفقات التطورية النفقات التطويرية: وهي النفقات التي لها طبيعة تختلف عن النفقات الجارية من حيث العمر الافتراضي والعائد من النفقة، وتمول من موازنة السلطة ومن المانحين (الحسني، 2020). و ان النفقات التطورية تمتاز بطول العمر الافتراضي ويوجد فيها البعد التتموي، حيث يكون للأنفاق التطويري عائد عائد حالي ومستتبلي، تكون هذه العوائد على عدة اشكال منها على شكل ارباح او زيادة في رأس المال الثابت او زيادة

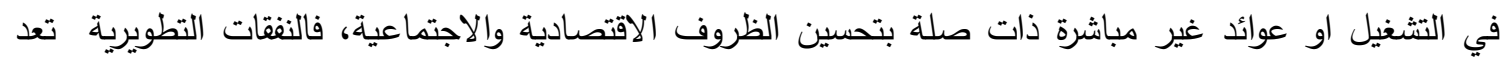
نفقات غير طارئة ولكن تأتي اوليتها متأخرة في الموازنة بسب قلت فلة الموارد المالية ، وغالبا يتم الاعتماد على المنح او الايرادات من خارج صندوق الايرادات الضريبية في تمويل النفقات التطوير (النجار ، 2017) فئنة

عجر الموازنة العامة يقصد بعجز الموازنة "هو الرصيد السالب للموازنة العامة للدولة، والناتج عن كون النفقات تفوق الإيرادات. وتضطر

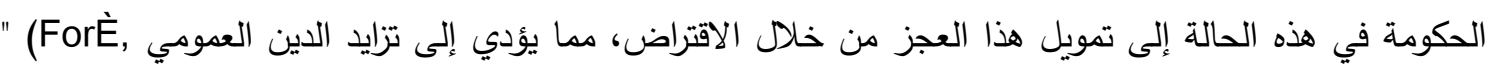
(LÄfzÄfrescu, \& loan, 2020)

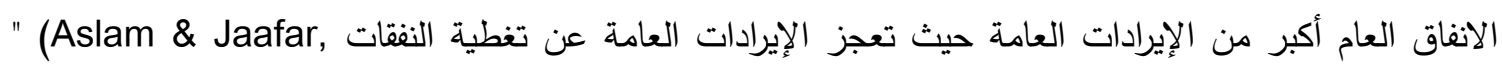

كما تم تعريفه على انه "مجموع الايرادات مطروحا منها النفقات يسمى عجزا إذا كان مجموع النفقات أكبر من

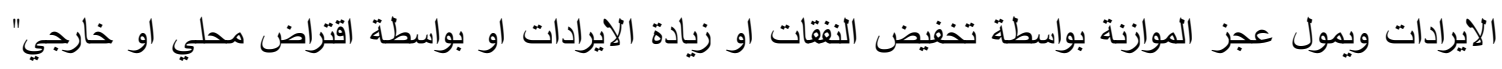
(الفهداوي، 2020). - - - مانواع عجر الموازنة العامة،

يمكن تصنيف العجز في الموازنة العامة الى عدة انواع على النحو التالي (جودة \& صالح، 2020): 1. العجر الثامل: هو المفهوم التقليدي للعجر المالي، وهو الذي يقيس الفروق بين اجمالي النفقات العامة متضمنة التهات مدفوعات الفوائد، ولكن لا تثمل على مدفوعات أصل الدين العام، وبين الايرادات العامة متضدنة الايرادات الضرببية وغير الضريبة والقروض. 
2. الدين العام: يعرف "على أنه الرصيد القائم (غير المسدد) للالتزامات الحكومية المباشرة وغير المباشرة، والمترتب

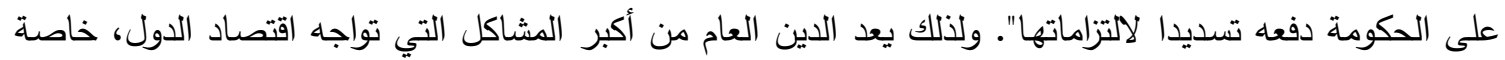

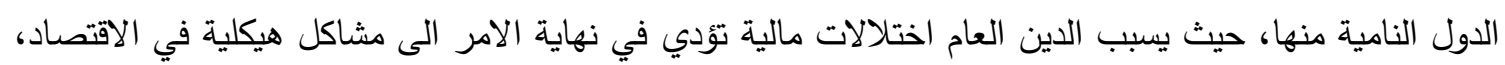

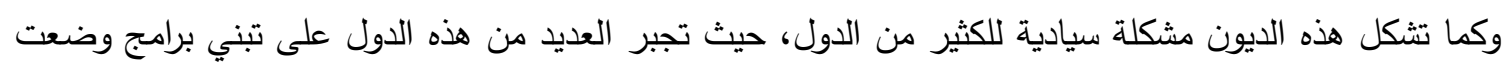

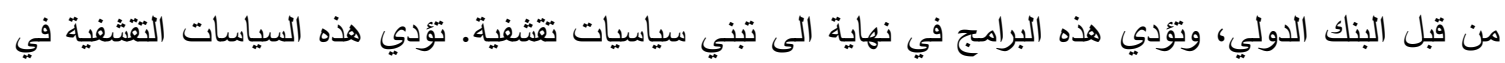

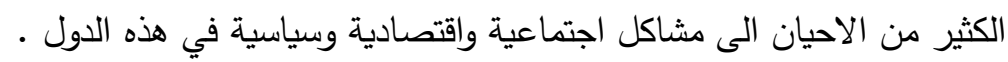

3. العجر الجاري: هو الفرق بين الايرادات الجارية والنفقات الجارية، ولكن يتم استثناء المساعدات الدولية لدعم

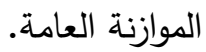

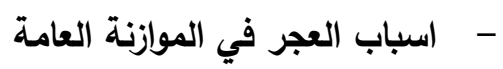
ترجع اسباب العجر في الموازنة العامة الى سببين رئيسين وهما كما يلي (فرحان \& محمد، 2020):

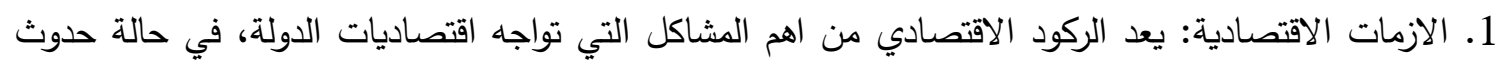
الركود الاقتصادي يجب على الدول وضع مجموعة من خطط وسياسات للخروج من هذه الازمة، من اهم هذه الهاته

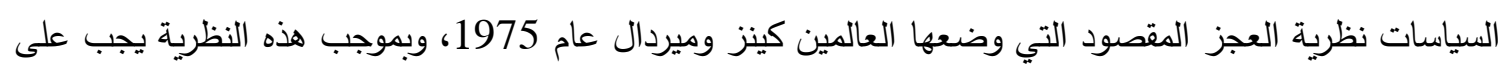
الدول التوسع في الانفاق الحكومي، حيث يعد الانفاق الحكومي اداة مهمة وفعالة في معالجة الركود الاقتصادي ودفع عجلة الاقتصاد. 2. ازدياد الأعباء المالية حيث يمكن ارجاع ازدياد الاعباء المالية في الموازنة في العصر الحديث الى خمس عناصر رئيسية وهي (الحسني، 2020): •ضخامة الجهاز الاداري الحكومي وتعقد العمليات الادارية فيه. •توسع في النفقات العسكرية للدول. •تعاظم حجم النفقات التحويلية التي تدفعها الدولة على شكل مساعدات واعانات . •تفاقم ازمة الديون السيادية للدول. •التضخم وتآكل القيمية الثرائية للنقود وعليه فإن الحكومة لكي تحصل على نفس الكمية من السلع والخدمات عليها أن تدفع عدداً أكبر من وحدات النقد.

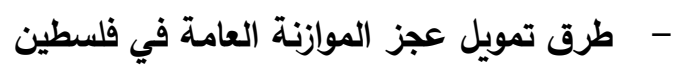
يمكن تمويل العجر في الموازنة العامة من خلال مصدين رئيسين وهما التمويل الخارجي والتمويل المحلي:

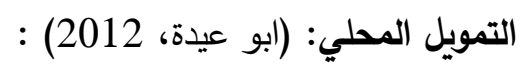
•الاقتراض من المصرف المركزي، حيث ان هذه الاسلوب في تمويل العجز لا يؤدي الى تأثير انكماشي في الطلب الكلي، وذلك لان البنك المركزي لا يقوم بتخفيض الائتمان في مكان اخر حتى يقوم بتوسيع الائتمان للحكومة.

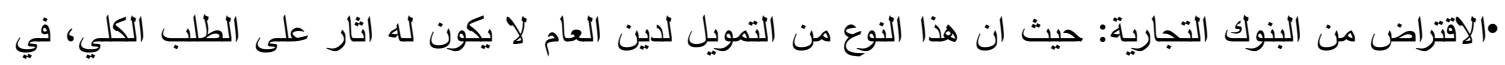

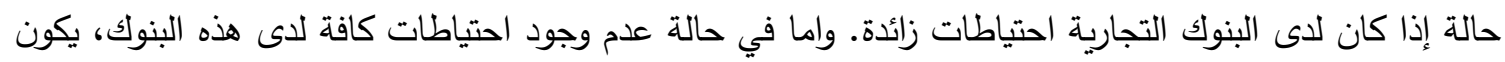
هذا على حساب القطاع الخاص. •الاقتراض من القطاع الخاص خارج نطاق البنوك: يكون لهذا النوع من الاقتراض اثار انكماشية في الطلب الكلي،

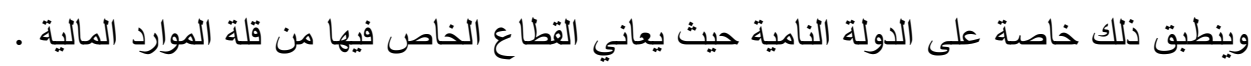

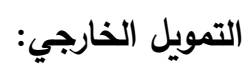


هو التمويل الذي يكون مصدره من خارج الدولة، ويأخذ شكلين رأسيين في الموازنة العامة الفلسطينية المنح المقدمة لدعم النفقات الجارية والمعونات المقدمة لدعم النفقات التطورية، حيث ان ان المعونات الخارجية ليست كلها تأتي لئي شكل منح، بل ان جزء منها يأتي بصورة قروض ميسرة، وتتميز هذه القروض بأسعار فائدة منخفضة و طول الفترة

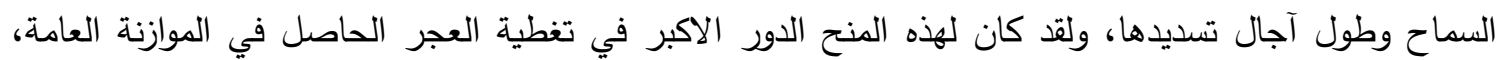
وكما كانت في بعض السنوات قيمة هذه المنح والمساعدات تتجاوز قيمة العجر الحاصل في الموازنة العامة (محمد،

الدراسات السابقة

دراسة (مدللة، 2018) بعنوان "محددات الإيرادات العامة الفلسطينية وتحليها" هدفت هذه الدراسة على التعرف على هيكل الايرادات العامة الفلسطينية، ودراسة التطور هذه الايرادات، كما هدفت ايضا هذه الدراسة على تعرف على اهم المحددات الداخلية والخارجية الى ادت الى عرقلة تطور الايرادات العامة

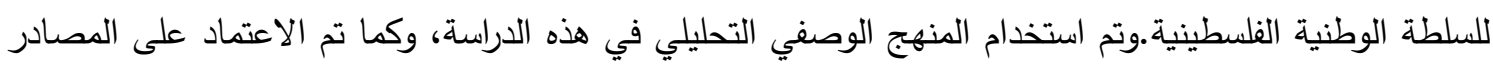
الرسمية للبيانات الصادرة عن الجهاز المركزي للإحصاء الفلسطيني وسلطة النقد الفلسطينية. وتوصلت الدراسة من مجموعة من النتائج وكان من اهمها، ان هناك تسرب مالي يقدر 313 مليون دولار عام 2014 ذلك بسب طبيعية العلاقات بين السلطة الوطنية الفلسطينية والاحتلال الاسرائيلي، كما توصلت أيضا ان ان فندان

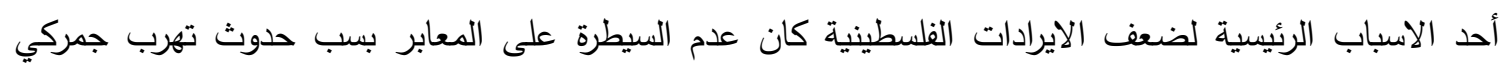
بشكل كبير • ولقد اوصت الدراسة الى ضرورة الحد من التبعية الاقتصادية دول الاحتلال الاسرائيلي. دراسة (العتابي، 2018) بعنوان "أثر الضرائب الجمركية في دعم الموازنة العامة (دراسة تطبيقية في الهيئة

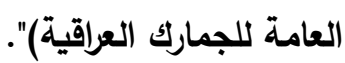

تحدث هذا البحث عن اهمية الايرادات الضريبية في ظل العجز الذي تمر فيه ميزانية العراق، وأثر ذلك على التتمية، وتحدث عن اهمية الضرائب في تمويل الخزينة، وانعكاس هذا على تحقيق الاهداف السياسية والاجتماعية والاقتصادية.وتحدث عن دور عملية التهرب الجمركي، والاثر المدمر المحتمل على زيادة العجز في الموازنة،

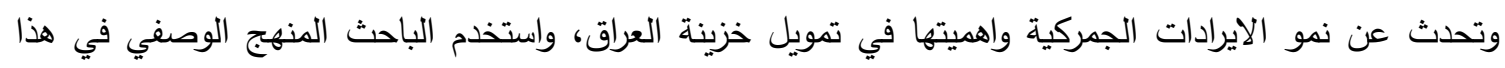

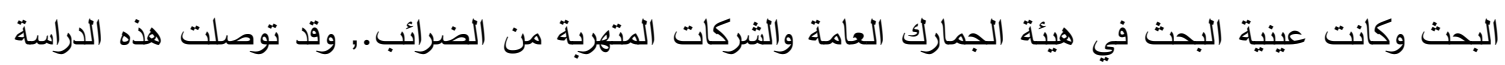

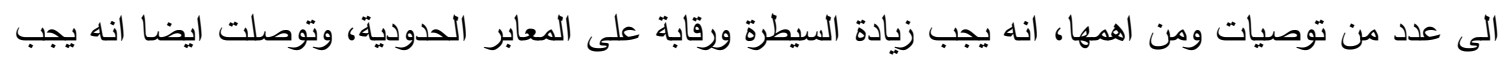

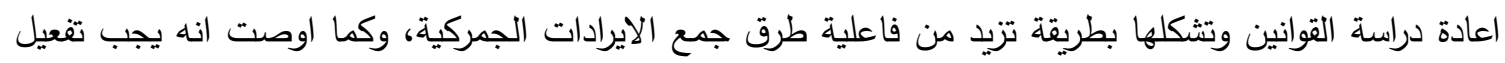
جهاز رقابي حتى يتم الحد من التهرب الضريبي. دراسة (عزريل، 2017) بعنوان "تأثير بروتوكول باريس الاقتصادي على الايرادات الضريبية في فلسطين" لتوبي

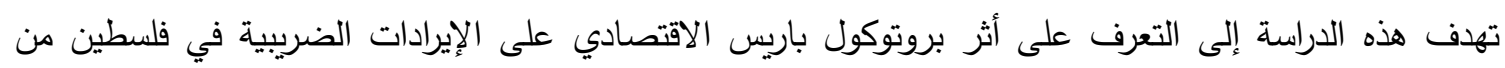

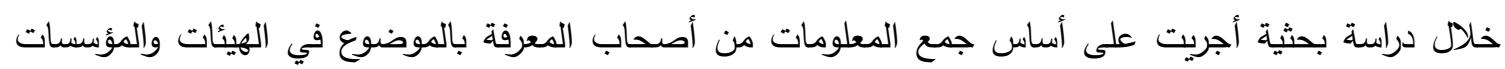

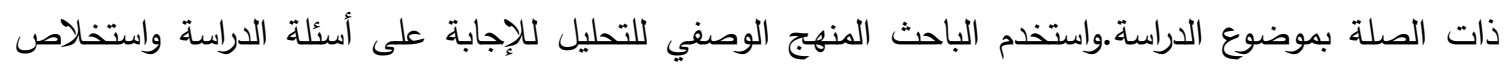

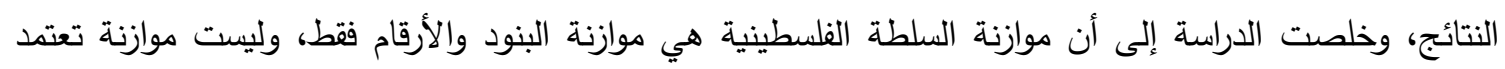
على البرامج والأداء، وفي ضوء نتائج الدراسة أوصى الباحث بعدة توصيات منها العمل على زيادة الإيرادات الضرببية الفلسطينية من خلال التركيز على توسيع قاعدة دافعي الضرائب لتثمل بالإضافة إلى موظفي السلطة موظفي القطاع الخاص والعاملين في القطاع الخاص في جميع المناطق الفلسطينية، من خلال رفع الوعي وزيادة الكفاءة، وإدارة الضرائب، وتفعيل القضاء. 
دراسة (ابو مدللة والخضري، 2016) بعنوان "الايرادات العامة والنفقات العامة الفلسطينية: المشكلات والحلول "(2015-1995) جاءت هذه الدراسة لتعرف على الواقع الايرادات والننقات العامة للسلطة الوطنية الفلسطينية في الفترة الواقعة من عام 1995 الى عام 2015، ودراسة العجر الحاصل في الموازنة العامة الفلسطينية، نتيجة لتضخم النفقات العامة والنقص الحاد في الايرادات، وتقديم حلول واقعية وعملية من اجل ضبط النفقات العامة وزيادة الايرادات العامة.,

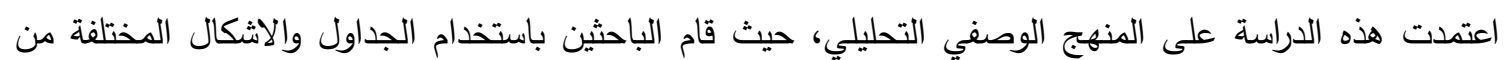

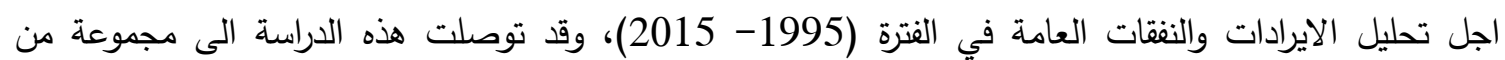
النتائج وكان من أهمها، ان الموازنة العامة الفلسطينية تعتمد على نوعين رئيسيين من الايرادات في تمويل الانفاق العام، اولا المساعدات الدولية التي شكلت ما نسبته 38.1\% من اجمان الهالي الايرادات العامة والمنح، وثانيا تحويلات

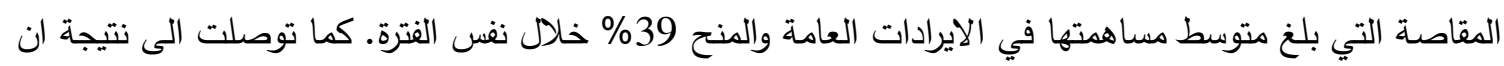
السبب الرئيسي للعجر الحاصل في الايرادات العامة للسلطة الفلسطينية كان اتفاق باريس الاقتصادي.وقد انتهات

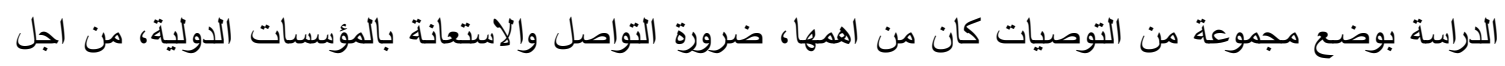

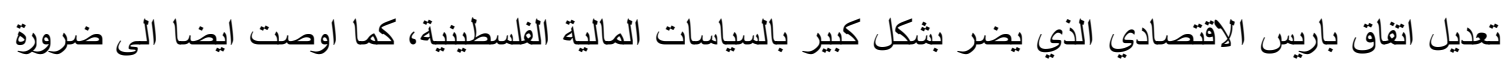

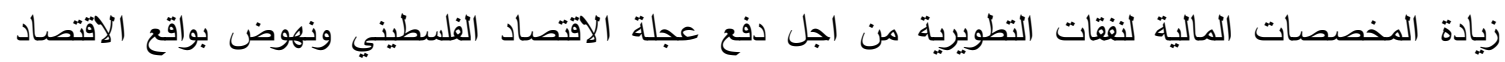
الفلسطيني. دراسة (عيدة، 2014) بعنوان "دراسة أثر الإنفاق الدكومي على النمو الاقتصادي في الأراضي الفلسطينية:

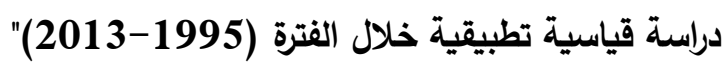
تهدف هذه الدراسة الى دراسة العلاقة السببية بين الانفاق الحكومي بشقيه (الجاري والتطوير)، والنمو الاقتصادي

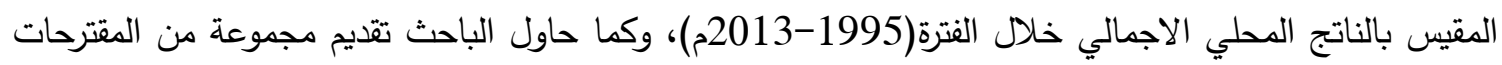
تساهم في ضبط عملية الانفاق الحكومي بشكل سليم. حيث استخدم الباحث المنهج الاحصائي الوصفي لتحليل

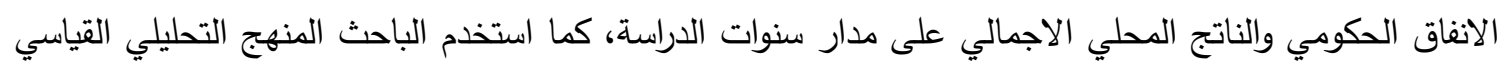
من خلال قيامه ببناء نموذج قياسي يفسر أثر الانفاق الحكومي على النمو الاقتصادي، حيث قام الباحث باستخدام برنامج spss في التحليل البيانات.وقد توصل الباحث ان هناك علاقة سببية موجبة بين اجمالي الانفاق الحكومي

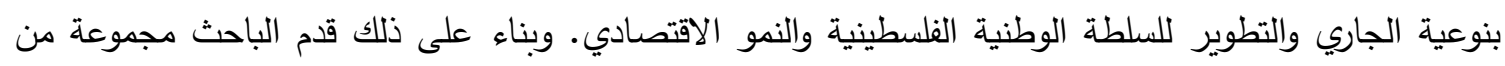
التوصيات كان من اهمها، انه يجب على السلطة الوطنية الفلسطينية زيادة حصة الانفاق الموجه للأنفاق التطويري

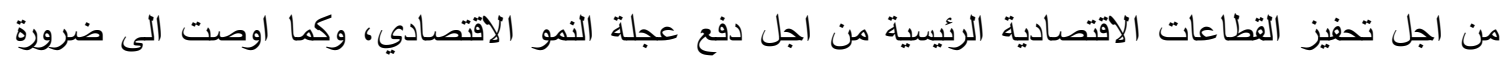

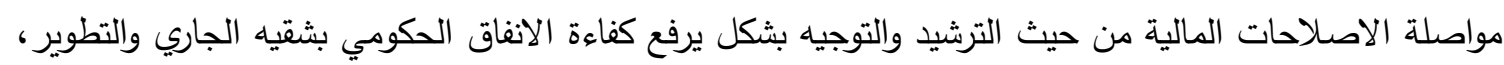
وذلك من اجل دعم صمود الاقتصاد الفلسطيني. دراسة (الأونكتاد، 2014) بعنوان "تسريب الايرادات المالية الفلسطينية الى اسرائيل في ظل بروتوكول باريس

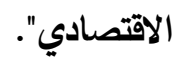
هدفت هذه الدراسة الى تقدير نسب التسرب المالي الحاصل لدى السلطة الوطنية الفلسطينية، كما هدفت ايضا الى

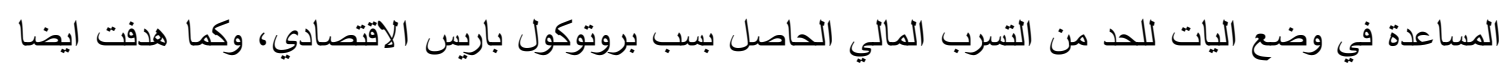

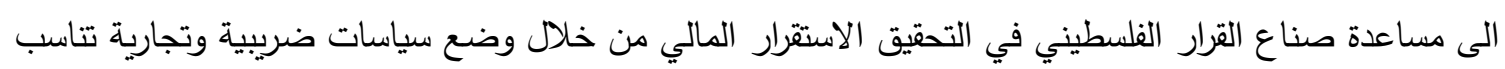
الوضع الفلسطيني. 
استخدمت هذه الدراسة لتقيم الخسائر الحاصلة في ضريبة القيمة المضافة وضريبة الثراء والتهرب الجمركي الحاصل عن الاستيراد الغير مباشر على المنهجية التالية: استخدام الدراسات ذات الصلة بموضوع الدراسة وايضا استخدام الادبيات السابقة ذات المتصلة بالموضوع، واستخدام البيانات الاولية الصادرة عن بيانات الجهاز المركزي للإحصاء الفلسطيني ومن ثم تحليل هذه البيانات وتحويلها من التصنيف الإحصائي السلعي الموحد إلى النظام

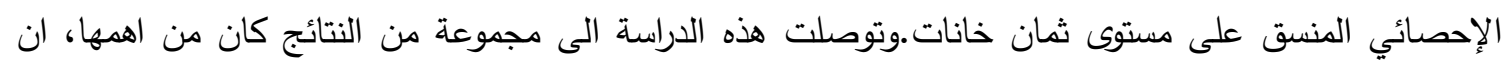
التسرب المالي الحاصل ناتج عن بنية اتفاق باريس الاقتصادي، وكما توصلت ايضا الى الدراسة الى ان دول

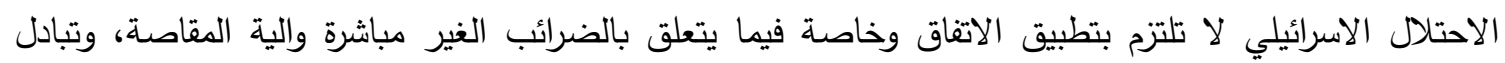

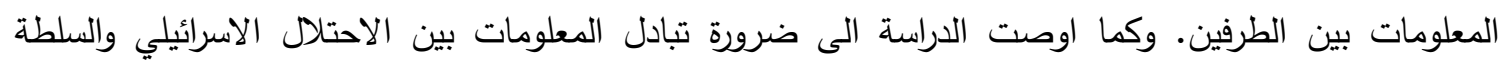
الوطنية الفلسطينية وفق الية واضحة فيما يخص فواتير المقاصة. دراسة (مدللة و زعيتر، 2013) بعنوان " دور الإيرادات المحلية في تمويل الموازنة العامة للسلطة الفلسطينية "2010-2000 هدفت الدراسة إلى التعرف على الموازنة العامة للسلطة الفلسطينية ومراحلها المختلفة، وتحليل إيراداتها ونفقاتها العامة، وتبيان دور إيراداتها العامة في تمويل موازنتها العامة بشكل عام، والتعرف على مدى قدرة الإيرادات المحلية في تغطية النفقات الجارية لها بشكل خاص، وركزت كذلك على تحليل الإيرادات المحلية في الفترة 2000 - 2010 بالاعتماد على استخدام أسلوب التحليل الوصفي المقارن بدراسة الواقع ووصفه من خلال تحليل الموازنات العامة والتقارير المالية الفعلية الصادرة عن الجهات الرسمية." "وتوصلت الدراسة إلى أن اتفاقية باريس الاقتصادية هي لإني

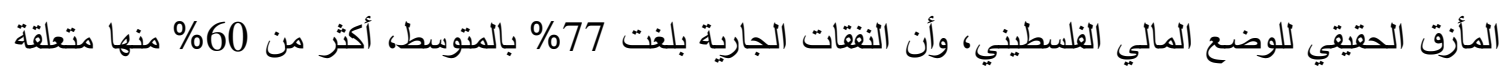
بالرواتب والأجور ، وخلصت الدراسة أيضاً إلى أن إسرائيل تتحكم في أكثر من 64 الوضعات من من الإيرادات المحلية للسلطة

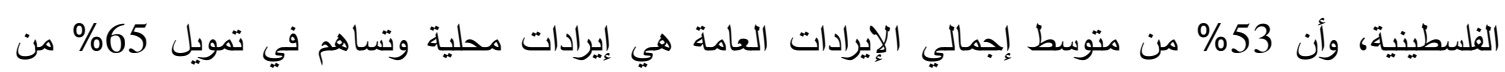

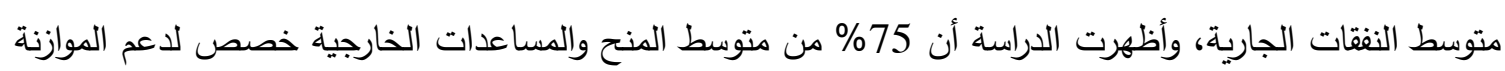

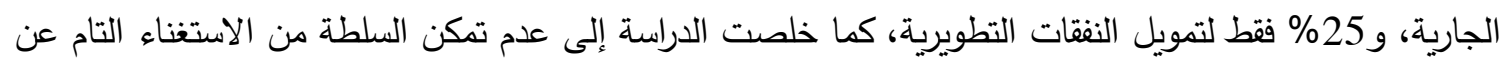
المساعدات الخارجية لدعم الموازنة الجارية في موازنة العام الجاري 2013 كما وعدت في مشروع موازنة العام

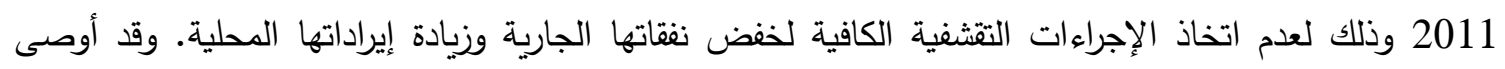
الباحثان بضرورة سعي السلطة لتعديل اتفاقية باريس الاقتصادية، والانتقال من موازنة البنود إلى موازنة البرامج

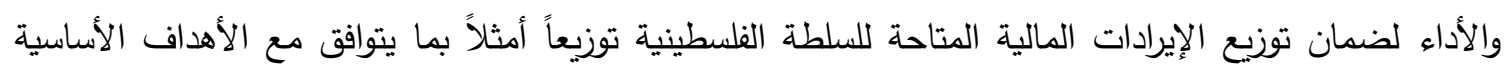

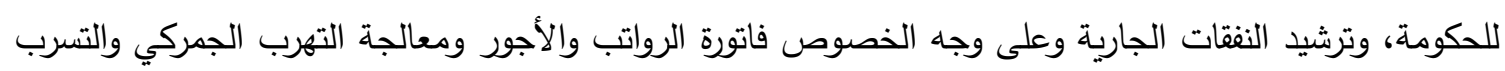

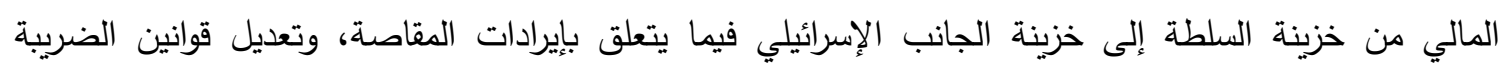

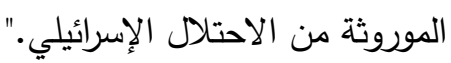

دراسة (صالح، 2007) بعنوان "العوامل المساهمة في زيادة حجم عائدات السلطة الفلسطينية من ضريبية القيمة

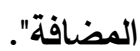

تحدثت هذه الدراسة ان الضريبية هي احدى المصادر الرئيسية، التي تمول خزينة الدولة حتى تقوم بأدوارها، وتحدث عن الضريبية الغير مباشرة، وهي التي تمثل اغلب الايرادات الضريبية مثل ضريبية القيمة المضافة.

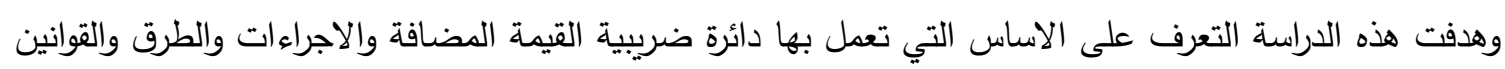

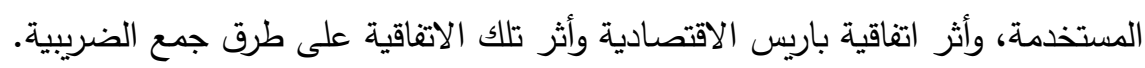


وتم استخدام المنهج الوصفي التحليلي، وتم استخدام الاستبانة في جمع البيانات وقد تم توزيع 40 شخص وتم استرداد من 39 شخص، واوصت هذه الدارسة على تطوير هيكل دائرة ضريبية القيمة المضافة بناء هذه الدائرة على اساس علمي، كما اوصت ايضا على رفع مستوى التدريب والكفاءة والتطوير المستمر لقدرات لدى الموظفين في دائرة الضربية.

دراسة (حميض، 2005) بعنوان "تأثير المقاصة على الايرادات الضريبية في فلسطين من (1995-2005)"

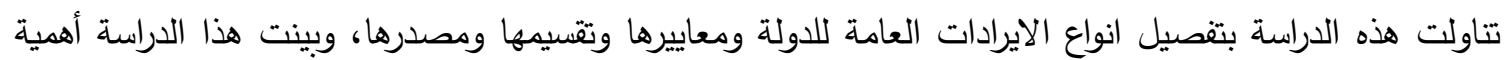
الضرائب في مد الخزينة الحكومة بالأموال التي تحتاجها لكي تقوم بالأدوار المناطة بها، وتوصلت هذه الدراسة الى لى

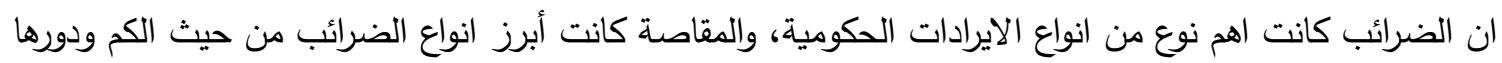
الكبير في مد الخزينة بالأموال، وأثر انتفاضة الاقصى انواعى على الايرادات اتصات الضربيبة. وهدفت هذه الدراسة الى تعرف على ايرادات الدولة وانواعها وحجمها، واهم القوانين المنظمة ما بين الفترة (19952005) والتعرف على ضريبة المقاصة بشكل مفصل، وقد تم استخدام المنهج الوصفي في هذه الدراسة وتم اجراء التحليل المالي للإيرادات الضريبية ومتطلبات المقاصة، وقد أوصت هذه الدراسة بعدة بعدة توصيات واهمها بضرورة زيادة

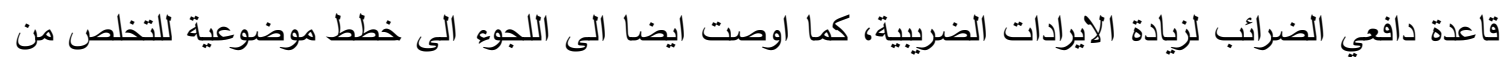
التبعية للاقتصاد الاسرائيلي من ابعاد مرحلية واستراتيجية.

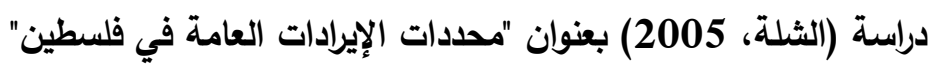

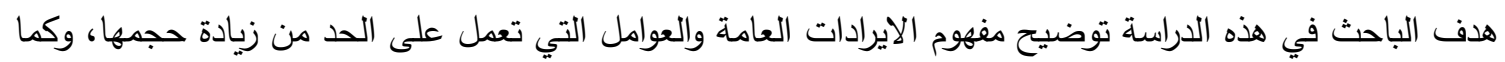
هدفت هذه الدراسة ايضا الى التعرف على الصعوبات التي تواجه الاقتصاد الفلسطيني وتمنعه من مجاراة الاقتصاديات المجاورة، وايضا هدفت الدراسة الى محاولة فهم أثر اتفاقية باريس الاقتصادية على الايرادات العامة

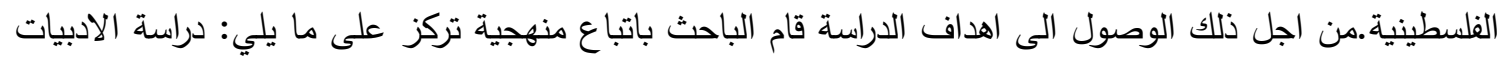

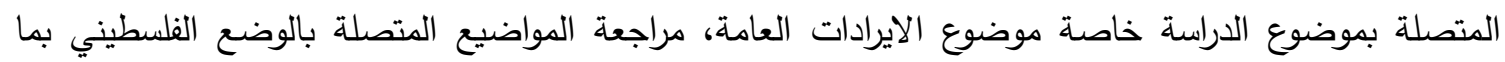

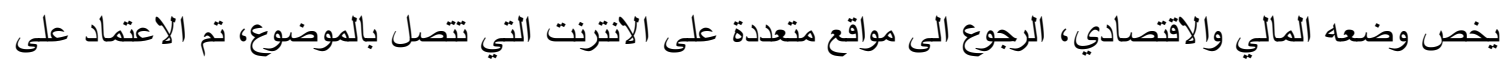
البيانات الصادرة عن الجهاز المركزي للإحصاء الفلسطيني وسلطة النقد الفلسطينية والبنك الدولي وبكدار والأمم المتحدة وجهات أخرى، والتحليل المنهجي للإيرادات العامة.وقد توصلت الدراسة الى مجموعة من النتائج كان من اهمها، ان اتفاق باريس الاقتصادي عانى من ثغرات خطيرة خاصة فيما يتعلق بالموارد الاقتصادية والمالية والسيطرة على الحدود، وكما توصلت ايضا الى ان التهرب الضريبي يؤثر بشكل كبير على الايرادات العامة. وبناء على هذه نئه

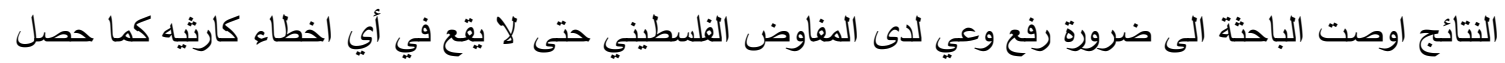

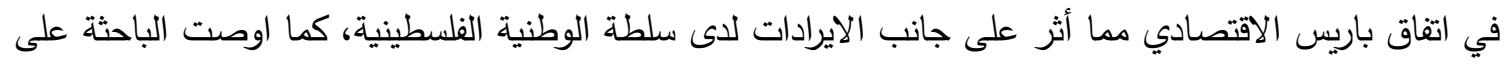
ضرورة الحد من التهرب الضريبي المشروع وغير المشروع.

دراسة (Ahuja \& Pandit, 2020) بعنوان " الإنفاق العام والنمو الاقتصادي: أدلة من البلدان النامية" تهدف هذه الدراسة الى دراسة العلاقة بين الإنفاق العام والنمو الاقتصادي باستخدام مجموعة بيانات أكثر وفرة

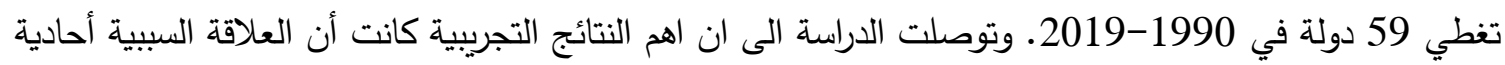
الاتجاه بين النمو الاقتصادي والإنفاق الحكومي حيث تمتد السببية بين الإنفاق العام ونمو الناتج المحلي الإجمالي. النتائج بثكل عام تدعم الإطار الكينزي الذي يؤكد أهمية الإنفاق الحكومي في تحفيز النمو الاقتصادي. علاوة على الإنى ذلك ، يكثف التحليل أنه بعد النظر في جميع متغيرات التحكم مثل إمكانية الوصول إلى التى التجارة والاستثمار والتضخم ، يؤثر الإنفاق العام بثكل إيجابي على النمو الاقتصادي. فيما يتعلق بمتغيرات التحكم ، وجد أن أن 
الاستثار له تأثير كبير وإيجابي على النمو الاقتصادي. تظهر الأدلة من تقديرات الانحدار كذلك أن الانفتاح

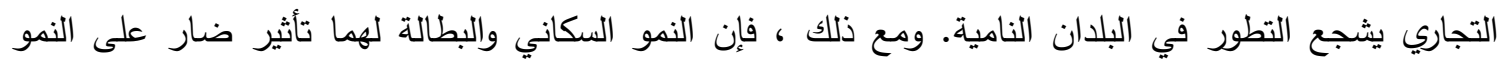

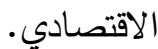

دراسة (kun Wang, Zhang, \& Ho, 2020) بعوان " أولوية استغلال الإيرادات المالية أو تقليل الإنفاق

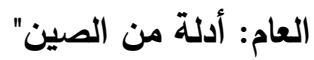

تهدف هذه الدراسة الى البحث في العلاقة السببية بين الإيرادات المالية للصين والنفقات العامة من عام 1990 إلى عام 2018. إذا كان للإيرادات المالية تأثير إيجابي على الإنفاق العام ، فإن ذلك يوضح العادئ أن على الحكومة تقليل

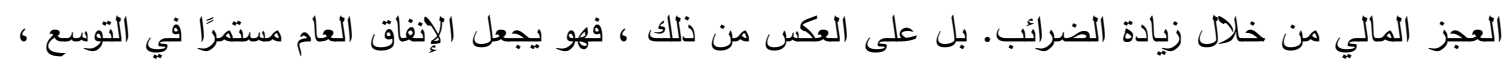

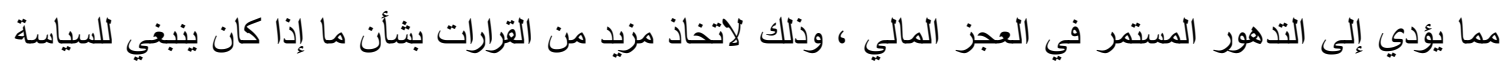

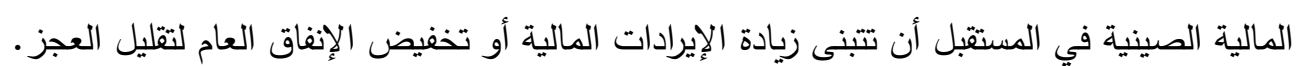
دراسة (Oumer \& Ramakrishna, 2020) بعنوان" الإيرادات الحكومية والنفقات والعجز المالي في إثيوبيا: نهج التكامل المشترك غير المتماثل". هذه الورقة هي محاولة للتحقق من العلاقة بين زيادة الإنفاق العام والإيرادات لإثيوبيا باستخدام بيانات سلسلة زمنية

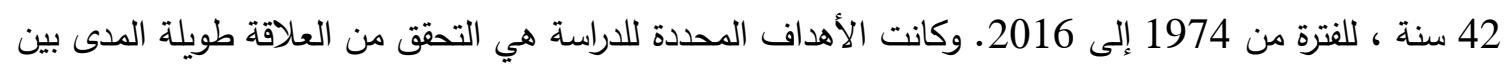
الإنفاق العام والإيرادات وتثييم آثار العجز المالي على النمو الاقتصادي. تم استخدام اختبار تكامل غير متماثل يعتمد على NARDL واستخدم اختبار Toda-Yamomoto للتحقق من السببية.تثير النتائج إلى وجود تكامل مشترك طويل المدى بين الإنفاق والإيرادات علاوة على ذلك ، وفيما يتعلق بالعجز المالي ، كثفت نتائج التكامل

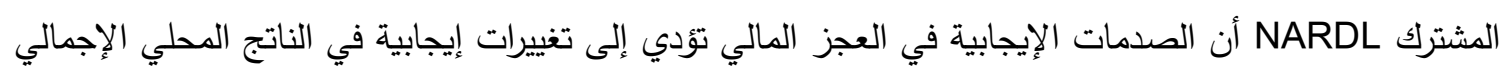

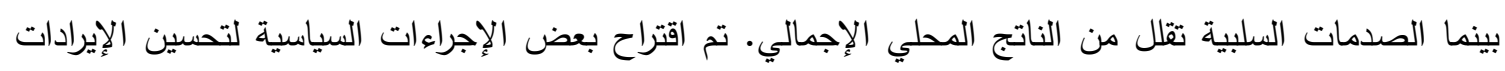
الضريبية وتقليل العجز المالي.

دراسة (Gazali, 2020) بعنوان " عجز الموازنة والديون: تحليل وصفي لحالة إندونيسيا"

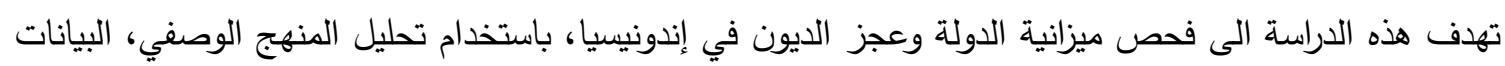
الثانوية التي تم جمعها من عام 1998 - 2014. وتوصلت لافراسة الى ان العجز الذي يحدث كان بسبب عدم كفاية

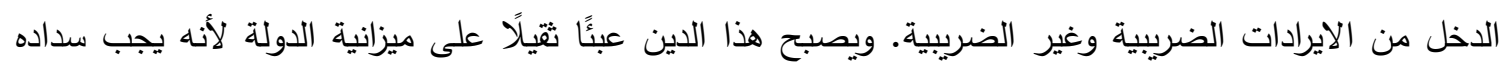
بأصل الدين والفائدة ولكن الموازنة لا تزال تعاني من العجز ، بعض الآثار المترتبة على العجز يجب العبئ أن يتم تمويلها

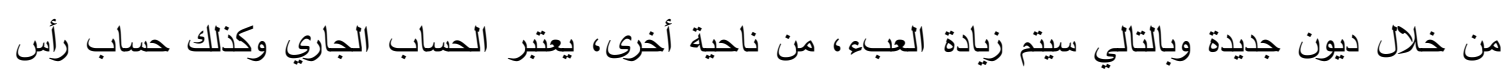
المال عجزًا أيضًا. دراسة (Kalloub \& Odabas, 2019) بعنوان "تقييم الاقتصاد الفلسطيني: الايرادات العامة، والنفقات، والقضايا الحالية" دراله

تهدف هذه الدراسة الى تقييم النظام الضريبي الفلسطيني إلى جانب النظام النقدي أيضًا، وتبدأ بمراجعة تاريخية للحالة الفلسطينية بما في ذلك التغيرات السياسية الرئيسية التي أثرت على شكل الاقتصاد الفلسطيني في الوقت

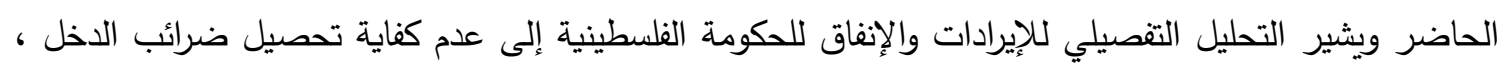
لكن الرقم الموثوق به للضرائب غير المباشرة، علاوة على ذلك، فإن سوء تخصيص الأموال العامة يحتل مكانة

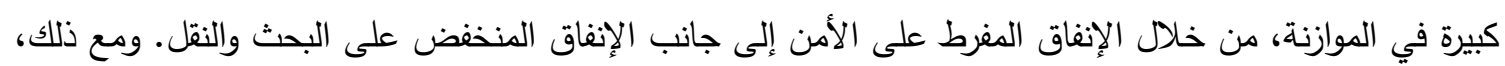

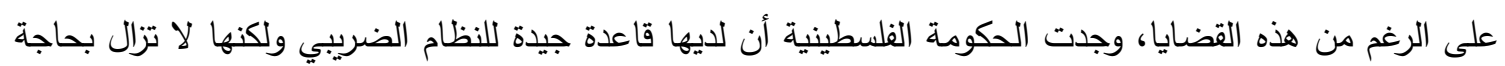


إلى العمل على زيادة تحصيل ضريبة الدخل وزيادة سيطرتها على الموارد المالية بما في ذلك تدابير ضد التهرب الضريبي وسوء تخصيص الأموال. التعقيب على الدراسات السابقة جاءت هذه الدراسة لقياس أثر الازمة المقاصة المتكررة عبر السنين في فلسطين على النفقات التشغيلية والتطويرية والعجز في الموازنة العامة، وعلى الرغم من الاهمية التي تحتلها هذه الظاهرة الى ان الباحث وجد ان هناك القليل من الدراسات التي تتاولتها بشكل متعمق، فدراسة (مقداد \& الكحلوت، 2016) تتاولت ازمة المقاصة والمعيقات التي لته يضعها الاحتلال الاسرائيلي امام الاقتصاد الفلسطيني. كما ان هناك عدة دراسات تتحدث عن النفات النقات العامة مثل دراسة (Ahuja \& Pandit, 2020; Kalloub \& Odabas, 2019) وغيرها تتحدث عن عجز الموازنة العامة مثل دراسة كل من (Kalloub \& Odabas, 2019; السبتي، 2019; عكاشة، 2018)، ولكن لا يوجد دراسات حسب علم الباحثان تربط بين ازمة المقاصة والنفقات العامة وعجز الموازنة، وعليه جاءت هذه الدراسة كأضافة بحثية نوعية في هذا المجال. المنهجية والاجراءات

تعتبر منهجية الدراسة وإجراءاتها محوراً رئيساً يتم من خلاله انجاز الجانب التطبيقي من الدراسة، وعن طريقها يتم

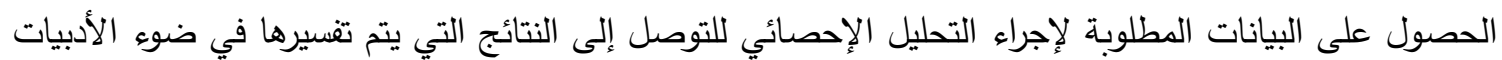
المتعلقة بموضوع الدراسة، وبالتالي تحقيق الأهداف التي تسعى الدراسة إليها. أولاً: منهج الاراسة:

من أجل تحقيق أهداف الدراسة استخدم الباحثان المنهج الوصفي التحليلي ، حيث استتد الى الدراسات السابقة والبحوث والاوراق العلمية في صياغة الاطار النظري للدراسة، وقام بجمع البيانات المالية من اصدارات سلطة النقد

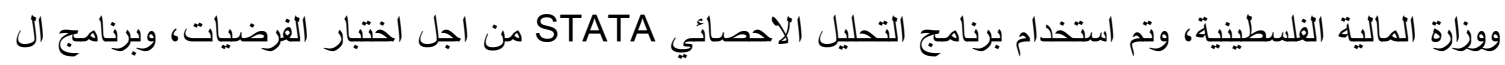
SPSS 23 ثانياً: بيانات الدراسة: يبين الجدول رقم (1) بيانات المتغيرات المستخدمة في الدراسة والتي قام بجمعها الباحثين من اصدارات سلطة النقد الفلسطينية ووزارة المالية ووزارة الاقتصاد.المصادر الثانوية: جدول رقم (1): بيانات الاراسة

\begin{tabular}{|c|c|c|c|c|c|c|c|}
\hline |الفالئي (العجز) & المقاصادات & الايرادات الياتي & التطورية & الجارية & النفالي & 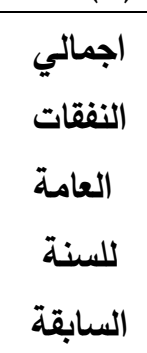 & السنة \\
\hline-54.78 & 475.94 & 1075.36 & 262.32 & 867.83 & 1130.14 & 1072.1 & 1997 \\
\hline 30.00 & 543.95 & 1104.74 & 235.79 & 838.95 & 1074.74 & 1301.1 & 1998 \\
\hline 4.59 & 579.71 & 1186.47 & 239.37 & 942.51 & 1181.88 & 1074.7 & 1999 \\
\hline
\end{tabular}




\begin{tabular}{|c|c|c|c|c|c|c|c|}
\hline-218.96 & 587.00 & 1449.00 & 469.00 & 1198.9 & 1667.96 & 1181.8 & 2000 \\
\hline-313.00 & 0.00 & 1122.00 & 340.00 & 1095.0 & 1435.00 & 1667.6 & 2001 \\
\hline-259.00 & 72.00 & 987.00 & 252.00 & 994.00 & 1246.00 & 1435.0 & 2002 \\
\hline-268.00 & 472.00 & 1367.00 & 395.00 & 1240.0 & 1635.00 & 1246.0 & 2003 \\
\hline-125.00 & 713.00 & 1403.00 & 0.00 & 1528.0 & 1528.00 & 1635.0 & 2004 \\
\hline-275.00 & 894.00 & 2006.00 & 287.00 & 1994.0 & 2281.00 & 1528.0 & 2005 \\
\hline 34.00 & 344.00 & 1741.00 & 281.00 & 1426.0 & 1707.00 & 2281.0 & 2006 \\
\hline 61.00 & 1318.00 & 2938.00 & 310.00 & 2567.0 & 2877.00 & 1707.0 & 2007 \\
\hline 270.10 & 1137.00 & 3757.80 & 215.00 & 3272.7 & 3487.70 & 2877.0 & 2008 \\
\hline-425.50 & 1090.00 & 2950.40 & 185.90 & 3190.0 & 3375.90 & 3487.7 & 2009 \\
\hline-144.37 & 1234.20 & 3055.70 & 272.80 & 2927.2 & 3200.07 & 3375.9 & 2010 \\
\hline-103.31 & 1487.44 & 3153.56 & 296.20 & 2960.6 & 3256.88 & 3200.0 & 2011 \\
\hline-85.90 & 1574.44 & 3172.25 & 211.01 & 3047.1 & 3258.16 & 3256.8 & 2012 \\
\hline 258.73 & 1690.48 & 3677.86 & 168.41 & 3250.7 & 3419.13 & 3258.1 & 2013 \\
\hline 414.80 & 2054.30 & 4021.70 & 160.90 & 3446.0 & 3606.90 & 3419.1 & 2014 \\
\hline 66.78 & 2046.87 & 3688.21 & 176.43 & 3445.0 & 3621.43 & 3606.8 & 2015 \\
\hline 440.03 & 2332.40 & 4318.22 & 216.53 & 3661.6 & 3878.19 & 3621.4 & 2016 \\
\hline 319.12 & 2482.98 & 4371.85 & 257.94 & 3794.7 & 4052.73 & 3878.1 & 2017 \\
\hline 197.05 & 2255.27 & 4127.73 & 276.86 & 3653.8 & 3930.68 & 4052.7 & 2018 \\
\hline-77.32 & 2219.17 & 3782.73 & 199.97 & 3660.0 & 3860.05 & 3930.6 & 2019 \\
\hline
\end{tabular}

المصدر : بيانات (سلطة النقد، وزارة المالية، وزارة الاقتصاد الفلسطينية) جدول رقم (2): الاحصاء الوصفي للبيانات

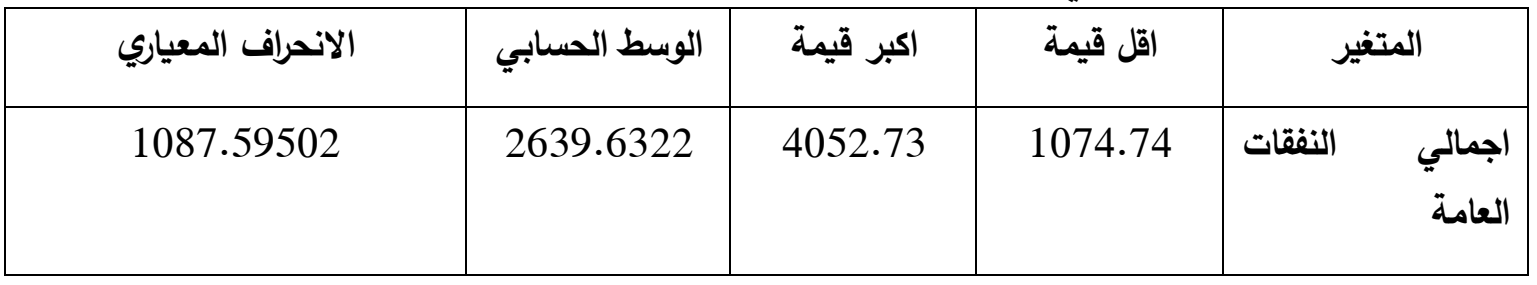


The International Journal of Business Ethics and Governance (IJBEG), Vol. 4, No. 1, 2021

\begin{tabular}{|c|c|c|c|c|}
\hline 1113.56394 & 2391.3957 & 3794.79 & 838.95 & النفقات الجارية \\
\hline 90.41306 & 248.2361 & 469.00 & 0.00 & النفقات التطويريـة \\
\hline 1230.39733 & 2628.5904 & 4371.85 & 987.00 & اجمالي الايرادات \\
\hline 769.98668 & 1200.1804 & 2482.98 & 0.00 & ايرادات المقاصة \\
\hline 239.19299 & -11.0409 & 440.03 & -425.50 & (العجز/الفائض) \\
\hline
\end{tabular}

يتضح من الجدول رقم (2) والذي يوضح الوسط الحسابي والانحراف المعياري واقل واكبر قيمة للمتغيرات ان

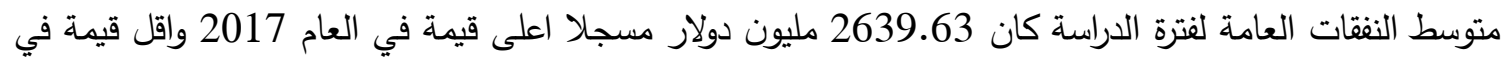

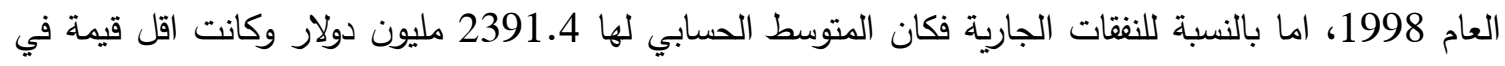

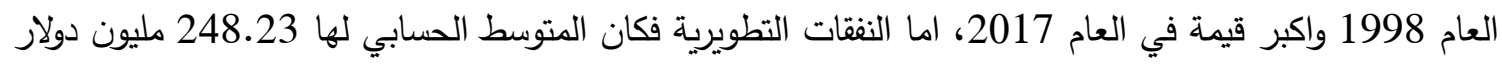

$$
\text { وسجلت اعلى قيمة في العام } 2000 \text { واقل قيمة في العام } 2004 \text { فالعام }
$$

اما فيما يتعلق بالايرادات العامة فانها سجلت اعلى قيمة لها في العام 2017 واقل قيمة في العام 2002 وذلك يعود الى بداية الانتفاضة الثانية في ذلك العام، وكان المتوسط الحسابي للايرادات العامة في فترة الدراسة 2628.6 مليون دولار، وكان متوسط ايرادات المقاصة ما بين الاعوام (1997-2019) 1200.18 مليون دولار مسجلا اعلى قيمة في العام 2017 وقل قيمة في العام 2001، وكان متونة متوسط اجمالي (العجز/فائض) الموازنة العامة في فترة الدراسة -11.04 مليون دولار وكانت اكبر قيمة عجز في 2009 واكبر فائض في العام 2016. جدول رقم (3): نسب التغير في النفقات العامة (جارية/تطويرية) وايرادات المقاصة في فلسطين

\begin{tabular}{|c|c|c|c|c|}
\hline نسبة ايرادات المقاصة & نسبة النفقات التطورية الى & الجبة النفقات & نسبة التغير في & السنة \\
\hline $44.26 \%$ & $23.21 \%$ & $76.79 \%$ & $5.41 \%$ & 1997 \\
\hline $49.24 \%$ & $21.94 \%$ & $78.06 \%$ & $-4.90 \%$ & 1998 \\
\hline $48.86 \%$ & $20.25 \%$ & $79.75 \%$ & $9.97 \%$ & 1999 \\
\hline $40.51 \%$ & $28.12 \%$ & $71.88 \%$ & $41.13 \%$ & 2000 \\
\hline $0.00 \%$ & $23.69 \%$ & $76.31 \%$ & $-13.97 \%$ & 2001 \\
\hline $7.29 \%$ & $20.22 \%$ & $79.78 \%$ & $-13.17 \%$ & 2002 \\
\hline $34.53 \%$ & $24.16 \%$ & $75.84 \%$ & $31.22 \%$ & 2003 \\
\hline
\end{tabular}




\begin{tabular}{|c|c|c|c|c|}
\hline $50.82 \%$ & $0.00 \%$ & $100.00 \%$ & $-6.54 \%$ & 2004 \\
\hline $44.57 \%$ & $12.58 \%$ & $87.42 \%$ & $49.28 \%$ & 2005 \\
\hline $19.76 \%$ & $16.46 \%$ & $83.54 \%$ & $-25.16 \%$ & 2006 \\
\hline $44.86 \%$ & $10.78 \%$ & $89.22 \%$ & $68.54 \%$ & 2007 \\
\hline $30.26 \%$ & $6.16 \%$ & $93.84 \%$ & $21.23 \%$ & 2008 \\
\hline $36.94 \%$ & $5.51 \%$ & $94.49 \%$ & $-3.21 \%$ & 2009 \\
\hline $40.39 \%$ & $8.52 \%$ & $91.48 \%$ & $-5.21 \%$ & 2010 \\
\hline $47.17 \%$ & $9.09 \%$ & $90.91 \%$ & $1.78 \%$ & 2011 \\
\hline $49.63 \%$ & $6.48 \%$ & $93.52 \%$ & $0.04 \%$ & 2012 \\
\hline $45.96 \%$ & $4.93 \%$ & $95.07 \%$ & $4.94 \%$ & 2013 \\
\hline $51.08 \%$ & $4.46 \%$ & $95.54 \%$ & $5.49 \%$ & 2014 \\
\hline $55.50 \%$ & $4.87 \%$ & $95.13 \%$ & $0.40 \%$ & 2015 \\
\hline $54.01 \%$ & $5.58 \%$ & $94.42 \%$ & $7.09 \%$ & 2016 \\
\hline $56.79 \%$ & $6.36 \%$ & $93.64 \%$ & $4.50 \%$ & 2017 \\
\hline $54.64 \%$ & $7.04 \%$ & $92.96 \%$ & $-3.01 \%$ & 2018 \\
\hline $58.67 \%$ & $5.18 \%$ & $94.82 \%$ & $-1.80 \%$ & 2019 \\
\hline $41.99 \%$ & $11.98 \%$ & $88.02 \%$ & $7.57 \%$ & المعدل \\
\hline
\end{tabular}

المصدر: تحليل الباحثين

يتضح من الجدول رقم (3) ان اعلى نسبة تغير في النفقات العامة عن السنة التي سبقتها كانت في العام 2007 بنسبة 68.54\% وذلك يعود غالبا الى انتهاء انتفاضة الاقصى وعودة الحياة في فلسطين الى وضعها الطبيعي تقريبا، واقل نسبة كانت في العام 2006 وهي -25.16\% ويعود ذلك الى الانقسام الفلسطيني وانفصال شطري الوطن بين الضفة الغربية وغزة في ذلك العام، اما فيما يتعلق في النفقات الجارية فاننا نلاحظ انها تثكل النسبة

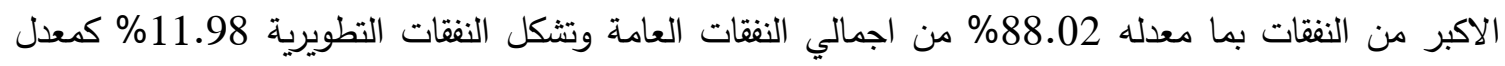
لنفس فترة الدراسة، وان ايرادات المقاصة تثكل ما نسبته بـ 41.99\% من الايرادات العامة كمعدل للسنوات محل الدراسة، وهذا يعني ان هناك اعتماد كبير على هذه النوع من الايراد في تغطية النفقات العامة. 
- - السنوات التي لم تحصل فيها ازمة مقاصة

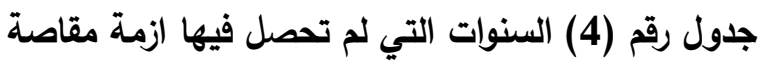

\begin{tabular}{|c|c|c|c|c|c|c|c|}
\hline |العمالي (العجز & اليرادات & الايرادات & التطقورية & الجارية النفقات & النفالي العامة & اللالمالي العامة السنة & التال السنوات لمصل \\
\hline 30.00 & 543.95 & $1,104.74$ & 235.7 & 838.95 & $1,074.7$ & $1,130.1$ & 1998 \\
\hline 4.59 & 579.71 & $1,186.47$ & 239.3 & 942.51 & $1,181.8$ & $1,074.7$ & 1999 \\
\hline-268.00 & 472.00 & $1,367.00$ & 395.0 & $1,240.00$ & $1,635.0$ & $1,246.0$ & 2003 \\
\hline-125.00 & 713.00 & $1,403.00$ & 0.00 & $1,528.00$ & $1,528.0$ & $1,635.0$ & 2004 \\
\hline-275.00 & 894.00 & $2,006.00$ & 287.0 & $1,994.00$ & $2,281.0$ & $1,528.0$ & 2005 \\
\hline-425.50 & $1,090.0$ & $2,950.40$ & 185.9 & $3,190.00$ & $3,375.9$ & $3,487.7$ & 2009 \\
\hline-144.37 & $1,234.2$ & $3,055.70$ & 272.8 & $2,927.27$ & $3,200.0$ & $3,375.9$ & 2010 \\
\hline 440.03 & $2,332.4$ & $4,318.22$ & 216.5 & $3,661.65$ & $3,878.1$ & $3,621.4$ & 2016 \\
\hline 319.12 & $2,482.9$ & $4,371.85$ & 257.9 & $3,794.79$ & $4,052.7$ & $3,878.1$ & 2017 \\
\hline 197.05 & $2,255.2$ & $4,127.73$ & 276.8 & $3,653.82$ & $3,930.6$ & $4,052.7$ & 2018 \\
\hline
\end{tabular}

المصدر : بيانات (سلطة النقد، وزارة المالية، وزارة الاقتصاد الفلسطينية)

يتبين من الجدول رقم (4) والذي يوضح السنوات التي لم يحصل فيها ازمة مقاصة، انه على الرغم من عدم وجود ازمة مقاصة في هذه السنوات الى ان ذلك لم يمنع من وجود عجز في الموازنة العامة في فلسطين في عدة سنوات

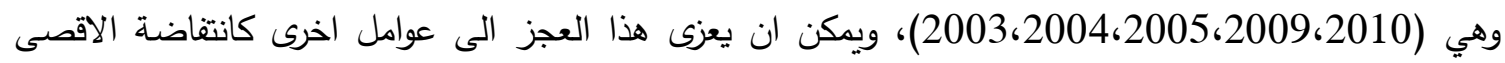

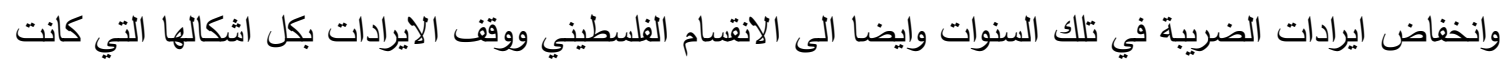
تأتي من محافظات قطاع غزة مع استمرار الانفاق على تلك المحافظات.

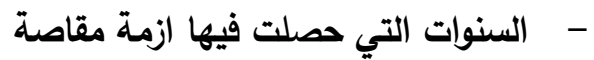
جدول رقم (5): السنوات التي حصل فيها ازمة مقاصة

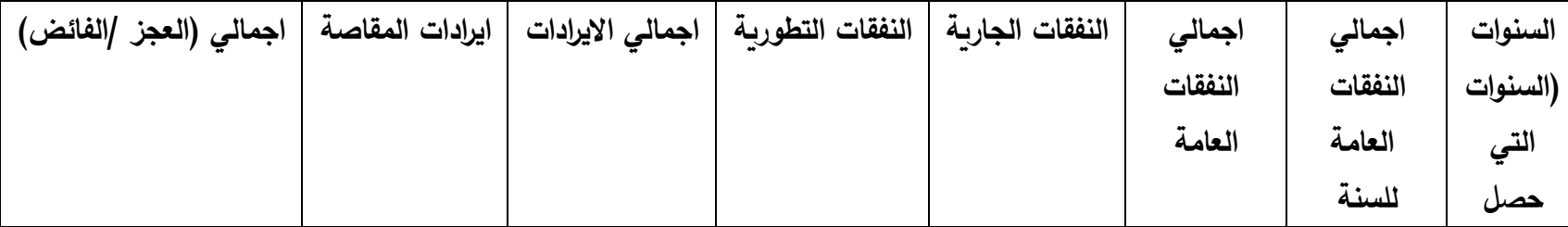




\begin{tabular}{|c|c|c|c|c|c|c|c|}
\hline & & & & & & السابقة & فلازمة) \\
\hline-54.78 & 475.94 & $1,075.36$ & 262.32 & 867.83 & $1,130.14$ & $1,072.10$ & 1997 \\
\hline-218.96 & 587.00 & $1,449.00$ & 469.00 & $1,198.96$ & $1,667.96$ & $1,181.88$ & 2000 \\
\hline-313.00 & 0.00 & $1,122.00$ & 340.00 & $1,095.00$ & $1,435.00$ & $1,667.96$ & 2001 \\
\hline-259.00 & 72.00 & 987.00 & 252.00 & 994.00 & $1,246.00$ & $1,435.00$ & 2002 \\
\hline 61.00 & $1,318.00$ & $2,938.00$ & 310.00 & $2,567.00$ & $2,877.00$ & $1,707.00$ & 2007 \\
\hline-103.31 & $1,487.44$ & $3,153.56$ & 296.20 & $2,960.68$ & $3,256.88$ & $3,200.07$ & 2011 \\
\hline-85.90 & $1,574.44$ & $3,172.25$ & 211.01 & $3,047.14$ & $3,258.16$ & $3,256.88$ & 2012 \\
\hline 258.73 & $1,690.48$ & $3,677.86$ & 168.41 & $3,250.72$ & $3,419.13$ & $3,258.16$ & 2013 \\
\hline 66.78 & $2,046.87$ & $3,688.21$ & 176.43 & $3,445.00$ & $3,621.43$ & $3,606.87$ & 2015 \\
\hline-77.32 & $2,219.17$ & $3,782.73$ & 199.97 & $3,660.08$ & $3,860.05$ & $3,930.68$ & 2019 \\
\hline
\end{tabular}

المصدر : بيانات (سلطة النقد، وزارة المالية، وزارة الاقتصاد الفلسطينية) يتبين من الجدول رقم (5) والذي يوضح السنوات التي حصل فيها ازمة مقاصة ان معظم السنوات ما عدا سنة (2007،2013،2015) حصل فيها عجز في الموازنة العامة وبالنظر الى الجدول اعلاه يتبين ان سنة 2001 لم لم يكن هناك اي ايراد متحصل عن المقاصة، وذلك يعود الى الظروف السياسية واندلاع انتفاضة الاقصى.

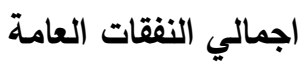
شكل رقم (2) اجمالي النفقات العامة ما بين الاعوام (1997-2019) في فلسطين:

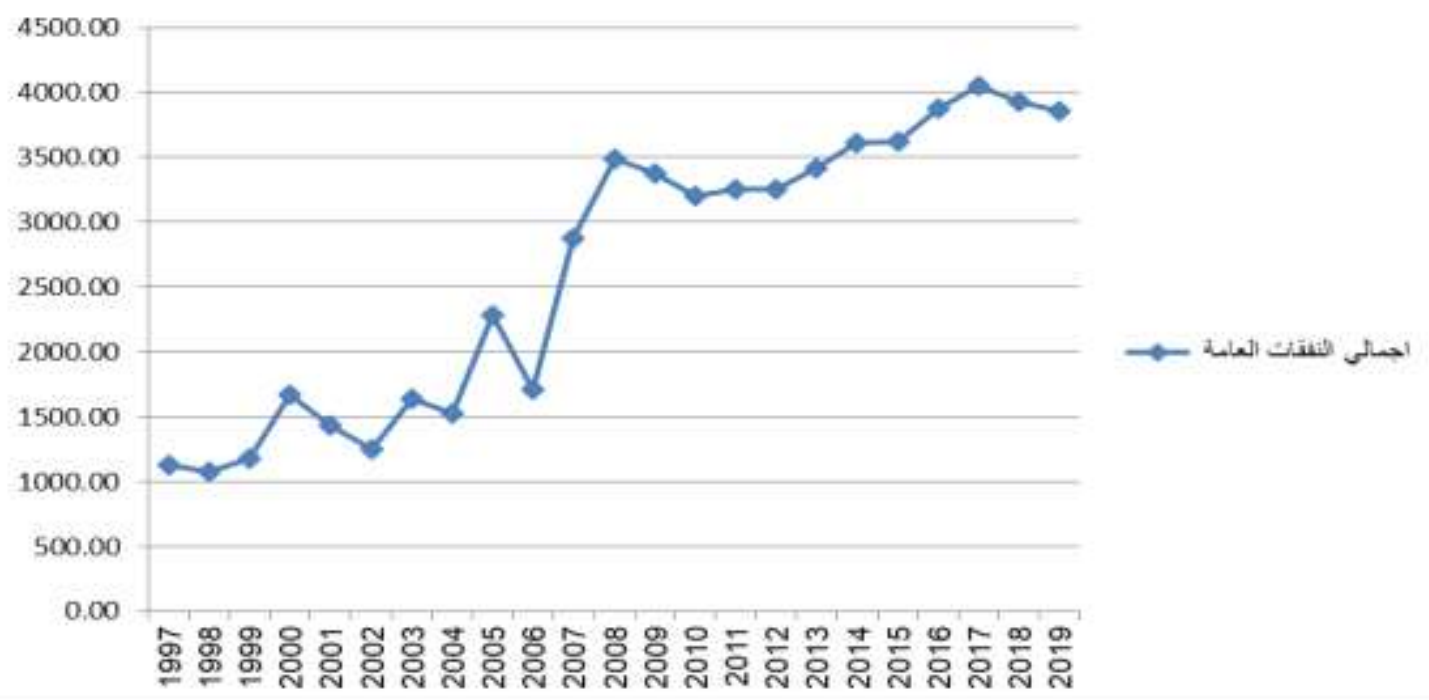

يتضح من الثكل رقم (2) ان النفقات العامة ما بين الاعوام (1997-2019) تتفاوت فكان هناك انخفاض ملحوظ في الاعوام التي حصل فيها ازمة مقاصة وهي الاعوام المذكورة في الجدول رقم (3.5)، وهناك ارتفاع في النفقات 
في الاعوام التي لم يكن فيها ازمة مقاصة كما هو موضح في الجدول رقم (3.4) السابق، ويمكن تقسير ذلك على انه في الاعوام التي حصلت فيها ازمة مقاصة اتخذت الحكومات المختلفة سياسة تقشف وتخفيض في الانفاق العات العام.

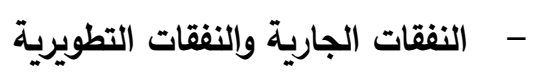
شكل رقم (3) النفقات الجارية والنفقات التطويرية ما بين الاعوام (1997-2019) في فلسطين.

$4,000.00$
$3,500.00$
$3,000.00$
$2,500.00$
$2,000.00$
$1,500.00$
$1,000.00$
500.00
0.00

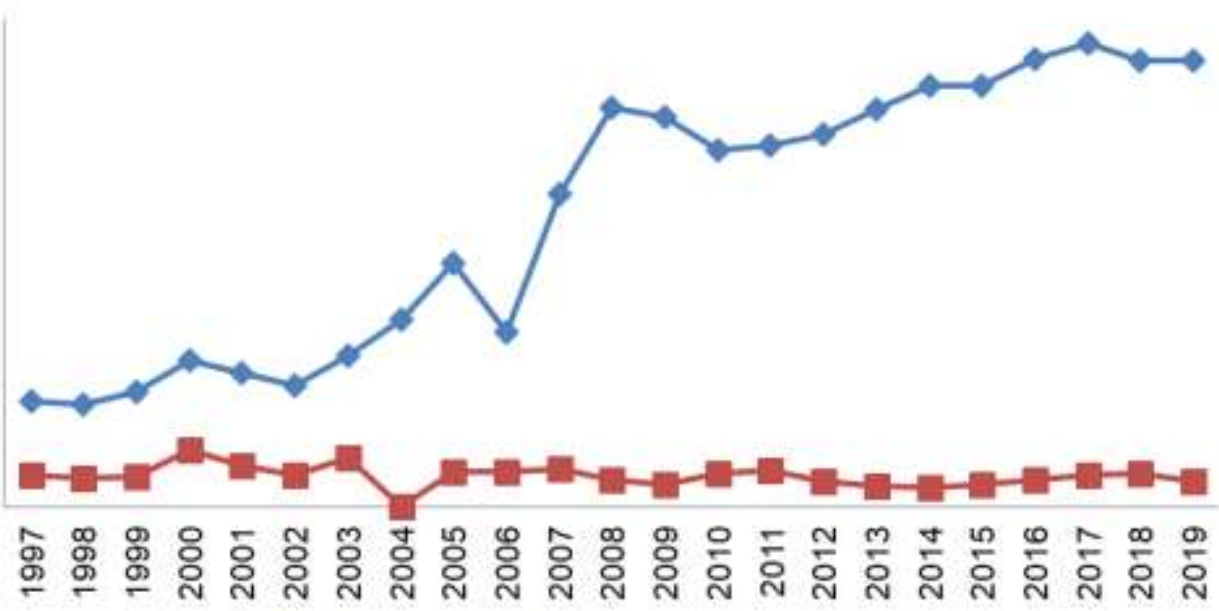

يتضح من الثكل رقم (3) انعكاس ازمة المقاصة على النفقات الجارية والنفقات التطويرية في فلسطين، فنلاحظ ان هناك انخفاض ملموس في السنوات التي حصلت فيها ازمة مقاصة وارتفاع في السنوات التي لم يحصل فيها ازمة على ايراد المقاصة، حيث نلاحظ ان هناك انخفاض في الاعوام ما بين (2000-2002) يمكن ان يعزى الى ازمة

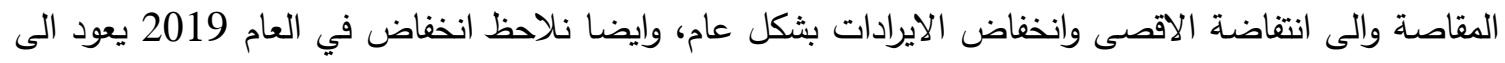
حجز اموال المقاصة من قبل الجانب الاسرائيلي وذلك كوسيلة للضغط على الحكومة الفلسطينية للقبول بصفقة القرن الامريكية، وايضا يمكن ان يعود ذلك الى تجميد المساعدات الامريكية في ذلك العام كذلك. شكل رقم (4): نسبة النفقات الجارية والتطويرية من النفقات العامة ما بين الاعوام (1997-2019) في في

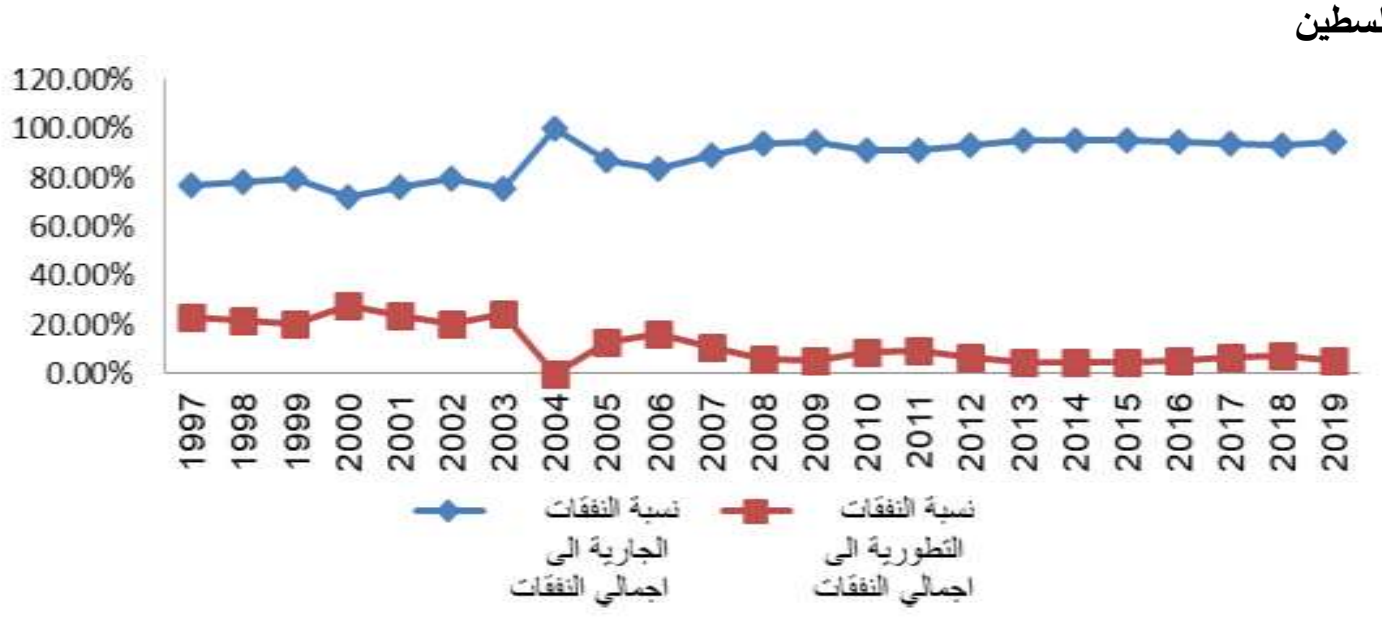

يوضح الشكل رقم (4) نسبة النفقات الجارية والنفقات التطويرية الى النفقات العامة ما بين الاعوام (1997-2019) في فلسطين، ونلاحظ ان النفقات الجارية تتراوح ما بين 71.88\% في العام 2000 و 100\% في العام 2004 
بمعدل 88.02\% على فترة الدراسة، اما النفقات التطويرية فقد تراوحت ما بين 0.00\% في العام 2004 و 28.12\% في العام 2000 بمعدل 11.98\% على فتلى فلترة الدراسة. ايرادات المقاصة

شكل رقم (5): نسبة ايرادات المقاصة الى اجمالى الايرادات ما بين الاعوام (1997-2019) في فلسطين $80.00 \%$

$60.00 \%$ $40.00 \%$

$20.00 \%$

$0.00 \%$

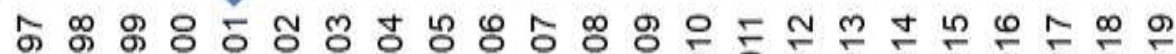

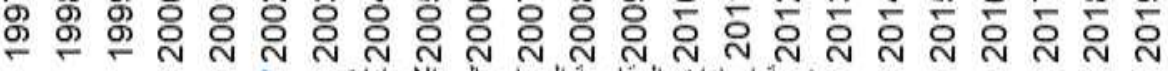

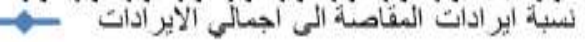

يتضح من الثكل رقم (5) نسبة ايرادات المقاصة الى الايراد العام، ونلاحظ تفاوت هذه النسب في فترة الدراسة فقد تراوحت ما بين 00.00\% في العام 2001 و 58.67\% في العام 2019 بمعدل 41.99\% من الايرادات العامة في فترة الدراسة، ويتضح ايضا انخفاض هذه النسبة في السنوات التي حصل فيها ازمة مقاصة وايضا السنوات التي

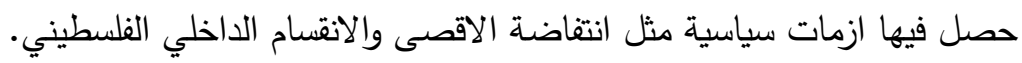
اجمالي (العجز/الفائض) في الموازنة العامة شكل رقم (6): اجمالي (العجز/الفائض) في الموازنة العامة ما بين الاعوام (1997-2019) في فلسطين.

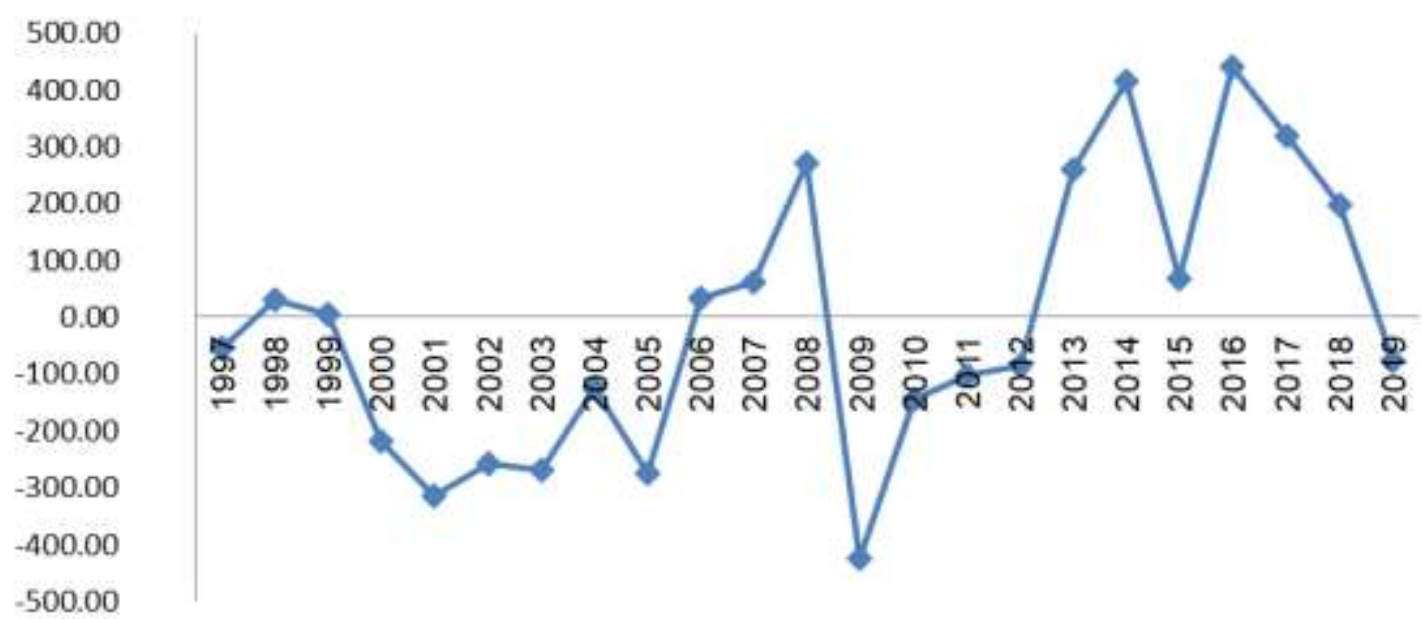

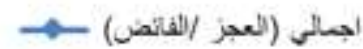

يتضح من الثكل رقم (6) انه بين الاعوام (2000-2005) كان هناك عجز في الموازنة العامة ويعود ذلك لانتفاضة الاقصى بالاضافة الى ازمة المقاصة التي حصلت في تلك السنوات من الدراسة، وان هناك فائض في الموازنة العامة ما بين الاعوام (2006-2008) وذلك يعود الى توقف السلطة الفلسطينية عن الانفاق على قطاع غزة بسبب الانقسام الفلسطيني الذي حصل في تلك الاعوام، اما ما بين الاعوام (2009-2012) حصل عجز فئ في الموازنة العامة ايضا، اما في الاعوام التي تلت العام 2012 فكان هناك فائض في الموازنة ما عدا سنة 2019 
التي سجل فيها عجز مقدار 77.32 مليون دولار امريكي ويعود السبب في هذا العجز الى حجز اموال المقاصة وانقطاع المساعدات الامريكية في محاولة للضغط على السلطة الفلسطينية للقول بصفقة القرن. ثالثا: المعالجات الإحصائية المستخدمة في الاراسة: تم استخدام عدة أساليب إحصائية مناسبة لتحليل بيانات الدراسة، باستخدام برنامج (Stata) الإحصائي، وذلك باستخدام الأساليب الإحصائية التالية:

1.المتوسطات الحسابية (Mean) القيمة الأعلى والأدني (Max, Min)، الانحراف المعياري ( Standard) .(Deviation

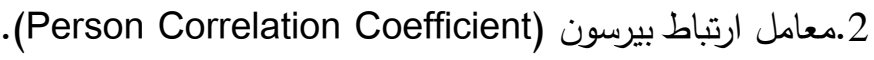
3.تحليل الانحدار الهرمي (Multiple Regression Analysis).

4.اختبار التوزيع الطبيعي للعينة (Normality) 5odel Specification Test)

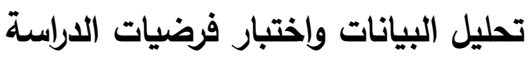
أولاً: معامل ارتباط بيرسون Person correlation matrix:

جلول رقم (6): معامل ارتباط بيرسون Person correlation matrix

\begin{tabular}{|c|c|c|c|c|c|}
\hline المقاصة المادات & (العجز/الفائض) (جمالي & التطويرية & الجارية النفات & الانفاق & \\
\hline & & & & 1 & الانفاق العام \\
\hline & & & 1 & 0.4321 & النفقات الجاربة \\
\hline & & 1 & -0.1548 & 0.4122 & النفقات التطويريـة \\
\hline & 1 & -0.2478 & -0.1125 & -0.1003 & $\begin{array}{c}\text { (العجز/الفائض) } \\
\text { (العمالي }\end{array}$ \\
\hline 1 & 0.6112 & $0.5154-$ & $0.5963-$ & $0.5789-$ & ازمة ايرادات المقاصة \\
\hline
\end{tabular}

يظهر الجدول رقم (6) اعلاه الارتباط بين متغيرات هذه الدراسة، ويسى هذا الاختبار بالاختبار الصفري أو مصفوفة معامل الارتباط الذي يشير الى قوّه الارتباط بين العوامل، وتثير العلامة السلبية إلى أن الزيادة بأحد

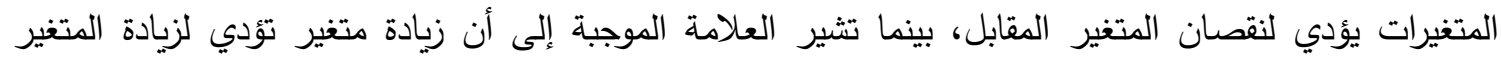

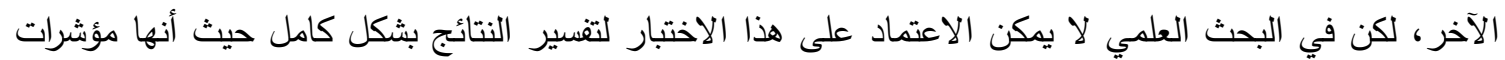
أولية قد تتغير في تحليل الانحدار، وقام علماء الاحصاء بتحديد نسبة الارتباط المقبولة بحيث إذا كانت قوة الارتباط لئل

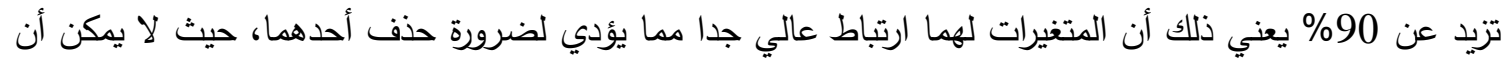
يتم تحليلهما في نفس النموذج الدراسي، ومن خلال الجدول أعلاه تبين أن نموذج هذه الدراسة يخلو من مشاكل

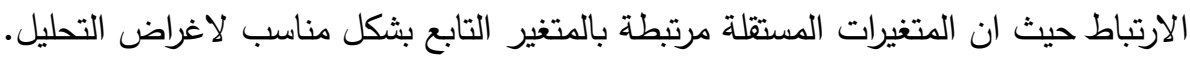


ثانبا: اختبار التوزيع الطبيعي للعينة (Normality): ومن جهة أخرى قام الباحثون باجراء اختبار توزيع البيانات (Normality) لفحص ما لفئهية اذا كانت البيانات موزعة

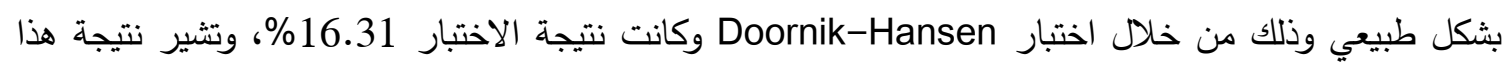
الاختبار إلا أنه لا يوجد مشاكل توزيع طبيعي في الدراسة، حيث أن النسبة أعلى من 5. تأثير هام وتعتبر هذه النسبة مقبولة.

ثالثا: اختبار وصف النموذج (Model Specification Test): جدول رقم (7): اختبار Pregibon ناختبار وصنف

\begin{tabular}{|c|c|c|c|c|}
\hline & Coef. & Std. Err. & $\mathbf{T}$ & $\mathbf{P}>|\mathbf{t}|$ \\
\hline Hat & 0.3664 & 0.0245 & 3.25 & $\mathbf{0 . 0 0 3}$ \\
\hline Hatsq & 0.7125 & 0.1638 & 0.69 & $\mathbf{0 . 6 7 8}$ \\
\hline Cons & 0.1328 & 0.0365 & 0.33 & $\mathbf{0 . 8 4 4}$ \\
\hline
\end{tabular}

قام الباحثان باجراء اختبار Pregibon للتأكد من ان النموذج تم وصفه بشكل جيّ وخالي من حذف العناصر

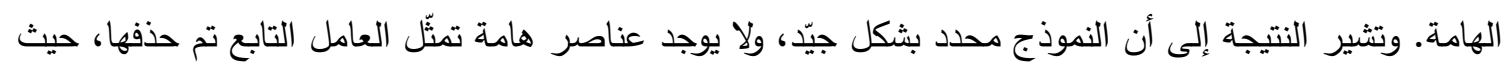

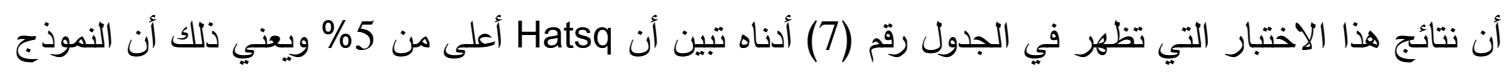
محدد بشكل جيد. رابعاً: اختبار القيم المتطرفة:

جدول رقم (8): اختبار القيم المتطرفة ال Skewness وال

\begin{tabular}{|c|c|c|}
\hline Kurtosis & Skewness & \\
\hline 0.841 & 3.142 & الانفاق العام \\
\hline 0.745 & 3.569 & النفقات الجارية \\
\hline 0.779 & 2.879 & النفقات التطويريـة \\
\hline 0.635 & 3.015 & اجمالي (العجز/الفائض) \\
\hline 0.751 & 3.144 & ايرادات المقاصة \\
\hline
\end{tabular}

قام الباحثان باختبار القيم المتطرفة كما بالجدول رقم (8)، ومن خلال النتيجة تبين أنه لا يوجد قيم متطرفة ومختلفة

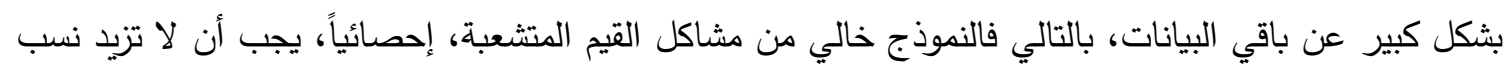
سكوينز Skewness عن 4 ويجب أن لا تزيد نسب كورتوزيز Kurtosis عن 1 وفي نفس السياق يتبين من خلال الجدول السابق أن نسب سكوينز لم تزيد عن 4، ونسب كورتوزيز لم تزيد عن 1، وهذا يدل على أن النسب غير عندين منطرفة. 


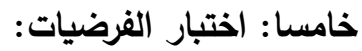

قام الباحثان في هذا الجزء باختبار فرضيات الدراسة وذلك بعد التاكد من دقة البيانات وصحتها وتوزيعها الطبيعي فكانت نتائج هذه الاختبارات كما يلي: لإني

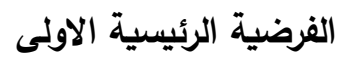

جدول رقم (9): نتائج اختبار ال Regression للفرضية الرئيسية الاولى والفرضيات المتفرعة عنها

\begin{tabular}{|c|c|c|c|c|c|c|}
\hline $\begin{array}{c}\mathrm{P}_{-} \\
\text {Value }\end{array}$ & $\begin{array}{c}\boldsymbol{\beta} \\
\text { Coefficient }\end{array}$ & $R^{2}$ & $\begin{array}{c}\text { Adjusted } \\
R^{2}\end{array}$ & $\begin{array}{c}\text { T- } \\
\text { Value }\end{array}$ & $\begin{array}{c}\text { F- } \\
\text { Value }\end{array}$ & \\
\hline$* * 0.000$ & -0.245 & 0.85 & 0.845 & -10.97 & 120.5 & ازمة ايرادات المقاصةــ الانفاق العام \\
\hline$* * 0.001$ & -0.369 & 0.85 & 0.851 & -11.26 & 126.9 & ازمة ايرادات المقاصة — النفقات الجارية \\
\hline 0.152 & -0.036 & 0.09 & 0.052 & -1.485 & 2.206 & ازمة ايرادات المقاصة ـ النفقات التطويرية \\
\hline
\end{tabular}

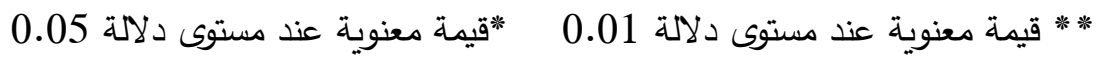

H01 لا يوجد أثر ذو دلالة إحصائية عند 0.05 > لأزمة إيرادات المقاصة على الإنفاق العام.

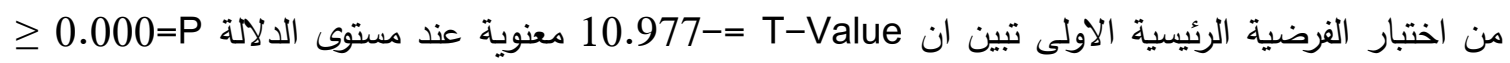

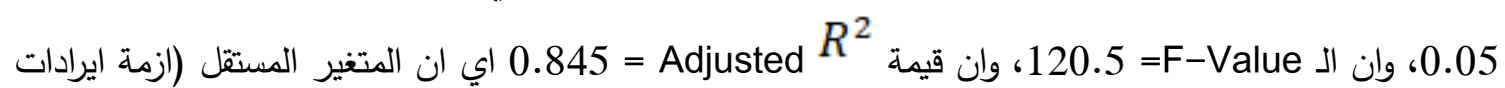

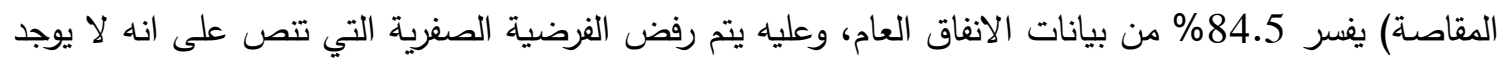

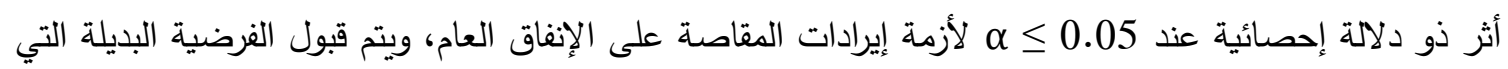

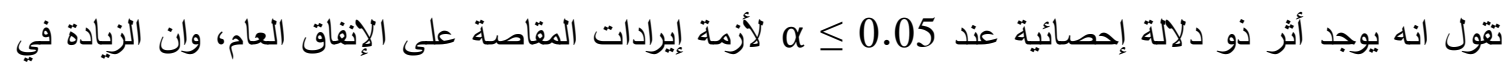

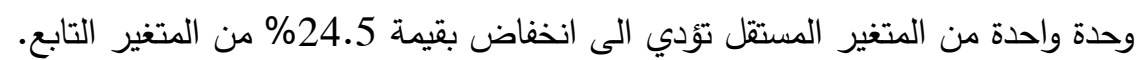

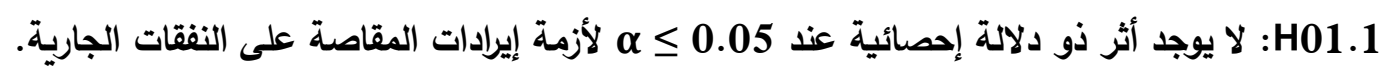

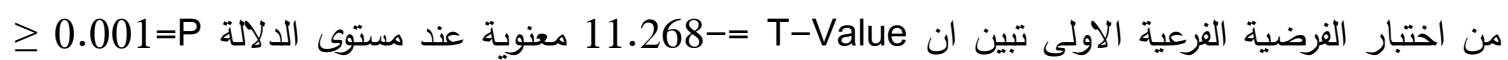

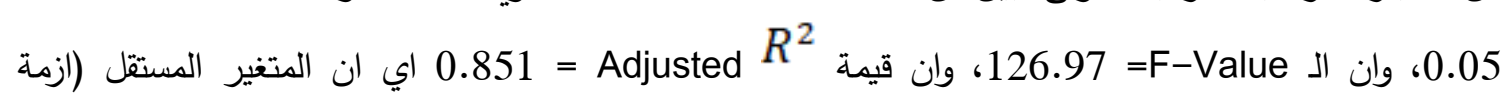

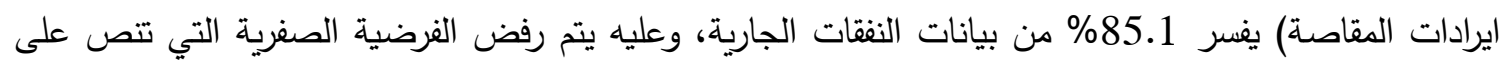

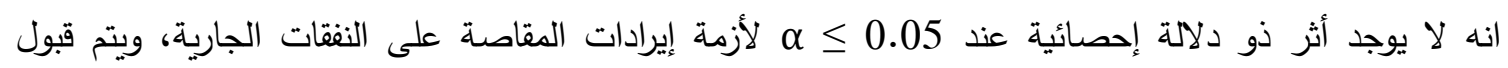

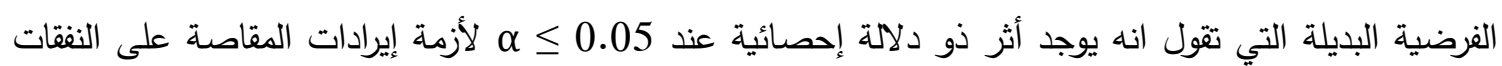

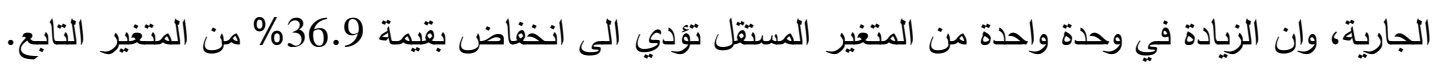

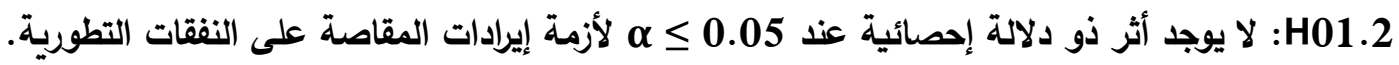
من اختبار الفرضية الفرعية الثانية تبين ان مستوى الدلالة P= التي تتص على انه لا يوجد أثر ذو دلالة إحصائية عند 0.05 م لأزمة إيرادات المقاصة على النفقات التطورية. 
الفرضية الرئيسية الثانية

جدول رقم (10): نتائج اختبار ال Regression للفرضية الرئيسية الثاني والفرضيات المتفرعة عنها

\begin{tabular}{|c|c|c|c|c|c|c|}
\hline P-Value & $\begin{array}{c}\beta \\
\text { Coefficie } \\
\text { nt }\end{array}$ & $R^{2}$ & $\begin{array}{c}\text { Adjuste } \\
\qquad \begin{array}{c}\text { d } \\
R^{2}\end{array}\end{array}$ & $\begin{array}{c}\text { T- } \\
\text { Value }\end{array}$ & $\begin{array}{c}\text { F- } \\
\text { Value }\end{array}$ & \\
\hline 11 **0.001 & -0.136 & 0.87 & 0.853 & -9.28 & 119.6 & الانفاق العام ـ ازمة ايرادات المقاصة \\
\hline$* * 0.002$ & -0.194 & 0.77 & 0.733 & -11.6 & 120.7 & النفقات الجارية ـ ـازمة ايرادات المقاصة \\
\hline 0.342 & -0.001 & 0.03 & 0.046 & -2.36 & 3.65 & النفقات التطويرية ـ ازمة ايرادات \\
\hline
\end{tabular}

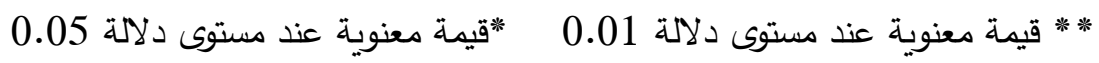

H02: لا يوجد فروق ذات دلالة إحصائية عند 0.05 > للإنفاق العام يعزى إلى أزمة إيرادات المقاصة.

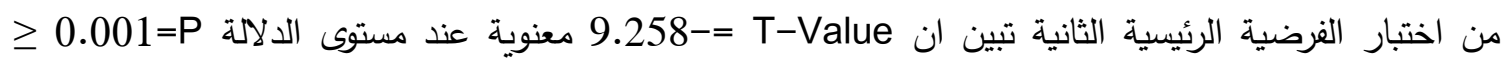

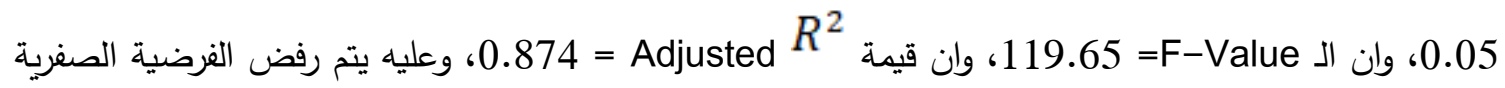
التي تتص على انه لا يوجد فروق ذات دلالة إحصائية عند 0.05 > $\alpha$ للإنفاق العام يعزى إلى أزمة إيرادات

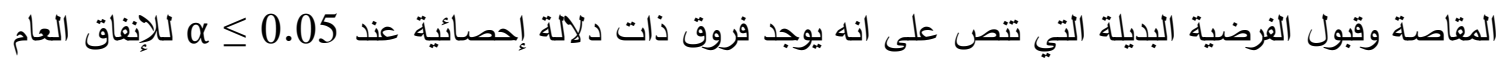

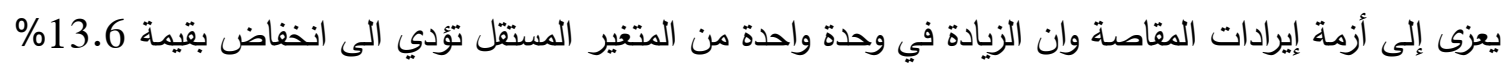
من المتغير التابع. H02.1 لا يوجد فروق ذات دلالة إحصائية عند 0.05 ك للنفقات الجارية تعزى إلى أزمة إيرادات المقاصة.

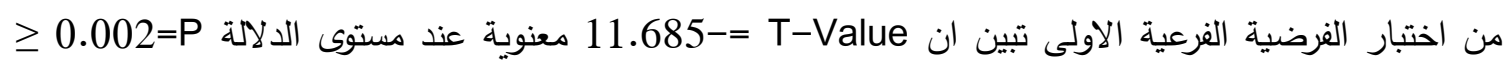

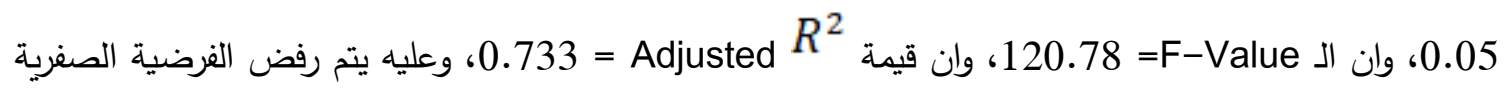
التي تتص على انه لا يوجد فروق ذات دلالة إحصائية عند 0.05 > للنفقات العامة يعزى إلى أزمة إيرادات المقاصة وقبول الفرضية البديلة التي تتص على انه يوجد فروق ذات دلالة إحصائية عند

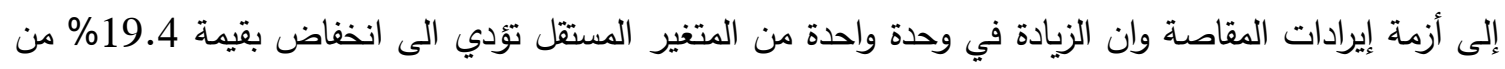
المتغير التابع. H02.2: لا يوجد فروق ذات دلالة إحصائية عند 0.05 > للنفقات التظويرية تعزى إلى أزمة إيرادات المقاصة. من اختبار الفرضية الفرعية الثانية تبين ان مستوى الدلالة P= 0.342 > 0.05، وعليه يتم قبول الفرضية الصفرية التي تتص على انه لا يوجد فروق ذات دلالة إحصائية عند 0.05 × ل للنفقات التطويرية تعزى إلى أزمة إيرادات المقاصة. الفرضية الرئيسة الثالثة H03: لا يوجد أثر ذو دلالة إحصائية عند 0.05 > لأزمة إيرادات المقاصة على إجمالي عجز أو فائض الموازنة. 
جدول رقم (11): نتائج اختبار ال Regression للفرضية الرئيسية الثالثة

\begin{tabular}{|c|c|c|c|c|c|c|}
\hline P-Value & $\begin{array}{c}\beta \\
\text { Coefficie } \\
\text { nt }\end{array}$ & $R^{2}$ & $\begin{array}{r}\text { Adjusted } \\
\qquad R^{2}\end{array}$ & $\begin{array}{r}T- \\
\text { Value }\end{array}$ & $\begin{array}{r}F_{-} \\
\text {Value }\end{array}$ & \\
\hline$* * 0.001$ & 0.369 & 0.89 & 0.848 & 7.69 & 123.6 & 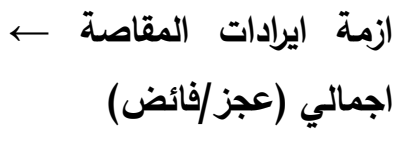 \\
\hline
\end{tabular}

0.05 * ق ميمة معنوية عند مستوى دلالة 0.01 *قيمة معنوية عند مستوى دلالة

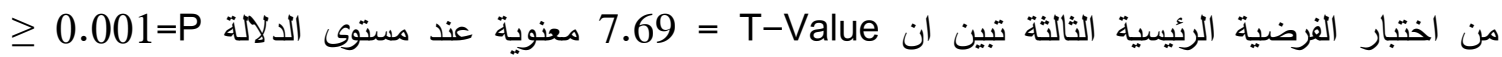

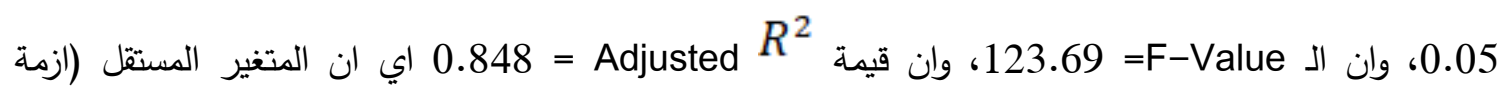
ايرادات المقاصة) يفسر 84.8\% من بيانات اجمالي (عجز/فائض) الموازنة العامة، وعليه يتم رفض الفرضية

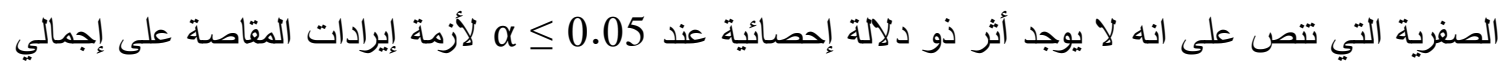

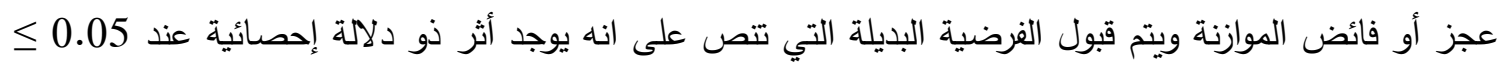
م لأزمة إيرادات المقاصة على إجمالي عجز أو فائض الموازنة وان الزيادة في وحدة واحدة من المتغير المستقل

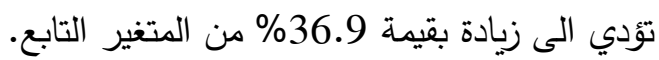
الفرضية الرئيسية الرابعة H04: لا يوجد فروق ذات دلالة إحصائية عند 0.05 > لعجز أو فائض الموازنة يعزى إلى أزمة إيرادات

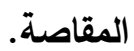
جدول رقم (12): نتائج اختبار ال Regression للفرضية الرئيسية الرابعة

\begin{tabular}{|c|c|c|c|c|c|c|}
\hline P-Value & $\begin{array}{c}\beta \\
\text { Coefficient }\end{array}$ & $R^{2}$ & $\begin{array}{c}\text { Adjusted } \\
\qquad R^{2}\end{array}$ & $\begin{array}{c}\text { T- } \\
\text { Value }\end{array}$ & $\begin{array}{c}\text { F- } \\
\text { Value }\end{array}$ & \\
\hline$* * 0.000$ & 0.325 & 0.75 & 0.711 & 13.61 & 119.2 & 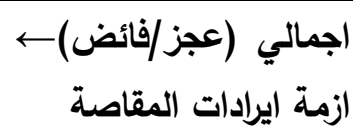 \\
\hline
\end{tabular}

0.05 * قيمة معنوية عند مستوى دلالة 0.01 *قيمة معنوية عند مستوى دلالة

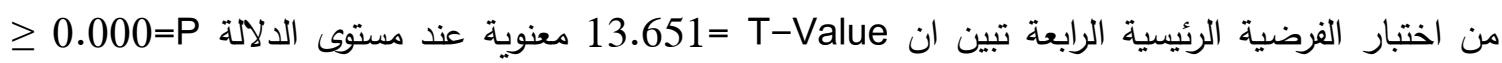

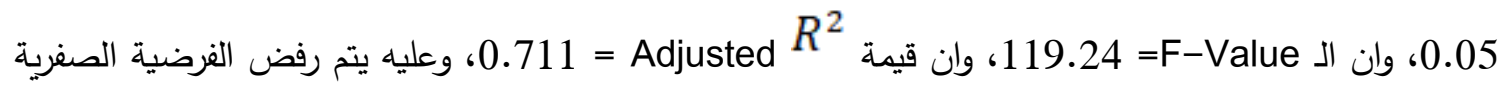
التي تتص على انه لا يوجد فروق ذات دلالة إحصائية عند 0.05 > 0 لعجز أو فائض الموازنة يعزى إلى أزمة

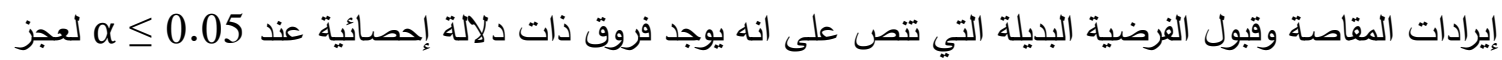

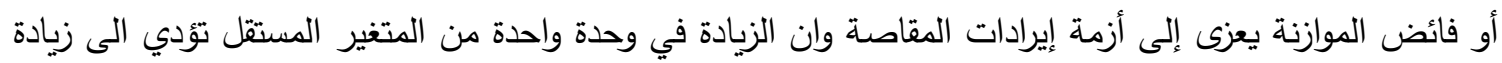
بقيمة 32.5\% من المتغير التابع.

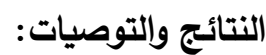
أولا: النتائج: بعد تحليل البيانات توصلت الدراسة الى عدة نتائج كما يلي: 
متوسط النفقات العامة لفترة الدراسة كان 2639.63 مليون دولار مسجلا اعلى قيمة في العام 2017 واقل قيمة في العام 1998. كان المتوسط الحسابي للنفقات الجارية 2391.4 مليون دولار وكانت اقل قيمة في العام 1998 واكبر قيمة في العام 2017، اما النفقات التطويرية فكان المتوسط الحسابي لها اعلى قيمة في العام 2000 واقل قيمة في العام 2004.

كان متوسط ايرادات المقاصة ما بين الاعوام (1997-2019) 1200.18 مليون دولار مسجلا اعلى في قيمة في العام 2017 وأقل قيمة في العام 2001. كان متوسط اجمالي (العجز/فائض) الموازنة العامة في فترة الدراسة -11.04 مليون دولار وكانت اكبر قيمة عجز في 2009 واكبر فائض في العام 2016. تفاوت نسبة ايرادات المقاصة الى الايراد العام في فترة الدراسة فقد تراوحت ما بين 0.00\% في في العام

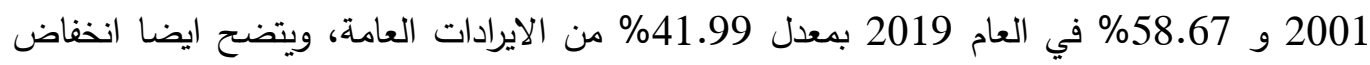
هذه النسبة في السنوات التي حصل فيها ازمة مقاصة وايضا السنوات التي حصل فيها ازمات سياسية مثل انتفاضة الاقصى والانقسام الداخلي الفلسطيني. يوجد أثر لأزمة إيرادات المقاصة على الإنفاق العام، وان الزيادة في وحدة واحدة في ازمة المقاصة يؤدي الى انخفاض بقيمة 24.5\% في الانفاق العام.

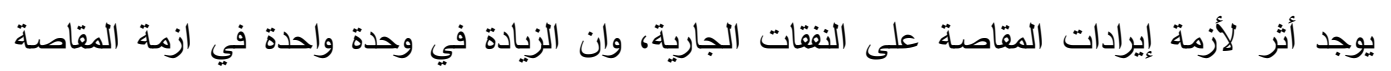
يؤدي الى انخفاض بقيمة 36.9\% في النفقات الجارية. لا يوجد أثر لأزمة إيرادات المقاصة على النفقات التطورية. يوجد أثر لأزمة إيرادات المقاصة على إجمالي عجز أو فائض المات الموازنة وان الزيادة في وحدة واحدة في

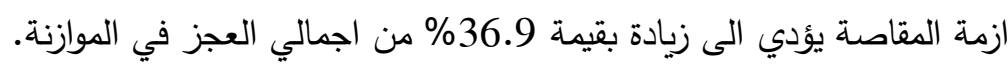
- تستخدم دولة الاحتلال عائدات الضرائب (ضريبة المقاصة) كأداة للضغط على الضئ السلطة الفلسطينية من اجل تقديم تتازلات سياسية. بروتوكول باريس الاقتصادي فيه ظلم واجحاف للحق الفلسطيني في رسم سياسياته الاقتصادية باستقلال. الاقتصاد الفلسطيني مرتبط ارتباط وثيق بالاقتصاد الاسرائيلي. - - الازمات السياسية تتعكس بشكل كبير على الحالة الاقتصادية في فلسطين وبشكل متكرر • ثانبا: التوصيات

بعد الاطلاع على نتائج الدراسة وتحليلها توصي الدراسة بالنقاط التالية:

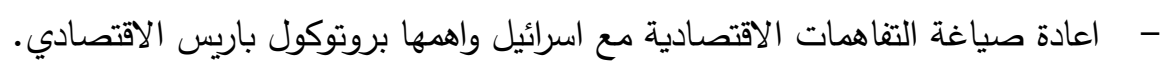

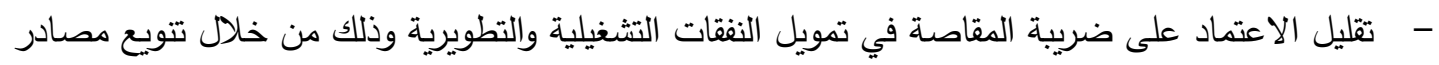
الايرادات العامة عن طريق المشاريع الاستثمارية المختلفة. - - اعادة هيكلة النظام الضريبي في فلسطين وتطوير نظام الجباية الضريبية. - - تخفيض الانفاق الحكومي الى الحد الاقصى من اجل تخفيض العجز في الموازنة وسداد الدين العام.

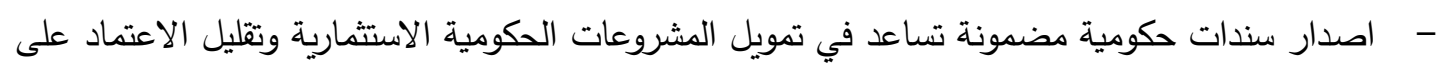
الضرائب. - - اعتماد موازنة البرامج بثكل فعلي وحقيقي وتتفيذها. 
- محاولة الانفكاك الاقتصادي عن اسرائيل والدفع باستقلال الاقتصاد الفلسطيني.

أبوعيدة، عمر • (2014). أثز الإنفاق الحكومي على النمو الاقتصادي في الأراضي الفلسطينية: دراسة قياسية تطبيقية خلال الفترة (1995-2013م). مجلة جامعة القدس المفتوحة للأبحاث والدراسات الإدارية

والاقتصادية، الصفحات 177-149.

ابومدللة، سمير والخضري، ايمان (2016). الإيرادات العامة والنفقات العامة الفلسطينية: المشكلات والحلول 2015-1995. مجلة البحوث الاقتصادية والمالية، الصفحات 235-219.

أبومدللة، سمير وزعيتر، أحمد. (2013)، دور الايرادات المحلية في تمويل الموازنة العامة للسلطة الفلسطينية

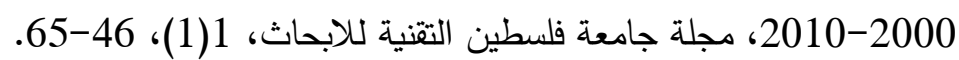

احمد، سيف الدين عماد وعلوان، علاء حسين. (2020). العلاقة بين زيادة الرواتب والاجور والرضا الوظيفي للموظفين دراسة تطبيقية في الهيئة العامة للضرائب. مجلة المستتصرية للدراسات العربية والدولية، .24-1، 1 ، 16 الأونكتاد. (2014). تسرب الإيرادات المالية الفلسطينية إلى إسرائيل في ظل بروتوكول باريس الاقتصادي. نيويورك وجنيف: الامم المتحدة.

جودة، نضال شاكر \& صالح، اسراء سعيد. (2020). قياس وتحليل اثر عجز الموازنة العامة في الدين العام في

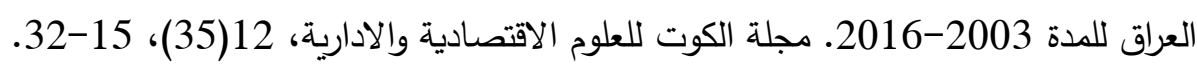

الحسني، زهير • (2020). توظيف الموازنة العامة لسنة 2019 في تحقيق التتمية المستدامة في العراق. مجلة

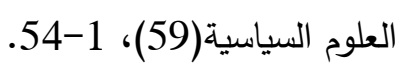

حمدان، م. ع. (2019). نحو سياسات اقتصادية وطنية لتعزيز الصمود الفلسطيني والتحرر الوطني. منتدى الشباب الفلسطيني للسياسات والتفكير الإستراتيجي.

حميض، حنين. (2005). تأثير المقاصة على الإيرادات الضريبية في فلسطين من 2005-1995. جامعة النجاح

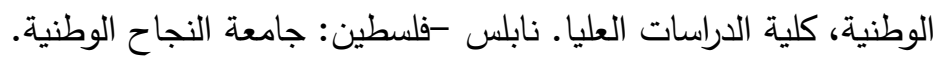
زهرة، شاكر • (2016). اتفاقية اوسلو وإنعكاساتها على القضية الفلسطينية 1993-1994. (ماجستير)، جامعة احمد دراية-ادرار، الجزائر. السبتي، وسيلة وعلون، محمد لمين \& عطية، حليمة. (2019). عجز الموازنة العامة وطرق تمويله في الإقتصاد.

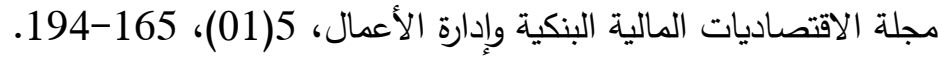
سلطة النقد. (2019). المؤشرات الاساسية للاقتصاد الفلسطيني الثعبي، هالة. (2013). بروتوكول باريس الاقتصادي. رام الله -فلسطين: معهد ابحاث السياسات الاقتصادية (ماس)

الثلة، علا. (2005). محددات الإيرادات العامة في فلسطين. جامعة النجاح الوطنية، كلية الدراسات العليا. نابلس-فلسطين: جامعة النجاح الوطنية. صالح، محمد. (2007). العوامل المساهمة في زيادة حجم عائدات السلطة الفلسطينية من ضريبة القيمة المضافة.

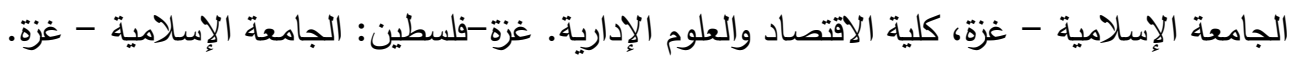


عباس، محسن خضير • (2020). تحليل العلاقة بين رأس المال البشري والنمو الاقتصادي في بيئة الاقتصاد العراقي. Al Kut Journal of Economic and Administrative Sciences، (12)، (163)،

عبود، سمير دصطفى. \& صالح، عبد الواحد عثمان. (2008). أثر اتفاق باريس على الاقتصاد الفلسطيني في الضفة الغربية وقطاع غزة 1967-2007م. جامعة السودان للعلوم والتكنولوجيا.

العتابي، صادق. (2018). اثر الضرائب الجمركية في دعم الموازنة العامة للدولة. العراق: مجلة المثنى للعلوم

الاقتصادية والادارية المجلد (8) العدد (3).

عزريل، بلال. (2017). تأثير بروتوكول باريس الاقتصادي على الإيرادات الضريبية في فلسطين. (ماجستير)، جامعة القدس، فلسطين.

عكاشة، احمد خالد. (2018). الاقتصاد الفلسطيني بين الوحدة ومحاولات التفكيك: قراءة في الدراسات السابقة.

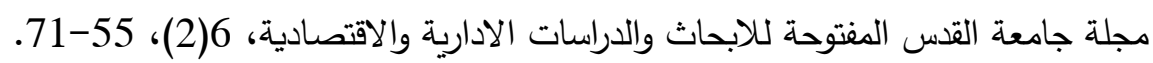
عوض، عزمي وصفي. (2016). تقديرات عرض النقد في فلسطين. مجلة الجامعة الإسلامية للدراسات الاقتصادية

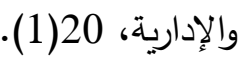

فرحان، اسراء \& محمد، شيماء فاضل. (2020). قياس العلاقة بين عجز الموازنة العامة والميزان التجاري- العجز

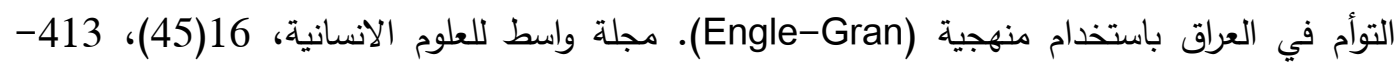
.446

الفهداوي، علي حسين احمد. (2020). الموازنة العامة والرقابة عليها في التشريعات العراقية. مجلة العلوم السياسية(59)، 413-462.

مجيد، نماء علي، \& عطية، احمد صبيح. (2020). التخصيص الامثل للانفاق العام... معالجة موضوعية لتحقيق Al Kut Journal of Economic and النمو الاقتصادي، العراق حالة دراسية للمدة 2004-2018. .73-91، 12(3)،Administrative Sciences

محمد، رسل جواد \& محيميد، خطاب سعيد. (2020). الانعكاسات الجيوبولتيكية لمشكلة التبعية الاقتصادية باستعمال مؤشرات القياس الكمي في العراق 2003-2018. مجلة آداب الفراهيدي، 12(42) ، 203-

محمد، محد حميد. (2020). عجز الموازنة العامة واساليب علاجه (الصكوك الاسلامية في السودان انموذجاً). .political issues (61)

مدللة، سمير مصطفى. (2018). محددات الإيرادات العامة الفلسطينية وتحليلها. مجلة الاقتصاديات المالية البنكية

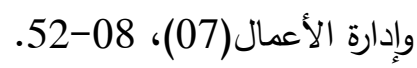

معهد ابحاث السياسات الاقتصادية الفلسطينية -ماس. (2019). اداء الموازنة العامة 2018 بالمقارنة 2017 وازمة المقاصة. فلسطين: معهد ابحاث السياسات الاقتصادية الفلسطيني (ماس). المغربي، احمد. (2019). المتغيرات السياسية في فلسطين وانعكاساتها على الأمن الاقتصادي. (رسالة ماجستير)، جامعة النجاح الوطنية فلسطين.

مقداد، محمد ابراهيم. \& الكحلوت، خالد عمر . (2016). واقع الإيرادات والنفقات الجارية للسلطة الوطنية

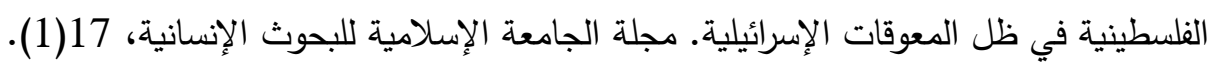




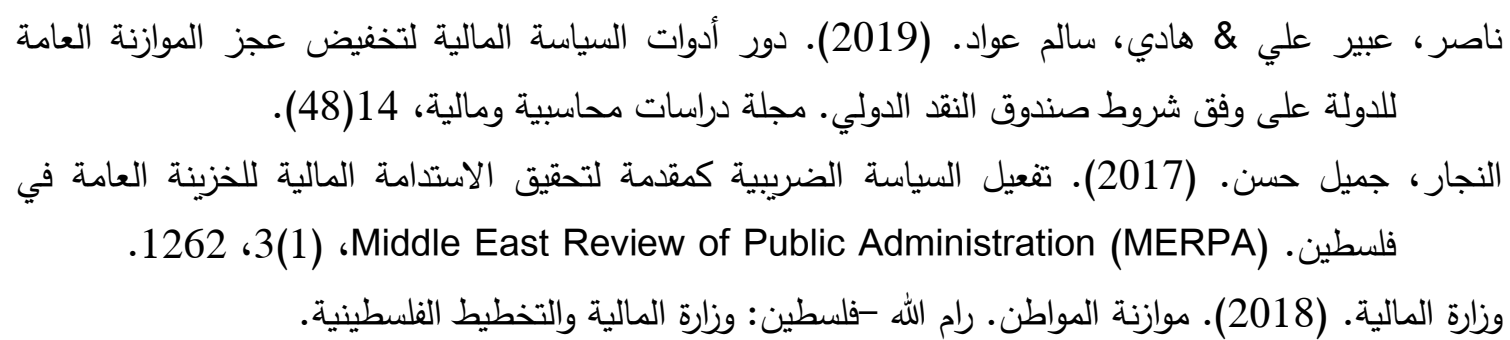

\section{References}

Alazzeh, D. A. (2020). Three essays on Self-Government Accounting Practices under Settler Colonialism: A Case study from Palestine. University of Essex .

Alshabi, Hala. (2013). Paris Economic Protocol. Ramallah - Palestine: Economic Policy Research Institute (MAS). (in Arabic)

Abbas, Mohsen Khudair. (2020). Analyzing the relationship between human capital and economic growth in the Iraqi economic environment. Al Kut Journal of Economic and Administrative Sciences, 12(36), 163-184. (in Arabic)

Abboud, Samir Mustafa. \& Saleh, Abdul Wahid Othman. (2008). The impact of the Paris Agreement on the Palestinian economy in the West Bank and Gaza Strip from 1967 to 2007. Sudan University of Science and Technology. (in Arabic)

Abu Mdallalh, Samir, Al-Khudri and Iman (2016). Palestinian Public and expenditures Revenues, Problems and Solutions 1995-2015. Journal of Economic and Financial Research, 235-219. (in Arabic)

Abu Mdallalh, Samir, Zuaiter and Ahmed. (2013), The Role of Local Revenues in Funding the General Budget of the Palestinian Authority 2000-2010, Palestine Technical University Journal for Research, 1(1), 46-65. (in Arabic)

Abu Oaida, Omar. (2014). The Impact of Governmental Expenditure on the Economic Growth in Palestinian Territories: An Applied Standard Study during the Period (1995-2013). Al-Quds Open University magazine for Research, Administrative and Economic Studies, 177-149. (in Arabic)

Abu-Eideh, O. M. (2015). Causality between public expenditure and GDP growth in Palestine: An econometric analysis of Wagner's law. Journal of Economics and Sustainable Development, 6(2), 189-199 .

Ahmed, Saif Al-Din Imad and Alwan, Alaa Hussein. (2020). The relationship between salary increases, wages and job satisfaction for employees for applied study for General Tax Authority. Al-Mustansiriya Journal of Arab and International Studies, 16(68), 1-24. (in Arabic)

Ahuja, D., \& Pandit, D. (2020). Public Expenditure and Economic Growth: Evidence from the Developing Countries. FIIB Business Review, 9(3), 228-236. https://doi.org/10.1177/2319714520938901

Al Hosani, Zuhair. (2020). Employing the general budget for the year 2019 to achieve sustainable development in Iraq. Journal of Political Science (59), 1-54. (in Arabic)

Al najjar, Jamil Hassan. (2017). Activating the tax policy as a prelude to achieving the financial sustainability of the public treasury in Palestine. Middle East Review of Public Administration (MERPA), 3(1), 12-62. (in Arabic)

Al-Afifi, A. A. M. (2019). Factors Affecting Decision Makers Preference of MSMEs in Financing Sources Choice, International Journal of Business Ethics and Governance, 2(2), 16-29. https://doi.org/10.51325/ijbeg.v2i2.31 
Alareeni, B. (2018). Does corporate governance influence earnings management in listed companies in Bahrain Bourse?, Journal of Asia Business Studies, 12(4), 551-570. https://doi.org/10.1108/JABS-06-2017-0082

Alareeni, B. (2019). A Review of Auditors' GCOs, Statistical Prediction Models and Artificial Intelligence Technology, International Journal of Business Ethics and Governance, 2(1), 19-31. https://doi.org/10.51325/ijbeg.v2i1.30

Al-Atabi, Sadeq. (2018). The effect of customs taxes on supporting the state's general budget. Iraq: Al-Muthanna Journal for Economic and Management Sciences, 8(3). (in Arabic)

Al-Fahdawi, Ali Hussein Ahmed. (2020). The general budget and control in Iraqi legislation. Journal of Political Science (59), 413-462. (in Arabic)

Aljamal, S. (2018). The Practice of Transformational Management and its Role in Achieving Institutional Excellence from the Point of View of Workers in the Directorates of Education in Hebron, International Journal of Business Ethics and Governance, 1(1), 64-90. https://doi.org/10.51325/ijbeg.v1i1.12

Almaghribi, Ahmed. (2019). Political changes in Palestine and their reflections on economic security. (Master Thesis), An-Najah National University, Palestine. (in Arabic)

Alqallaf, H. and Alareeni, B. (2018). Evolving of Selected Integrated Reporting Capitals among Listed Bahraini Banks, International Journal of Business Ethics and Governance, 1(1), 15-36. https://doi.org/10.51325/ijbeg.v1i1.10

Al-Sabti, Wassila Wa Aloun, Mohamed Lamine \& Attia, Halima. (2019). The public budget deficit financing methods in the economy. Journal of Banking Financial Economics and Business Administration, 5(01), 165-194. (in Arabic)

Alsuwaigh, M. A., Mohd Noor, A. B. \& Abdullah Othman, A. H. (2020). The Importance of the Accounting Disclosure as a Mediator Factor between the Shareholders of the Cash Waqf in the Kingdom of Saudi Arabia: The Theory of Planned Behavior, International Journal of Business Ethics and Governance, 3(1), 15-24. https://doi.org/10.51325/ijbeg.v3i1.26

Asfour, H. (2018). Withdrawing from the Oslo Accords: The Day After. Palestine-Israel Journal of Politics, Economics, and Culture, 23(2/3), 67-72 .

Aslam, M., \& Jaafar, R. (2020). Budget Deficit and the Federal Government Debt in Malaysia Perspectives on Economic Development-Public Policy, Culture, and Economic Development: IntechOpen. https://doi.org/10.5772/intechopen.91457

Awad, Azmi and Wasfi. (2016). assessment the money supply in Palestine. The Islamic University Journal of Economic and Administrative Studies, 20(1). (in Arabic)

Azriel, Bilal. (2017). The impact of the Paris Economic Protocol on tax revenues in Palestine. (MA), Al-Quds University, Palestine. (in Arabic)

Dana, T. (2020). Localising the Economy as a Resistance Response: A Contribution to the "Resistance Economy" Debate in the Occupied Palestinian Territories. Journal of Peacebuilding \& Development, 1542316620925274. https://doi.org/10.1177/1542316620925274

Darwish, s. (2013). Unemployment problem in Palestine in the period 1994-1992 and its treatment methods. Palestine University Journal for Research and Studies, (5), 63 87.

El-Kelety, I. A. E.-M., \& Al-Kishan, I. M. (2020). The Influence of Applying VAT on Revenues of the General Authority of Zakat and Tax "A Field Study on Makkah Region4 .(5)

Elseed, A. A. K. (2020). Sudan's accession to the World Trade Organization and its impact on the proceeds of tax and customs revenues (Field study) 4(2). 
Fannoun, Z. M. I. (2019). Exports, imports and economic growth Evidence from Palestine. (Master), Hebron University, Palestine .

Farhan, Israa \& Mohamed, Shaima Fadel. (2020). Measuring the relationship between the general budget deficit and the trade balance - twin deficits in Iraq using (EngleGran) methodology. Wasit Journal for the Humanities, 16(45), 413-446. (in Arabic)

ForÈ, C., LÄ $f$ zÄfrescu, I., \& Ioan, V. (2020). Budget Deficit-An Overview. Ovidius University Annals, Economic Sciences Series, 20(1), 930-936 .

Frenken, K., \& Schor, J. (2019). Putting the sharing economy into perspective A Research Agenda for Sustainable Consumption Governance: Edward Elgar Publishing. https://doi.org/10.4337/9781788117814.00017

Gazali, M. (2020). Budget Deficit and Debt: Descriptive Analysis of Indonesia's Case. Paper presented at the International Conference on Management, Accounting, and Economy (ICMAE 2020). https://doi.org/10.2991/aebmr.k.200915.069

Haji, A. M., \& Akrawee, Z. M. (2020), The economic effects of some macroeconomic variables on unemployment in Iraq for the period (2003-2017): a standard study. Academic Journal of Nawroz University, 9(3), 380-396. https://doi.org/10.25007/ajnu.v9n3a843

Hamdan, M. A. (2019). Toward national economic policies to enhance Palestinian steadfastness and national liberation. Palestinian Youth Forum for Policies and Strategic Thinking. (in Arabic)

Hamed, Hanin. (2005). The effect of clearing on tax revenues in Palestine from 19952005. An-Najah National University, College of Graduate Studies. Nablus Palestine: An-Najah National University. (in Arabic)

Hasan Al-Naser, M. (2019). Public Governance and Economic Growth: Conceptual Framework, International Journal of Business Ethics and Governance, 2(2), 1-15. https://doi.org/10.51325/ijbeg.v2i2.21

Ilmakunnas, I. (2019). Economic difficulties during the transition into adulthood in Finland: a register-based study. Turun Yliopiston Julkaisuja-Annales Universitatis Turkuensis Sarja-Ser. B-Osa, 474 .

Judeh, Nidal Shaker \& Saleh, Israa Saeed. (2020). Measuring and analyzing the impact of the public budget deficit on the public debt in Iraq for the period 2003-2016. Al Koot Journal of Economic and Management Sciences, 12(35), 15-32. (in Arabic)

Kalloub, M., \& Odabas, H. (2019). Palestinian Economy Assessment: Public Revenues, Expenditures and Current Issues. Paper presented at the 8th SCF International Conference on "The Economic and Social Impacts of the Globalization and Liberalization", Antalya/Turkey .

Khalidi, R. (2019). The structural transformation of the Palestinian economy after Oslo. From the river to the sea: Palestine and Israel in the shadow of "peace, 95-123.

Klein, M. (2018). The Endurance of the Fragile Oslo Accords. Palestine-Israel Journal of Politics, Economics, and Culture, 23(2/3), 58-66.

kun Wang, Y., Zhang, L., \& Ho, W.-m. (2020). The Priority of Exploiting Fiscal Revenue or Lessening Public Expenditure: Evidence from China. Applied Finance and Accounting, 6(1), 54-65. https://doi.org/10.11114/afa.v6i1.4731

Lang, B., Botha, E., Robertson, J., Kemper, J. A., Dolan, R., \& Kietzmann, J. (2020). How to grow the sharing economy? Create Prosumers! Australasian Marketing Journal (AMJ). https://doi.org/10.1016/j.ausmj.2020.06.012

Majeed, Namaa Ali, \& Attia, Ahmed Sobeih. (2020). The optimal allocation of public expenditures ... An objective treatment to achieve economic growth, Iraq is a case 
study for the period 2004-2018. Al Kut Journal of Economic and Administrative Sciences, 12(3), 73-91. (in Arabic)

Martin, A., \& Boatman, R. (2019). From Failed to Fair: Learning from the Oslo Accords to foster a new rights-based approach to peace for Palestinians and Israelis.

Michaillat, P., \& Saez, E. (2019). Optimal public expenditure with inefficient unemployment. The Review of Economic Studies, 86(3), 1301-1331. https://doi.org/10.1093/restud/rdy030

Ministry of Finance. (2018). Citizen Budget. Ramallah-Palestine: Palestinian Ministry of Finance and Planning. (in Arabic)

Miqdad, Mohamed Ibrahim. \& Kahlout, Khaled Omar. (2016). The reality of the current revenues and expenditures of the Palestinian National Authority in light of the Israeli obstacles. The Journal of the Islamic University for Humanitarian Research, 17 (1). (in Arabic)

Modalla, Samir Mostafa. (2018). Determinants the Palestinian public revenues and their analysis. Journal of Banking Financial Economics and Business Administration, (07), 08-52. (in Arabic)

Monetary Authority. (2019). Basic indicators to Palestinian economy. (in Arabic)

Moreno-Enguix, M. D. R., \& Lorente Bayona, L. V. (2017). Factors affecting public expenditure efficiency in developed countries. Politics \& Policy, 45(1), 105-143. https://doi.org/10.1111/polp.12194

Muhammad, Muhammad Hamid. (2020). The public budget deficit and tratment methods (Islamic instruments in Sudan as a model). Political Issues (61). (in Arabic)

Muhammad, Russell Jawad \& Muhaimid, Saeed Khattab. (2020). Geopolitical implications of the problem of economic dependency using quantitative indicators in Iraq 2003-2018. Journal of Adab Al-Farahidi, 12 (42), 203-222. (in Arabic)

Nasser, Abeer Ali \& Hadi, Salem Awad. (2019). The role of fiscal policy tools to reduce the state's public budget deficit in accordance with the terms of the International Monetary Fund. Journal of Accounting and Financial Studies, 14 (48). (in Arabic)

Oberschall, A. (2019). Contours of an Israeli-Palestinian peace settlement. Corvinus Journal of Sociology and Social Policy, 10(2), 95-102. https://doi.org/10.14267/CJSSP.2019.2.5

Okasha, Ahmed Khaled. (2018). The Palestinian Economy Between Unity and Attempts at Dismantling: A Reading in Previous Studies. Journal of Al-Quds Open

Oumer, H., \& Ramakrishna, G. (2020). Government Revenue, Expenditure and Fiscal Deficits in Ethiopia: An asymmetric Co-Integration Approach. Paper presented at the seventeenth international conference on the ethiopian economy .

Palestinian Economic Policy Research Institute - Mas. (2019). The performance of the general budget 2018 compared to 2017 and the clearing crisis. Palestine: Palestinian Economic Policy Research Institute (MAS). (in Arabic)

PMA. (2019). Economic main indicators in Palestine from http://www.pma.ps

Qwader, A. S., \& Aloshaibat, S. D. (2020). Components of the Public Budget and their Effects on Public Debt in Jordan. International Journal of Economics and Financial Issues, 10(3), 88-96. https://doi.org/10.32479/ijefi.9717

Saleh, Mohammed. (2007). The contributing Factors to increase the Palestinian Authority's revenue from value-added tax. The Islamic University - Gaza, Faculty of Economics and Administrative Sciences. Gaza-Palestine: The Islamic University - Gaza. (in Arabic) 
Saqer, S. (2019). Public Administration in Palestine. AARMS-Academic and Applied Research in Military Science, 18(1), 129-136-129-136. https://doi.org/10.32565/aarms.2019.1.8

Sasmal, R., \& Sasmal, J. (2016). Public expenditure, economic growth and poverty alleviation. International Journal of Social Economics. https://doi.org/10.1108/IJSE-08-2014-0161

Schenker, H., \& AbuZayyad, Z. (2018). 25 Years Since the Oslo Accords-What Next? Palestine-Israel Journal of Politics, Economics, and Culture, 23(2/3), 117-134.

Shikaki, I. (2019). The Political Economy of Growth and Distribution in Palestine: History, Measurement, and Applications. The New School .

Silla, Ola. (2005). Determinants of public revenues in Palestine. An-Najah National University, College of Graduate Studies. Nablus-Palestine: An-Najah National University. (in Arabic)

Smol, M. (2019). The importance of sustainable phosphorus management in the circular economy (CE) model: the Polish case study. Journal of Material Cycles and Waste Management, 21(2), 227-238. https://doi.org/10.1007/s10163-018-0794-6

UNCTAD. (2014). The leakage of Palestinian financial revenues to Israel under the Paris Economic Protocol. New York and Geneva: United Nations. (in Arabic)

University for Research and Administrative and Economic Studies, 6 (2), 55-71. (in Arabic)

Williams, D. W., \& Calabrese, T. D. (2016). The status of budget forecasting. Journal of Public and Nonprofit Affairs, 2(2), 127-160. https://doi.org/10.20899/jpna.2.2.127$\underline{160}$

Zahra, shaker. (2016). Oslo Agreement and its reflections on Palestinian issue 19931994. (MA), University of Ahmed Deraya-Adrar, Algeria. (in Arabic) 